Economic Origins of Cultural Norms:

The Case of Animal Husbandry and Bastardy

by

Christoph EDER

Martin HALLA

Working Paper No. 1719

This Version: January 2020

First Version: August 2017

Johannes Kepler University of Linz

Department of Economics Altenberger Strasse 69

A-4040 Linz - Auhof, Austria www.econ.jku.at 


\title{
Economic Origins of Cultural Norms: The Case of Animal Husbandry and Bastardy*
}

\author{
Christoph Eder ${ }^{\mathrm{a}}$ and Martin Halla \\ a Johannes Kepler University Linz, Austria \\ ${ }^{\mathrm{b}}$ Christian Doppler Laboratory Aging, Health and the Labor Market, Linz \\ ${ }^{\mathrm{c}}$ IZA, Institute for the Study of Labor, Bonn \\ ${ }^{\mathrm{d}}$ Austrian Public Health Institute, Vienna \\ forthcoming in: \\ European Economic Review
}

Last update: January 8, 2020

\begin{abstract}
This paper explores the historical origins of the cultural norm regarding illegitimacy (formerly known as bastardy) in the context of the Habsburg Empire. We test the hypothesis that traditional agricultural production structures influenced the historical illegitimacy ratio, and have a lasting effect until today. We show that regions that focused in preindustrial periods on animal husbandry (as compared to crop farming) had significantly higher illegitimacy ratios in the past, and female descendants of these societies are still more likely to approve illegitimacy and give birth outside of marriage today. To establish causality, we exploit for Austria, within an IV approach, variation in the local agricultural suitability, which determined the historical dominance of animal husbandry. Since differences in the agricultural production structure are completely obsolete in today's economy, we suggest interpreting the persistence in revealed and stated preferences as a cultural norm. Complementary evidence shows that this norm is passed down through generations, and the family is the most important transmission channel. Our findings are one example for the more general phenomenon that cultural norms can be shaped by economic conditions, and may persist, even if economic conditions become irrelevant.
\end{abstract}

JEL Classification: Z1, A13, J12, J13, J43, N33.

Keywords: Cultural norms, persistence, historic agricultural practices, illegitimacy.

*Corresponding author: Martin Halla, Johannes Kepler University Linz, Department of Economics, Altenbergerstraße 69, 4040 Linz, Austria; email: martin.halla@jku.at. We thank four anonymous Referees for excellent comments that significantly improved the paper. For helpful discussions and comments we would further like to thank Davide Cantoni, Uwe Dulleck, Ernst Langthaler, James A. Robinson, Andreas Steinmayr, Steven Stillman, Uwe Sunde, Joachim Winter, David Yanagizawa-Drott, participants of the WEast workshop in Prague, of the 13th eeecon workshop at the University of Innsbruck, of the Workshop Empirical Economics at the University of Munich, of the Ski-Labor Economics Workshop in Landeck-Zams, of the Economic Research Seminar of the University of Salzburg, of the Economic Research Seminar of the Masaryk University in Brno, of the Second Bolzano Applied Microeconomics Workshop of the Free University of Bozen, of the NOeG conference in Linz, and of the department workshop of the University of Linz. Michael Lapinski and Philipp Henning provided excellent research assistance. The usual disclaimer applies. 


\section{Introduction}

It is widely acknowledged among economic scholars that individuals' decisions are not only based on economic incentives, but also on prevailing cultural norms. ${ }^{1}$ This fact is documented in numerous experimental and empirical settings and has led to a revision of economic decision models. In contrast, very little is known about how cultural norms are formed, and how they change over time (Giuliano and Nunn, 2017). We aim to contribute to the burgeoning literature on the origins of cultural norms. We study the case of illegitimacy (formerly known as bastardy), which describes the status of being born to an unmarried mother. The context of our study is the Habsburg Empire and its successor countries.

Virtually all societies distinguish between legitimate and illegitimate births (Hartley, 1975). This explicit distinction is related to the concern over the welfare of unmarried mothers and their children. In the absence of a clear paternal link, the physical, emotional, and economic support for mother and child may be inefficiently low. This concern is confirmed by a robust negative correlation between illegitimacy and a wide array of child outcomes. ${ }^{2}$ There is substantial variation in the incidence and acceptance of illegitimacy across societies and over time. Today, the social acceptance of illegitimacy is typically linked to cultural differences (such as the religiosity of the population). Relatedly, the rise in extramarital births in Western countries is often associated with the ongoing secularization and emancipation of women. In the US, race has traditionally been the most important factor (see, e.g., the controversially discussed Moynihan Report) and continues to be at the center of the debate, as Black-White disparities in illegitimacy are rising (Martin et al., 2015). Typically, these debates stress the idea that illegitimacy is, besides economic factors, also determined by cultural norms (e.g. Kearney and Wilson, 2017). Our interest is in exploring the origins of this cultural norm.

We test the hypothesis that differences in this cultural norm have their origins in the form of agricultural production structures traditionally employed in pre-industrial periods in the context of the Habsburg Empire ${ }^{3}$ Our estimation sample covers a period of more than a century and comprises regions from eight current states (Austria, Croatia, Czech Republic, Italy, Poland, Romania, Slovenia, and Ukraine; see Appendix Figure C.1). We show that regions that focused on animal husbandry (as compared to crop farming) had significantly higher illegitimacy ratios

\footnotetext{
${ }^{1}$ See, for instance, Guiso et al. (2006); Fernández (2011); Alesina and Giuliano (2015). We use the terms 'cultural norm', 'culture' and 'social norm' interchangeably.

${ }^{2}$ See, for instance, von Borosini (1913) for evidence in historical data and Shah et al. (2011); Buckles and Price (2013) for contemporaneous data. Using data from the Austrian Birth Register we find that children born to unmarried mothers are 17 percent more likely to be born pre-term. This association persist after controlling for a large set of socio-economic control variables (details are available upon request). Frimmel and Pruckner (2014) derive, based on the same data, equivalent conclusions for low birth weight using mother fixed-effects estimations.

${ }^{3}$ Our historical data are from the period of the Austro-Hungarian Empire (1867-1918), which constituted the last phase in the constitutional evolution of the Habsburg Monarchy. It was a result of the Austro-Hungarian Compromise of 1867 and was a constitutional union of two monarchies: the Austrian Empire ruled by the House of Habsburg and the Kingdom of Hungary. In our analysis, we focus on the region of the Austrian Empire, which was commonly denoted Cisleithania.
} 
in the past, and female descendants of these societies are still more likely to approve illegitimacy and give birth outside of marriage today. To establish causality, we exploit in data for today's Austria variation in the local agricultural suitability, which determined the historical dominance of animal husbandry. Over our sample period, the agricultural sector has declined in terms of employment from 50 percent in 1900 to 5 percent today. At the same time, the effect of historical agricultural production structures on illegitimacy has remained strong. We interpret our findings as an example of a more general phenomenon whereby cultural norms are shaped by economic conditions, and persist, if economic conditions become irrelevant (Giuliano, 2017).

An important distinction among rural societies in the pre- and proto industrial Habsburg Empire is whether the focus was on crop farming or animal husbandry. In crop farming, the work load and the resulting demand for additional labor, was determined by the rhythm of the seasons. While fluctuation could be partially offset by secondary works in the 'dead season', additional manpower was needed in the harvest season. In contrast, in animal husbandry the workload was distributed relatively evenly throughout the year. As a result, in rural societies dominated by animal husbandry, most workers in the 18th and 19th centuries had long-term labor contracts as farmhands, while in rural societies dominated by crop farming most workers had short-term labor contracts as day laborers. Farmhands were regarded as household members, who lived permanently at the farm, and were predominantly paid in kind. The lack of cash income prevented farmhands from establishing their own households and from marrying. As a result, their offspring was born illegitimately and was tolerated by society as a pool of disenfranchised cheap labor. Since children born out of wedlock grew up as servant members to the household, their chances of marrying were almost zero, and they were thus likely to produce another generation of illegitimate children. In contrast, day laborers typically lived as cottagers, meaning they had simple dwellings (cottages), but typically lacked sufficient land to sustain their livelihood. They supplemented their income as day laborers on bigger farms (and with craft and trade) for which they received cash. This additional cash income enabled young couples to establish their own households, which led to marital fertility. ${ }^{4}$

Clearly, no region in the Habsburg Empire focused exclusively on either crop farming or animal husbandry. Thus, one cannot find farmhand societies or day laborer societies in their pure form. Nevertheless, societies dominated by animal husbandry, and the resulting clustering of farmhands with their illegitimate children, may have developed the belief that illegitimate births are a normal event. This belief may have persisted even if the economy shifted its focus from agriculture to manufacturing and services, and became a long-lasting cultural norm. We derive the hypothesis that women residing today in regions that were historically farmhand societies, are more likely to give birth outside marriage, compared to those residing in former day laborer societies.

\footnotetext{
${ }^{4}$ The historical correlation between agricultural production structures and illegitimacy has been discussed by historians, such as Mitterauer (1983, 1986, 1992); Ortmayr (1989, 1996); Ehmer (1991).
} 
To test this hypothesis, we link the current incidence of non-marital births to variation in the historical agricultural production structures. Such an analysis requires exceptionally rich historical data that can be linked to recent population statistics. The context of the Habsburg Empire is well-suited, since starting from the mid-19th century, detailed official statistics exist. These include, among others, regional information on the agricultural sector and on the incidence of non-marital births. The former allows us to categorize a region as either a predominantly farmhand society or a day laborer society. We compile a dataset that links, on a district level, this historical information with recent data sources from Austria, Croatia, Czech Republic, Italy, Poland, and Slovenia. In the case of Austria, we can, in addition, link historical municipality level data to the Austrian Birth Register. The latter comprises comprehensive individual-level information on all births since 1971.

The starting point for our empirical analysis are three strong and robust correlations in data covering the entire Habsburg Empire. First, we find a positive relationship between the relative dominance of animal husbandry versus crop farming and the share of farmhands in the population in 1900. Thus, our data confirm that workers in animal husbandry predominantly had long-term contracts, while workers in crop farming had short-term contracts. Second, in the historical data, we find a clear pattern of high illegitimacy ratios in farmhand societies and comparably low ratios in day laborer societies. During this period, fertility behavior was driven by the prevailing economic conditions. Third, we find a positive relationship between the local historical and current illegitimacy ratios.

In our main analysis, we document the direct relationship between the historical agricultural production structure and the current likelihood of a non-marital birth. To be able to make causal statements we refer to data from the region of today's Austria. We use variation in the local agricultural suitability, which determined the historical agricultural production structure. The potential yield of crop farming versus animal husbandry is determined by different biophysical factors (mainly climate, soil, and terrain). These factors are not readily amenable to change by human activity or institutions and as such are exogenous. We focus on the variability in terrain. Sloping terrain is more difficult to cultivate than flatland, and is subject to higher rates of water runoff and soil erosion (van Velthuizen et al., 2007). While this applies to both crop farming and animal husbandry, the productivity constraints of a higher slope gradient are comparably higher for crop farming. In line with this, we find a higher historical dominance of animal husbandry (and farmhand societies) in Austrian regions characterized by steep slopes. We offer two different causal estimates. First, our instrumental variable estimate relates the variation in historical agricultural production structure (due to the slope of terrain) to the current likelihood of an illegitimate birth. This estimate shows that the existing cultural norm regarding non-marital births has its origins in the form of agricultural production structures traditionally employed in pre-industrial periods. We provide a number of additional estimates addressing potential threats to identification due to differences in the influence of the church, human capital, health infrastructure, migration, poverty, tourism, religiosity, and 
social capital. All these alternative specifications confirm our baseline result. We replicate our analysis also with individual-level data that allows us to control very effectively for differences between mothers in municipalities with different slopes of terrain. Our data include, among other, information on mothers' educational attainment and their religious denomination. Moreover, we demonstrate that our results are not driven by mountainous areas, but are also present in lower-lying areas. Second, our reduced form estimate-relating the terrain slope to the current likelihood of an illegitimate birth — shows that biophysical factors structurally affect demographic outcomes in modern societies. Figure 1 summarizes the suggested theory of change, the empirical variables, and our instrumental variable approach.

To underpin our causal interpretation, we complement our analysis with two further approaches. First, we provide evidence based on stated preferences. We link recent survey responses on attitude towards illegitimacy to the historical illegitimacy ratio and the historical agricultural production structure in the respondent's region of residence. This analysis shows equivalent links for stated preferences and corroborates our conclusion derived from our main analysis. Second, we provide an analysis of so-called shotgun weddings. In line with our main results, we find that the historical agricultural production structure affects the likelihood that an illegitimate birth today is averted by a wedding between conception and birth.

Finally, we explore the transmission channel of this cultural norm. We use immigrant mothers to Austria and internal migrant mothers to test the relative importance of vertical socialization (inside family) versus horizontal socialization (by a wider social group). Exploiting differences in the prevailing cultural norm in the sending and receiving region, we find for both types of immigrants evidence which suggest that the norm is predominantly shaped inside the family and socialization by the wider social group is of minor importance.

Our findings have to be interpreted in the specific historical and political context of the Habsburg Empire and its successor countries. However, the mechanism by which the production structure of animal husbandry has affected illegitimacy - i.e., the subordination of propertyless workers for the economic and social benefit of property owners - is not a unique setting. We see five guideposts that can be used to situate this analysis within the context of the existing literature. First, we add to the growing literature on the persistence of cultural attitudes over long periods of time (see, e. g., Voigtländer and Voth, 2012; Grosjean, 2014). One previous study pays attention to illegitimacy. Ragan (2012) demonstrates that regional historical illegitimacy ratios in Sweden are very persistent over time, and that they are a strong and robust predictor of the demand for oral contraceptives. She argues that both behaviors (i. e., illegitimacy and use of contraceptives) are driven by a particular cultural norm on sexual behavior. In line with this hypothesis, she finds that in Sweden teenage childbearing declined after the introduction of oral contraceptives. Second, we contribute specifically to the burgeoning literature that aims to go beyond showing the mere existence of persistence, but instead to identify the origins of specific cultural norms. We are not aware of any previous study on the historical origins of a cultural norm regarding illegitimacy. An important paper in this strand of literature is 
Alesina et al. (2013), who test the hypothesis that traditional agricultural practices influenced the historical division of labor and the evolution of gender norms. Their paper has a global focus and shows that descendants of societies that traditionally practiced plough agriculture today have less equal gender norms and a lower female labor force participation. In a similar vain, Becker (2019) tests the anthropological theory that historic pastoral animal husbandry ( $\approx$ nomadism) led to constraints on female sexual behavior (such as, female genital cutting), because in such nomadic societies men were often away from home and wanted to reduced paternal uncertainty in this way. ${ }^{5}$ The findings of Alesina et al. (2013), Becker (2019) and other papers in this literature ${ }^{6}$ point to a more general phenomenon that cultural norms can be shaped by economic conditions and may persist even if economic conditions become irrelevant. Our main empirical finding on the origins of the cultural norm regarding illegitimacy in the context of the Habsburg Empire is another example for this phenomenon. Third, we speak to the literature that identifies cultural norms as determinants of family outcomes. A number of papers proxy culture among US immigrants by their country of ancestry to study the role of culture in family-related outcomes such as fertility (Fernández and Fogli, 2006, 2009), living arrangements (Giuliano, 2007), and divorce (Furtado et al., 2013). While these papers clearly show that individuals react to cultural norms in fertility decisions and family formation, they do not explore the origins of these cultural norms. Fourth, more specifically, we also contribute to the literature on the determinants of illegitimate births. ${ }^{7}$ We provide empirical evidencefor the widely held belief - that cultural norms are an important factor and explore the deep roots of this norm. Fifth, our work relates to existing studies that link the emergence of the socalled European Marriage Pattern (EMP) to changes in the agricultural production structure. ${ }^{8}$

\footnotetext{
${ }^{5}$ In our setting of Austria there is no pastoralism (i.e., no mobility of livestock and people). We focus on a proto-industrial period and a form of animal husbandry with very limited mobility. In Alpine regions there has been a seasonal movement of livestock between fixed summer and winter pastures. However, only the livestock travels (with a certain number of people necessary to tend them), while the main population stays at the base. Thus, in our setting the mechanism at work is not paternal uncertainty caused by the production structure of animal husbandry.

${ }^{6}$ In a similar vain, Ang and Fredriksson (2017) link agricultural legacies to prevalent differences in family ties. They provide evidence that societies which historically have been oriented towards growing wheat, tend to have weak family ties. Galor and Özak (2016) show that geographical variations in the natural return to agricultural investment have persistent effects on the distribution of long-term orientation across societies today. Other studies in this strand of literature exploit large-scale human interventions. There is evidence of the effect of slavery on trust towards others (Nunn and Wantchekon, 2011), on the Jewish presence in Russia before WW2 on an anti-market culture (Grosfeld et al., 2013), on the Habsburg Empire on trust in institutions (Becker et al., 2016), on historic gender imbalance on attitudes towards women (Grosjean and Khattar, forthcoming), and of the effect of self-government in Italian cities in the Middle Ages on civic capital today (Guiso et al., 2016).

${ }^{7}$ Existing papers discuss several potential explanations for the variation in the share of non-marital child births across time and space. The literature on pre- and proto-industrial societies discusses the elimination of formal marriage restrictions (Knodel, 1967), variations in real wages (Lee, 1977, 1978), a changing sexual mentality among the poor (Shorter, 1978), and rural inheritance patterns (Khera, 1981; Kytir and Münz, 1986). The literature on industrial societies discusses the increased availability of contraception and abortion (Akerlof et al., 1996; Fernández-Villaverde et al., 2014; Nuevo-Chiquero, 2015), the liberalization of divorce law (Alesina and Giuliano, 2007), joint custody laws (Halla, 2013), welfare state arrangements (Lackner et al., 2016), distorted adult sex ratios (Bethmann and Kvasnicka, 2013), and income inequality (Kearney and Levine, 2014).

${ }^{8}$ John Hajnal pointed out that women in Western Europe (in particular, in the area west of the so-called Hajnal line, which is drawn from St. Petersburg to Trieste) have exhibited a distinct marriage pattern since the
} 
Most importantly, Voigtländer and Voth (2013) (henceforth VV) argue that the Black Death contributed crucially to the EMP. Their key-argument is that the drastic loss in population increased the land-labor ratio and favored land-intensive animal husbandry. This provided enhanced employment opportunities for females as servants. In their model, they rule out illegitimacy and female servants had to remain unmarried as a condition of employment in animal husbandry. Thus, females faced the trade-off between higher income against having children. Their empirical analysis of English data from the 14th century confirms that after the Black Death more women chose to work in animal husbandry and to postpone (or forgo) marriage and fertility. We also find that a focus on animal husbandry leads to later (or no) marriage; but we do not find a dampening effect of animal husbandry on fertility. It is hard to rationalize this difference, since the two settings differ substantially. Most importantly, in our setting employment in animal husbandry is financially not attractive and does not rule out an illegitimate birth. Our empirical setting is from a much later period, where a social norm prevails that decouples marriage and fertility.

The remainder of the paper is organized as follows. We begin, in Section 2, by linking historical and contemporaneous data on illegitimacy to document the persistence in this behavior over time. In Section 3, we describe the proto-industrial agricultural society in the Habsburg Empire and characterize farmhand and day-laborer societies. Section 4 presents our analytical results. We link the historical agricultural production structure with illegitimacy today. We present stepwise results from different estimation strategies to establish a causal link. In the first step, we control for selection based on observables. In the second step, we exploit, in Austrian data, exogenous variation in the local agricultural suitability due to variation in the local slope of terrain. In Section 5, we provide our two complementary analyses of stated preferences and shotgun weddings. In that section, we examine also several other historical demographic outcomes. In Section 6, we present our evidence on the transmission channel of the cultural norm. Section 7 concludes the paper.

\section{Persistence in illegitimacy}

Illegitimacy is the main outcome in our analysis. ${ }^{9}$ There is an underlying process of interdependent events, which give rise to this outcome. First, the proportion of females who are potentially at risk of giving birth outside of marriage is decisive. A society with many unmarried females of child-bearing age is, in principle, more prone to having a high illegitimacy ratio. Second,

late Middle Ages (Hajnal, 1965, 1982). In this area, age at first marriage was high, high percentages of the population remained unmarried, and the nuclear family household predominated (Carmichael et al., 2016). The literature discusses several other co-factors, such as limited parental authority, neolocality, and the importance of urban labor markets (De Moor and van Zanden, 2010) as potential causes of the EMP. Further, several local and regional case studies reveal substantial variation within this area (e.g. Teibenbacher, 2009).

${ }^{9}$ Although illegitimacy is not the same as out-of-wedlock birth in all societies, we use these terms interchangeably. This is in line with the interpretation of illegitimacy in 19th century Habsburg Empire (Mitterauer, 1983, p.13). 
the sexual behavior of this population is important. The illegitimacy ratio is affected by the incidence of unprotected sexual intercourse. Third, the responses of those females who conceive out of wedlock matter. When large proportions decide to marry before childbirth (or to abort), the illegitimacy ratios can still be low. At each stage, individual decisions are made under the influence of societal factors. We consider illegitimacy to be the best variable to capture and summarize this chain of events. To complement our analysis, we also examine the prevalence of so-called shotgun marriages in the contemporaneous data in Section 5.2, as well as other demographic outcomes (such as age at marriage and level of marital and non-marital fertility) in the historical data in Section 5.3.

As Figure 2 shows, the illegitimacy ratio has varied substantially over the last 200 years in Austria. While the ratio increased for most of the 19th century, there was a sharp drop in the 1870s, when formal marriage restrictions were mostly abolished. ${ }^{10}$ After some ups and downs around the two World Wars, the lowest ratio was reached in the late 1950s. Ever since, the ratio has been on the rise and reached an all-time high in 2014 at over 40 percent. This rise has been very comparable in regions with different historic agricultural practices (see Appendix Figure C.2). ${ }^{11}$

While the development of the illegitimacy ratio over time is, in itself, an interesting phenomenon, our focus is on the persistence of regional patterns. We employ three different estimation samples, which vary in regional scope and depth of information, to show this persistence. First, the 'Habsburg Empire' sample consists of 255 districts covering regions from six current states (Austria, Croatia, Czech Republic, Italy, Poland, and Slovenia). Second, we consider separately the subset of all districts, which are within the boundaries of today's Austria. This leaves us with 66 districts, which comprise 96 percent of the area of Austria. We refer to this sample as 'Austria'. ${ }^{12}$ Table 1 provides descriptive statistics for both samples. Third, we use an individual-level sample covering the region of today's Austria, based on the Austrian Birth Register that covers the universe of births between 1971 and 2007. One advantage of an individual-level analysis is that we can control (besides our standard set of district-level covariates) also for mothers' characteristics. See Panel B of Table 2 for descriptive statistics of this sample. Our main measure of interest is the illegitimacy ratio, which is the share of live births to unmarried mothers of all live births. ${ }^{13}$ In the individual-level sample, the illegitimacy

\footnotetext{
${ }^{10}$ Legal marriage restrictions allowed members of the lower classes to marry only with the prior consent of the village authorities (Mantl, 1999; Veichtlbauer et al., 2006). This so-called political marriage consent was removed in all provinces in 1868 with the exception of Salzburg (in 1883), Tyrol, and Vorarlberg (in 1921) (Ehmer, 1991, p.61). Since we include province fixed effects in all our estimations, our results will not be influenced by the differential timing in the removal of legal marriage restrictions.

${ }^{11}$ The development of the illegitimacy ratio in Austria corresponds well with the average European trend. Most European countries experienced a comparable drop between the mid-19th and the mid-20th centuries (Shorter et al., 1971) and a rise thereafter (Heuveline et al., 2003) as part of the so-called second demographic transition (Van de Kaa, 1987).

${ }^{12}$ This sample excludes today's province of Burgenland, which was part of the Hungarian part of the Empire in 1900. Appendix Section A.1 provides a detailed description of both estimation samples and Appendix Table A.1 summarizes the data sources.

${ }^{13}$ An alternative measure of illegitimacy would be the illegitimacy rate, which is typically defined as the
} 
variable is a binary variable equal to one if the mother is unmarried at the time of birth and zero otherwise.

The upper panel of Figure 3 displays the variation in the historical illegitimacy ratio across districts for 1900. The lower map in Figure 3 shows the equivalent regional variation in contemporaneous data provided by national statistical offices. A visual comparison of these two maps indicates an increase in the level of the illegitimacy ratio across regions and a spatial correlation over time. To obtain a more formal comparison, we regress today's illegitimacy measure on the historic district-level illegitimacy ratio and include step-by-step province fixed effects, a large set of historic district-level controls, and, in the case of the individual-level analysis, socio-economic characteristics of the mother. Historic controls comprise information on the share of Catholics, the share of males, the age structure of the population, the share of illiterate persons, the sectoral composition, the teacher income, and the degree of urbanization. Teacher income is a proxy for non-agricultural wages and the urbanization rate serves also as a proxy for the size of the marriage market, which determines the arrival rate of potential partners.

Table 3 summarizes the estimation output. Columns (1) to (3) refer to the Habsburg Empire, while columns (4) to (6) focus on Austria. The last three columns employ the individual-level dataset to estimate a linear probability model. There is a strong positive correlation between the historic illegitimacy ratio and today's illegitimacy measures. A one percentage point increase in the historic illegitimacy ratio corresponds to roughly a 0.4 percentage point increase in today's illegitimacy ratio. The point estimate is stable across samples and does not change much when we include province fixed effects (columns 2 and 5), and additional historic controls (columns 3 and 6 ). Even the detailed control variables in the individual level estimation comprising information on mothers' education and religious denomination leave the estimate unchanged (compare columns 7 and 9). ${ }^{14}$ Beta coefficients are between 0.3 for the Habsburg Empire and 0.5 for the Austrian sample. ${ }^{15}$

number of illegitimate lives births per 1,000 unmarried women of childbearing age. In our sample, the correlation between the illegitimacy ratio and illegitimacy rate is very high (see Appendix Figure C.3) and we obtain very similar results if we use the illegitimacy rate instead of the illegitimacy ratio (see Appendix Table ).

${ }^{14}$ Note, some of the individual-level control variables (e.g. mothers' education) are potentially bad control variables. It is nevertheless reassuring that their inclusion has virtually no impact on our estimate of primary interest.

${ }^{15}$ While the literature in contemporary Austrian history has dealt extensively with illegitimacy in preindustrial Austria (Haslinger, 1982; Mitterauer, 1983, 1986, 1992), we are the first to empirically examine the connection to today's regional pattern of illegitimacy. Kytir and Münz (1986) loosely discuss the persistence of illegitimate births in Austria and show suggestive maps. Ragan (2012) finds in her Swedish county data a comparable persistence in illegitimacy between 1860 and 1910, as well as between 1910 and 1960 . 


\section{Agricultural production structure and illegitimacy}

For a long time, the economy in the Habsburg Empire was dominated by agriculture. ${ }^{16}$ In 1900 , more than 50 percent of the population was still employed in the agricultural sector. ${ }^{17}$ Given this dominance of agriculture across most of the population, a strong connection between the predominant forms of agricultural production structure and all aspects of life can be expected.

\subsection{Agricultural specialization and types of labor contracts}

The agricultural sector in the pre-industrial Habsburg Empire was organized on a spectrum between crop farming and animal husbandry. Thus, in most areas, there are features of both forms of agricultural specialization: farmers not only grew crops, but also kept animals to supplement their diet. In our empirical analysis, we will therefore speak of the relative dominance of one form of agriculture. However, for the benefit of the following discussion, it is helpful to describe two extreme forms of agricultural specialization.

\subsubsection{Crop farming and day laborer societies}

The planting, growing, and harvesting of plants required large amounts of labor during peak seasons, but relatively little during downtime. The additional labor needed during peak seasons, was hired on short-term contracts. These day laborers were mostly paid in cash and did not become part of the extended family of the farmer. Due to the large demand for day laborers during the peak season, wages were relatively high (Mitterauer, 1986, p.213f). Farmers in crop farming areas often provided small dwellings for cottager families, who provided a certain amount of labor in exchange. This form of dependency allowed the farmer access to additional workers when required, but avoided having a permanent contract with the worker (Mitterauer, 1986, p.216). Since day laborers and cottagers could not find employment in agriculture year round, they performed different kinds of crafts and trades during the low seasons (Ortmayr, 1984, p.107). The additional cash income and the requirement to find a different kind of work during the low seasons, prevented the non-landholding population from forming a relationship of dependency with landholding farmers.

\subsubsection{Animal husbandry and farmhand societies}

Animal husbandry is at the opposite extreme of the spectrum of the agricultural production structure. It was labor intensive throughout the year, since animals had to be tended every day. Farmers employed servants to perform the necessary tasks of feeding, milking, and minding

\footnotetext{
${ }^{16}$ Serfdom had been abolished in 1781 . Until 1848, peasants still had to provide labor and produce to the seignior. After that there was no dependence of peasants to the local aristocracy. Peasants were citizens and had to pay taxes to the government. Taxes did not vary within provinces.

${ }^{17}$ Over time, this share has declined sharply (see Appendix Figure C.4). In 2001, the share of the population in agriculture was below 5 percent. These figures refer to the territory of today's Austria.
} 
the cattle in the meadows. Due to the close relationship between workers and animals, these farmhands (or servants) had to learn the peculiarities of each animal (analogous to firm-specific human capital). The relation-specific knowledge and more or less even distribution of the workload throughout the year made long-term labor contracts the prevalent form (Mitterauer, 1986, p.200). Servants were usually hired for a year and contracts were regularly renewed. In this way, servants became part of the larger family of the farmer. A large part of the compensation package was paid in kind by providing food and residence. Data from a historical wage survey show that the income (sum of in-kind and cash payments) of servants was substantially lower than that of day laborers (see Panel A of Appendix Table D.2). Most servants received almost two-thirds of their compensation in kind (see Panel B of Appendix Table D.2). A low degree of intergenerational mobility due to little inherited property and knowledge of crafts and trades from parents made it very likely that the children of farmhands would become farmhands themselves (Mitterauer, 1992).

\subsubsection{Linking agricultural specialization to types of labor contracts}

We now estimate the relationship between the relative dominance of animal husbandry and the presence of a farmhand society in 1900. To empirically capture the relative dominance of animal husbandry we contrast livestock units with the number of agricultural workers. A livestock unit is a reference unit for the aggregation of livestock from varies species. We use an official Swiss definition (Schweizerische Bundesrat, 1998) to calculate it as follows: livestock units $=$ cattle $+0.7 \cdot$ horses $+0.25 \cdot$ sheep $+0.26 \cdot$ pigs. $^{18}$ We then define a variable animal husbandry ${ }_{l p}^{1900}$, which is calculated as the ratio of livestock units to agricultural workers in location $l$ (located in province $p$ ) in 1900. On average, there were 1.62 livestock units per agricultural worker. To quantify the relative dominance of a farmhand society, we use the share of servants in agriculture of the total population. More precisely, it is the ratio of agricultural servants in 1902 to the total population in 1900. The resulting variable varies between 0.0003 and 0.20 with a mean of $0.05 .{ }^{19}$ We relate these two variables of primary interest in a regression framework. Estimation results are summarized in Panel A of Table 4. We distinguish between the estimation sample for the Habsburg Empire (in columns A1 to A3) and for Austria (in columns A4 to A6). Across specifications, we expand the set of covariates. Columns (A1) and (A4) show a strong positive unconditional relationship between the relative dominance of animal husbandry and the share of servants in agriculture of the total population. The correlations are very

\footnotetext{
${ }^{18}$ We have check the robustness of our results across a wide range of alternative definitions of a livestock unit (see Appendix Table D.7). An alternative approach to capture the relative dominance of animal husbandry would be to use the share of land used for pastures. We have applied this approach in district-level data and we obtain very comparable results (see Appendix Table D.8). However, we refrain from applying this measure in municipality-level data, since it would require an enormous amount of data entry at the village-level.

${ }^{19}$ Below, we demonstrate the robustness of our findings to using other quantifications of the relative dominance of a farmhand society based on servants. An equivalent measure for day laborers cannot be meaningfully constructed. The number of day laborers varies substantially across seasons. At the cutoff date of the agricultural census (June 3rd, 1902), relatively few day laborers were present.
} 
comparable in both samples. The inclusion of province fixed effects in columns (A2) and (A5) reduces the estimates slightly in size, but they remain highly statistically significant. In a final step, we include our large set of historic control variables. This hardly affects our estimates. Across all specifications, the estimated relationship between the relative dominance of animal husbandry and the presence of a farmhand society remains significant with a beta coefficient of approximately 0.5. This set of estimates highlight the close connection between the relative dominance of animal husbandry and the occurrence of a farmhand society.

\subsection{Linking animal husbandry to illegitimacy in a proto-industrial agricultural society}

We now turn to studying the link between a farmhand society and the prevalence of illegitimacy. Since servants in agriculture were closely integrated into the family of the farmer and were paid mostly in kind, the farmer had substantial power over them. In particular, the servants' individual liberty to marry was very restricted (even in the absence of formal marriage restrictions). Newlyweds were expected to set up a new household. This cultural norm of socalled neo-locality, de facto prevented all couples from marriage, who were not in an economic situation to establish their own household. As a consequence, many adults spent a substantial number of years as so-called life cycle servants, during which time they earned the means to establish their own households (Laslett, 1977a,b). For some areas, historians highlight also a high prevalence of so-called life time servants. Thus, in many cases, servants not only delayed marriage, but remained single all their lives. In contrast, day laborers (and cottagers) in agriculture were in a completely different situation. They earned cash income through their work in agriculture and also in crafts and trades during the low seasons. That group was also not in a relationship of dependence with the landholding farmers that could dictate a certain family arrangement. ${ }^{20}$

The two groups of agricultural workers, servants and day laborers, had in common that they produced offspring. The marital situation of each group, however, typically generated illegitimate children in the case of servants and legitimate offspring for day laborers. Official population statistics show the legitimacy status for all children born to fathers or unmarried mothers working as servants or day laborers in agriculture in 1900 . While almost 80 percent of births were illegitimate for servants, only 15.7 percent were so for day laborers. The high illegitimacy ratio among servants seems surprising given that the Roman Catholic church clearly

\footnotetext{
${ }^{20}$ Another way to look at the economic situation of these two agricultural workers is in terms of dependency of the two sexes on each other with respect to child support and parenting. One could argue that mothers in crop-farming societies had a higher dependence as compared to their counterparts in animal husbandry societies, where the child was automatically part of an established household; which should provide at least a baseline level of support. This is in line with one prediction by the model of Bethmann and Kvasnicka (2011), who provide a microeconomic foundation for the institution of marriage, and conclude that marriage should be less important, when the degree of substitutability between maternal and paternal investments into the quality of their offspring is high.
} 
objected to pregnancy of unmarried women. Among other measures, they charged higher fees for christenings or special repentance (Klammer, 1992, p.91). In some cases, unmarried mothers had to give their children away to another farm, pledging a number of years of free labor by the child in the future. According to Hecke (1930, p.581), about 5 percent of illegitimate children. However, in general, for farmers in labor-intensive animal husbandry, illegitimate children of servants formed a welcome pool of future disenfranchised labor.

Some important aspects of illegitimate children's lives can be assessed from the official statistics from 1900 (see Appendix Table D.3). First, non-marital childbearing was not confined to very young mothers. In contrast, about 68 percent of illegitimate children were born to mothers between 20 and 30 years of age. Second, the illegitimacy ratio was higher in more urban areas (about 32 percent in towns with more than 20,000 inhabitants), but it was also quite common in small villages (about 19 percent in villages with less than 500 inhabitants). Third, if agricultural servants married, the tend to this at a somewhat younger age as compared to day laborers. The mean age of a groom among agricultural servants was 32.2 years and among day laborers 34.7 years. Fourth, it is documented that illegitimate children had a substantially higher likelihood of early death. Referring to children from the birth cohorts from 1900 through 1904, we can see that among legitimate children, 14.2 percent died during their first year after birth. For illegitimate children, this share amounted to 19.2 percent (see Appendix Figure C.5). Fifth, despite the comparable bad situation of these children, only a few public institutions devoted to this vulnerable group existed. In 1900, in the entire Habsburg Empire, there existed only three so-called foundling hospitals. These institutions provided help with its free childbirth facilities to expecting mothers and newborns. Mothers could give birth and, if they desired, give their children to foster parents (Kaser, 1987). There are neither representative figures on how many mothers opted for foster parents, nor on the living arrangements of the children who stayed with their mother. Sixth, we see that the vast majority of children born out of wedlock from these birth cohorts remained illegitimate. Five years after birth, only approximately 20 percent had experienced a post-birth legitimation through the marriage of their mother (see Appendix Figure C.6).

To more formally explore the relationship between the predominant labor relationship in agriculture and the prevalence of illegitimacy, we run regressions (summarized in Panel B of Table 4). Across samples and specifications we find a robust relationship between the share of agricultural servants in the total population and the illegitimacy ratio. The two richest specifications give a beta-coefficient of about one half (see columns B3 and B6). Alternative measurements of the dominance of a farmhand society provide equivalent results (see Appendix Table D.4). 


\section{Illegitimacy beyond animal husbandry: The origin of a cultural norm}

\subsection{Linking historical animal husbandry to illegitimacy today}

Our main hypothesis is that the historic agricultural structure has formed a cultural norm in relation to illegitimacy that persists until today. To test this hypothesis, we now regress the contemporary illegitimacy ratio in the region $r$ (located in province $p$ ) on the historical ratio of livestock units to agricultural workers denoted by animal husbandry ${ }_{r p}^{1900}$

$$
\text { illegitimacy ratio } \text { today }_{r p}^{\text {tan }}=\alpha+\beta \cdot \text { animal husbandry }{ }_{r p}^{1900}+X_{r p}^{1900} \cdot \gamma+\phi_{p}+\varepsilon_{r p}^{\text {today }}
$$

Depending on the sample, we can perform this regression on different levels of aggregation. For the Habsburg Empire sample we use district-level data $(r=d)$. In the case of the Austrian sample, we can run this regression at the municipality level $(r=m) .{ }^{21}$ Since municipalities are much smaller geographic units than districts, our number of observations increases substantially. The municipality sample comprises 1,318 municipalities that we can cleanly track since 1900 . In the upper panel of Figure 4, municipalities with intense animal husbandry are shown in dark red. The gray areas depict municipalities that we cannot track over time (until today), while white areas are not part of our estimation sample (see Appendix Section A.1). The lower panel shows the contemporaneous distribution of the illegitimacy ratio. The dark red areas indicate a high prevalence of illegitimate births. The comparison of the two panels shows well the correlation between the spatial distribution of historic animal husbandry and illegitimate births today. The only disadvantage of using municipality-level data is the smaller set of available historical covariates $X_{m p}^{1900}$. Besides province fixed effects, we can control for the share of people in agriculture, the population level, the share of males in the population, the share of Catholics, the existence of large landholdings, the existence of large factories, and the municipalities market status. Panel A in Table 2 provides descriptive statistics for all variables on the municipality level. ${ }^{22}$

The Austrian Birth Register also allows us to observe the legitimacy status on an individual level for the universe of births between 1984 and 2007. We exploit this disaggregated information to consider a linear probability model, where the dependent variable is equal to one if a mother was not married at the time of birth. The explanatory variable of primary interest is (as

\footnotetext{
${ }^{21}$ While for Austria all contemporaneous variables are available on this level, historical variables are often not. In our estimations above, we had to resort to the district level since the historical illegitimacy ratio illegitimacy ratio ${ }_{r p}^{1900}$ is not available on a more disaggregated level. In contrast, the historical ratio of live stock to agricultural workers animal husbandry ${ }_{r p}^{1900}$ is available at the municipality level.

${ }^{22}$ At the municipality level, we need to approximate the number of people in agriculture in 1900 with the share of people in agriculture measured in 1934 times the total population in 1900. The census of 1934 was the first census in Austria to publish detailed information on the employment sector at the municipality level. The correlation of the share of the population in agriculture in 1900 and 1934 at the district level is 0.929. This suggests that there was little regional variation in the reduction of the agricultural sector.
} 
in equation 1) the ratio of live stock unit to agricultural workers in the municipality of residence in 1900. One advantage of measuring illegitimacy on an individual level is that we can control (besides our standard set of municipality-level covariates, and province fixed-effects) also for individual-level covariates and year of conception effects.

\subsection{OLS estimates}

Table 5 summarizes OLS estimates of equation (1) using district-level data covering the Habsburg Empire (in columns 1 to 3), municipality-level data covering Austria (in columns 4 to 6), and individual-level data from the Austrian Birth Register (in columns 7 to 9). In each case, we present three specifications, where we increase the set of covariates stepwise. Across data-sets and specifications, we find a positive relationship between the historic dominance of animal husbandry and today's illegitimacy. For the Habsburg Empire, we find that one more livestock unit per agricultural worker in 1900, is associated with an increase in today's illegitimacy ratio by 2.3 percentage points (see column 3 ). This is equivalent to a beta-coefficient of 0.12 . For the Austrian sample, we find a somewhat larger beta-coefficient of 0.18 (see column 6 ). The estimated coefficients vary little; once we control for province fixed effects. This also holds for the linear probability model (see column 9), where we use detailed information on mother's socio-economic background and religious denomination.

Clearly, these OLS estimates should not be interpreted in a causal manner. First, persistent omitted factors that are not captured by our covariates could have influenced the dominant form of agriculture in the past, and also affect today's illegitimacy ratio. Second, the causality could run the other way. A region with a persistently high share of illegitimate children offers a large pool of cheap labor. Labor-intensive animal husbandry would have had a comparative advantage over crop farming in the past. The correlation between the historic agricultural structure and today's prevalence of illegitimacy would then be spurious. Third, measurement error in the explanatory variable could attenuate the estimated effect. These three potential issues do not allow a clear prediction of the bias of the OLS estimates. Reverse causality would over-estimate the causal effect, while measurement error would lead to attenuation bias of the OLS estimates. An omitted variable could bias the estimates in either direction. In the next section, we address these issues by employing an instrumental variable strategy. We perform this analysis only in the Austrian sample, since we do not have access to the required data for the other regions.

\subsection{Addressing causality}

We exploit variation in the comparative advantages of animal husbandry across regions as an exogenous determinant of the historical dominance of live stock (over crop) farming. The notion that persistent environmental factors have a strong effect on agricultural production can already be found in the early anthropological literature (e.g. Löfgren, 1976). In line with this 
supposition, we suggest using the slope of the terrain as an instrumental variable (IV) for the historical dominance of animal husbandry. ${ }^{23}$

Slope of terrain IV The slope of the terrain is an important landscape characteristic for crop farming. It affects the productivity of the soil in multiple ways. The higher the slope, the more water runoff and the higher the hazard of soil erosion. Steep terrain soils also tend to be low in natural fertility due to the loss of topsoil from past erosion. Thus, in steep-slope regions it is comparably more efficient to focus on animal husbandry. The slope of terrain is highly time-invariant. Therefore, we can use modern GIS data for Austria to capture the historical situation. Our data allow us to calculate the mean slope of a certain region based on $10 \mathrm{~m} \times 10 \mathrm{~m}$ grid cells. ${ }^{24}$ Panel B of Table 6 summarizes the estimation results for the first-stage relationship of our IV approach. We find a robust positive effect of the slope of terrain on animal husbandry, with beta coefficients of around 0.2. The F-statistic on the excluded instrument is sufficiently high in all specifications.

For our IV to be a valid, we must assume (i) that the slope affects illegitimacy today only through the channel of historical dominance of animal husbandry, and (ii) that it is not correlated with any unobserved determinants of illegitimacy today. The validity of these assumptions can be rationalized by the fact that life in a modern economy is very much detached from nature, such that the topography should have no systematic impact. Even for women employed in agriculture, a direct effect of the slope on fertility seems unreasonable today. Technological progress and governmental interventions have fundamentally changed the physical production process and labor contracts in the agricultural sector. Given the minor importance of agriculture today, we can easily exclude the few remaining workers in the agricultural sector from our analysis with little loss of generality (see below).

Panel A of Table 6 shows estimations of equation (1), where the ratio of livestock units to agricultural workers is instrumented with the mean terrain slope. Thus, we focus on exogenous variation in the historical dominance of animal husbandry. The estimated coefficient can be interpreted as the effect of a strong dominance of animal husbandry (due to steep slope of terrain) on today's illegitimacy ratio. Columns (1) to (3) of Table 6 sequentially include province fixed effects and control variables. An increase in the ratio of live stock to agricultural workers by one unit increases the share of illegitimate births by 12.5 percentage points in column (3). This corresponds to a beta-coefficient of 1.03. This indicates the important role of the historic agricultural structure in explaining the contemporary variation in illegitimacy ratios. This estimate is approximately five times larger than the corresponding OLS estimate. The difference between these two estimates can be explained either by measurement error or confounding factors in the OLS estimate, which are negatively correlated with the illegitimacy ratio.

\footnotetext{
${ }^{23}$ Another potential determinant of the predominant form of agriculture is soil type and quality. However, soil quality is endogenous to the form of past land usage (Dell, 2010), which invalidates its use as an IV.

${ }^{24}$ The slope of terrain is very similar to terrain ruggedness with a correlation coefficient of 0.996 in our sample.
} 
Columns (4) to (6) of Table 6 exploit the individual-level data and summarize three linear probability models, which differ with respect to the set of included control variables. In the richest specification we control for the mother's age (binary indicators capturing five different age-groups), her religious denomination (binary indicators capturing Catholics, Protestants, Muslims, other denominations, and unknown/atheist), her educational attainment (binary indicators capturing compulsory schooling, apprenticeship, intermediate technical or vocational school, university degree, or unknown), and the parity of birth. This specification addresses several potential concerns with the exclusion restriction. Across specifications, we consistently find that a strong regional dominance of animal husbandry in a municipality (due to steep slope of terrain) significantly increases the likelihood of an illegitimate birth for a woman residing in that municipality today. The estimated quantitative effects hardly change due to the inclusion of covariates. An increase in the ratio of live stock to agricultural workers by one increases the probability of an illegitimate birth by approximately 10 percentage points (or 30 percent). This analysis also points to a downward bias of OLS estimates (compare columns 7 to 9 in Table 5). Finally, Panel C of Table 6 summarizes the estimates of our reduced forms. These identify the net effect of the mean terrain slope on illegitimacy today and show that biophysical factors structurally affect illegitimacy in a modern society. ${ }^{25}$ While these estimates are silent on the causal mechanisms, they impose relatively few identification assumptions and allow a strong causal interpretation (Dell et al., 2014).

We have also explored the effect in various sub-samples of mothers (see upper Panel of Appendix Figure C.7). First, our results are completely unchanged, when we exclude the 5 percent of all women, who are employed in agriculture before birth. Second, we do not observe differences between young mothers (below the median age of 27 mothers) and older mothers. The same holds true for mothers with a low attainment versus a higher educational attainment (at least upper secondary education). Only, for the sub-group of first-time mothers (approximately 44 percent), we find somewhat larger effects. The estimated effects are also very robust across different sub-samples of municipalities and sample periods (see lower Panel of Appendix Figure C.7). For instance, we do not find different results in sub-samples defined by population size.

A recent contribution by Kelly (2019) argues that estimates in the literature on persistence have likely inflated t-statistics due to spatially correlated observations. We evaluate this critique in our context in two steps. First, we adjust our standard errors as suggested by (Conley, 1999). Since there is not a single correct specification of, we show Conley standard errors for a whole range of cutoff distances. Figure 5 summarizes corresponding t-values for our main specifications. We see that t-values are consistently above three, which corresponds to a pvalue of 0.003 . Second, we perform simulations with a spatially correlated noise variable. This

\footnotetext{
${ }^{25} \mathrm{~A}$ link between biophysical factors and characteristics of marriage market has been discussed in other contexts. The literature explaining the occurrence of polyandry considers 'harsh environments' as one important factor (e.g. Cassidy and Lee, 1989; Wolff and Macdonald, 2004).
} 
noise never outperforms our explanatory variable if the spatial correlation structure is similar to our data (see Appendix Table B.1). This suggests that the relationship between historical dominance of animal husbandry and illegitimacy today is not an artefact of spatial correlation. Appendix B.2 provides a more detailed discussion.

Potential threats to identification Our IV estimates are valid if terrain slope affects illegitimacy today only through the channel of historical dominance of animal husbandry and if it is not correlated with any unobserved determinants of illegitimacy today. One way to assess the plausibility of these assumptions and to test the robustness of our IV estimates, is to include control variables for alternative pathways of the IV. We perform a series of such tests. First, we focus on additional historic covariates (see Panel A of Table 7). Then we add additional contemporary control variables (see Panel B of Table 7). Another concern could be that our IV approach is driven by peculiarities present in mountainous regions. Thus, we drop high-lying municipalities from our analysis (see Panel $\mathrm{C}$ of Table 7). Finally, we also exclude flat(er) municipalities (see Panel D of Table 7).

Influence of the Roman Catholic Church A first potential violation of the exclusion restriction runs through religion and the Roman Catholic Church. Steeper terrain could indicate a more remote location, therefore less reach of the Roman Catholic Church, and less enforcement of moral standards, or differences in reporting of illegitimacy (to please the church). The presence of the church and its influence on moral standards could have persisted until today. While we already control in our baseline specification for urbanity, we add now more specific variables to rule out this channel. In column (A1) of Table 7 we include two binary variables, which capture the local presence of affiliates of the Roman Catholic Church. First, we control for the availability of a priest in the municipality in 1900. About 25 percent of the all municipalities did not host a priest. Second, we control for the existence of a monastery in 1900 within 10 kilometers of the municipality. The inclusion of these two additional covariates does not change our estimate. We further address this concern below, where we control for religiosity.

Human capital Another source of concern could be differences in education or human capital. While we already control for mothers' educational attainment in our individual-level analysis, areas with a steeper terrain might have had historically different access to or view on formal education, which in turn affected views on fertility, which may persist until today. To address this concern, we control in column (A2) with two binary variables for the existence of an elementary school and a kindergarten within the municipality in 1900. About 84 percent of all municipalities had an elementary school, and about 7 percent had a kindergarten. Controlling for these two variables does not affect our estimate. We further address this concern below, by controlling for differences in educational attainment today.

Health infrastructure Given that childbirth was a comparably risky event for mother's health in the past, the availability of (basic) health infrastructure might had a direct effect on fertility behavior. This might have been in particular relevant for unmarried mothers, who were 
less likely to have access to a supportive family network. While Austria has a comprehensive health care system today, which covers all regions, we still control for historical differences. In column (A3), we control for the availability of (basic) health infrastructure by including three binary variables capturing the local availability of a midwife, a doctor, and a hospital in 1900. Controlling for differences in historical health infrastructure has no impact on our estimate.

Migration The slope of terrain of a municipality might also affect the degree of in- and outmigration. Migration certainly has an effect on the local marriage market and a potential impact on our outcome variable of interest. To account for this possible violation of the exclusion restriction, we control in column (B1) for the municipalities' population growth between 1900 and 1971 (i. e., before we measure our dependent variable) and the share of foreigners in a municipality in 2011. While both covariates have an impact on today's illegitimacy ratio, their inclusion has no effect on our estimate of primary interest. We conclude that migration patterns that are correlated with terrain slope (and hence with the form of historic agricultural production structure) do not confound our estimates.

Income distribution In our baseline specification, we already control for a number of variables to capture the historical socio-economic condition in a given municipality. However, it could be that our covariates are not sufficient to capture persistent income differences between municipalities with different slopes of terrain. To address this concern, we additional historic and contemporary covariates. First, we use changes in local population as an additional proxy for historical poverty. This is based on the simple idea that population is more likely to leave impoverished places and to migrate to more prosperous areas. Our estimate is robust to the inclusion of the total population change between 1890 and 1900 in column (A4). The same holds true, when we include all additional historic covariates simultaneously in column (A5). Second, we control in column (B2) for the contemporaneous educational attainment distribution and in column (B3) for the mean income and the share of unemployed population. Including these variables does not change our main estimate either.

Tourism A further potential violation of the exclusion restriction is the tourism industry. Regions with a steep slope may have more tourism due to skiing and hiking. A strong dominance of tourism may have an independent effect on the fertility behavior of the local population through contact with many potential sex partners. We approximate the size of the tourism industry with the number of beds for touristic purposes per capita in 2013, see column (B4). Again, the estimate of interest does not react to the inclusion of this covariate. Finally, in column (B5), we include all additional contemporaneous variables at the same time.

Alpine municipalities Our IV is correlated with mountainous areas and the corresponding lack of social and economic integration. One might be concerned that people in Alpine municipalities have developed, over the centuries, a different culture and mindset, shaped by a harsh environment and remoteness. This mindset might have led to a distinct cultural norm regarding illegitimacy. In order to make sure that our estimates do not pick up this confounding factor, we re-run our estimations for municipalities in lower-lying areas. In columns (C1) to 
(C5), we focus stepwise on municipalities with elevations below a certain threshold. We see that the estimated effects is even larger in lower-lying areas. Thus, we are confident that we do not pick up an 'Alpine-mindset' in lower-lying areas (i.e., below 700 metres), but only a comparative advantage for animal husbandry due to steep terrain. In comparable specifications, we successively drop flat(er) municipalities. The estimation results summarized in columns (D1) to (D5) show that we obtain almost unchanged estimates across samples. ${ }^{26}$

Religiosity Another concern we want to address is a potential correlation between the slope of the terrain and religiosity. While we have already controlled for mothers' religious denomination in our individual-level analysis, the intensity of their beliefs could have a separate and direct effect on today's illegitimacy. To measure religiosity we use data from the Generations 86 Gender Programme (GGP) survey, which includes a question on the number of attended religious services and on respondent's evaluation of the importance of infant baptism. The GGP includes information on the respondents' districts of residence, which allows us to construct a measure of the average religiosity in a given district (but not municipality). Estimations show that higher religiosity is negatively correlated with illegitimacy, but the inclusion of these controls has no effect on our estimate of primary interest (see Appendix Table D.5).

Informal insurance arrangements and trust Further potentially important institutional features are informal insurance arrangements and trust. There is evidence that the exposure to agricultural risks (mainly due to climate variability) has historically led to higher internal risk sharing (Ager and Ciccone, 2018), to an early adoption of inclusive political institutions, and to persistently higher levels of trust (Litina, 2016; Buggle and Durante, 2017). ${ }^{27}$ This is relevant in our context, since both livestock and marriage can be seen as insurance devices. Using the same additional data source and data structure as in the case of religiosity, we capture the average level of trust and cooperation in a given district. The inclusion of these two additional controls has no effect on our estimate of primary interest (see Table 8).

Inheritance system Differences in (legal) institutions are already captured by our province fixed effects, the lowest administrative level at which legal regulations vary. One potential exception is the inheritance system. This had been regulated by federal and provincial law at least since 1786. Thus, de jure, there should have been no differences within provinces. However, it is noted that the rural population may have rather followed their (local) custom (Zuckerkandl, 1889). De facto, the system of impartible inheritance was dominant in most parts of today's Austria. The only exceptions are West Tyrol, Vorarlberg and Burgenland, where partible inheritance for male and female descendants was the guiding norm (Mitterauer, 1992). Thus, in Tyrol we have some potential intra-province variation. Ideally, we would like

\footnotetext{
${ }^{26}$ In untabulated results, we also directly control for one aspect of economic isolation: access to a railway in 1900. The inclusion of control variables capturing the existence of a train station and/or a train stop does not change the estimated effects.

${ }^{27}$ Relatedly, Ang (2019) shows a relationship between the historical cultivation of different crops and the emergence of individualistic culture. Individualism has emerged predominantly in societies engaged in the farming of less labor-intensive crops.
} 
to observe the de facto inheritance practice on a disaggregated level and control for it in our regression. While this information is not available (at least, not in a systematic manner), we can proxy for the prevailing inheritance practice in all districts very well with the farm size distribution. A partible inheritance practice will ceteris paribus lead to a high number of small farms. Our baseline specification already includes a binary variable capturing the existence of large landholdings. In additional specifications, we control for the share of farms below 5 hectare land (ha), between 5 and 10 ha, between 10 and 20 ha, and above 20 ha. The inclusion of these additional covariates reduces our estimated effect of the historic dominance of animal husbandry on today's illegitimacy ratio somewhat, but it remains highly statistically significant.

Reverse causality It could also be instructive to study the historical development of animal husbandry and illegitimacy over longer periods of time. Ideally, one could even observe periods before the introduction of (widespread) animal husbandry and examine its impact on illegitimacy. This timing would allow reverse causality to be ruled out. We obtained data that allow us to measure the illegitimacy ratio and the ratio of cattle to people consistently from 1830 through 1900 on the province level (see Appendix Figure C.8). It emerges that animal husbandry (proxied by cattle) was already very common in 1830 and there had been little variation between 1830 and 1900 in half of the provinces. Nevertheless, it is instructive to see that in those provinces with little (to no) variation in the ratio of cattle to population, the illegitimacy ratio had also been constant. Even more importantly, in those provinces (Carinthia, Salzburg, Styria) in which the ratio of cattle to agricultural workers varied over time, we observe with some lag the same pattern in the illegitimacy ratio. We interpret these figures as suggestive evidence that animal husbandry affects illegitimacy (and not vice versa).

\subsection{Interpretation of empirical findings}

The evidence presented so far strongly suggests that the relative dominance of animal husbandry affected illegitimacy in the past, and has a lasting effect on it today. Our IV estimates highlight a causal chain, where local agricultural suitability determined the historical dominance of animal husbandry. This specific agricultural production structure led in turn to predominantly longterm labor contracts for farmhands with a high share of wages paid in kind. These labor arrangements caused illegitimate births to be an acceptable (if not desired) phenomenon for all parties involved in these pre-industrial farmhand societies. All steps in this causal chain involve a clear economic rationale. Thus, we interpret the high illegitimacy ratios in these proto-industrial farmhand societies as the result of clear economic incentives.

The final link we have identified, which shows the persistent effects of this past economic outcome on illegitimacy today, stands out. There is no economic rationale (in the narrower sense), which can explain this persistence in behavior for individuals in today's economy. Although the economic rationale linking the dominance of animal husbandry and illegitimacy has completely vanished, individuals have not changed their behavior. There is no evidence that 
this pattern is getting any weaker over time; a decade-specific analysis reveals that the quantitative effect is quite stable (see lower Panel of Appendix Figure C.7). Our findings are also robust to re-defining our measurement of the historical dominance of animal husbandry. These findings let us suggest interpreting the persistence in revealed preferences regarding illegitimacy as a cultural norm. Our findings highlight the more general phenomenon that cultural norms can be shaped by economic conditions, and may persist, even if economic conditions become irrelevant.

Another potential mechanism would be a comparative advantage of women in animal husbandry that led to better employment opportunities, later marriages, and more illegitimate births. Three pieces of evidence speak against this interpretation: first, historically, women had lower earnings as agricultural servants than as day laborers (see Panel A of Appendix Table D.2). The male-female gradient is around 30 percent in both groups. Second, there is no relationship between the historical dominance of animal husbandry and female labor force participation rates today (see Panel A of Appendix Table D.9). The same holds for earnings today (see Panel B of Appendix Table D.9).

\section{Supportive evidence and other demographic outcomes}

In this section, we provide two complementary analyses with Austrian data to underpin our interpretation. First, we present evidence based on stated preferences. Second, we provide an analysis of so-called shotgun weddings. Finally, we briefly study several other historical demographic outcomes to provide more context for our main result.

\subsection{Evidence from stated preferences}

So far, we have examined revealed preferences by looking at actual behavior. We now make use of individual-level survey data to study stated preferences. This analysis is instructive for two reasons. First, there might be a gap between these two dimensions (beyond survey response bias) due to unintended illegitimate births. Second, stated and revealed preferences may be correlated with a different set of confounding factors. Thus, if we find the same pattern in stated preferences, this would clearly underpin the conclusion derived from our main analysis.

We use data from the Generations 85 Gender Programme (GGP) survey, which includes two useful questions. The first question is on whether 'It should be accepted if a single woman wants a child, but not a long-term relationship.' The second question is on whether 'It is all right for an unmarried couple to live together even if they have no interest in marriage'. In each case, respondents are asked to evaluate this statement on a 5-point scale ranging from 'strongly disagree (1)' to 'strongly agree (5)'. While neither survey question is ideal (since it does not explicitly refer to illegitimate births), the GGP survey has the clear advantage over other surveys that it includes quite detailed information on the respondents place of residence. This allows us 
to link the historical illegitimacy ratio (and animal husbandry) of the respective respondents' districts of residence to their stated preferences. Our estimation sample comprises about 2, 820 respondents from 63 different districts. In our OLS estimations of stated preferences, we control for the same set of district-level covariates as used above, and a basic set of individual-level controls. Standard errors are clustered at the district-level. ${ }^{28}$

The estimation results are summarized in Table 9 . In each specification, the dependent variable is a binary indicator equal to one if a respondent strongly agrees with the respective statement. Columns (1) and (2) focus on the approval of being a single parent, while columns (3) and (4) examine the acceptance of cohabitation. Across specifications, we find a significant positive associations between both historical measures and the strong approval of both statements. An increase in the historical illegitimacy ratio by one standard deviation, increases the likelihood of a strong approval of single parenthood and cohabitation around 4 percentage points. The respective values for an equivalent increase in the historical animal husbandry are 2 and 4 percentage points.

\subsection{Evidence from shotgun weddings}

If illegitimate births are socially unwanted events, individuals will exert more effort to avoid them. Most of the potential actions to avoid an illegitimate birth (such as chastity, contraception, or abortion) are difficult to observe and thus difficult to study. However, there is the exception of so-called shotgun weddings. This describes the common practice of averting an illegitimate birth, in the case of an unmarried woman becoming pregnant, by arranging a wedding on short notice. ${ }^{29}$ Given that shotgun weddings and low illegitimacy ratios should depend on the same social norm, we can check empirically whether we find equivalent patterns between a strong regional historical dominance of animal husbandry and these two measurements, respectively.

We define all cases where a woman was unmarried at the time of conception, but married before birth, as a shotgun wedding. The conception date can be approximated by combining information on the date of birth and gestation length. While we do not observe who was the driving force behind this wedding, we associate this particular timing with the intent to avoid the embarrassment of an illegitimate birth. Starting from 1984, we are able to observe the conception date in the Austrian Birth Register. Shotgun weddings are a common phenomenon. In 1984, in approximately 40 percent of cases of pre-marital conception, we observed shotgun weddings. Over time, this share decreased steadily to approximately 20 percent in 2007 (see Appendix Figure C.9).

\footnotetext{
${ }^{28}$ We do not have information on the respondents' municipality. We do not present IV-estimates, since the first stage is not sufficiently strong at the district level.

${ }^{29}$ In the American colloquialism, the term shotgun wedding is used to describe a hypothetical scenario in which the father of the pregnant girl must resort to using coercion (e.g., a threat with a shotgun) to ensure that the man who supposedly impregnated his daughter follows through with the wedding.
} 
Using the sample of all births to first-time Austrian mothers, which were conceived before marriage, we estimate an OLS and an IV model, where the dependent variable is equal to one if a wedding took place before birth, and zero otherwise. Thus, we estimate conditional on a pre-marital conception, the likelihood of a wedding before child birth. Table 10 summarizes six different specifications, which differ with respect to the estimation method and the set of included control variables. Across specifications, we find that a strong regional historical dominance of animal husbandry significantly decreases the likelihood of a shotgun wedding today. The corresponding OLS estimates are, consistent with our estimates presented above, comparably smaller. In the IV model, an increase in the ratio of livestock unit to agricultural workers by 1 , decreases the probability of a shotgun wedding by approximately 11 percentage points (or 45 percent).

\subsection{Other historical demographic outcomes}

On the district level, information is available on several historic demographic outcomes. We have collected data on age at marriage, the stock of married people, and the level of marital and non-marital fertility. The analyses of these additional outcomes allow us to put our estimated effects of the relative dominance of animal husbandry on past illegitimacy into perspective and to extend our conclusions. In the following, we briefly discuss our main qualitative findings. ${ }^{30}$

Across estimation methods, we do not find evidence that animal husbandry significantly affected age at marriage. This finding suggests that servants in animal husbandry did not postpone marriage, but, in most cases, remained unmarried for their whole lives. This is in line with our evidence that the legitimization of children born out of wedlock, was a rather rare event (see Appendix Figure C.6). It also supports the concept of the life long servant discussed in qualitative studies on contemporary Austrian history (Ehmer, 1991). Consistent with this supposition, we observe a significantly lower share of married women in regions with a higher dominance of animal husbandry. We purposely refer here to the group of women of 46 years of age and above, since a later marriage is unlikely for this group, and thus, the measurement can essentially be interpreted as a measure of the share of never married. ${ }^{31}$ With respect to fertility levels, we find a significant positive effect of the relative dominance of animal husbandry on the non-married fertility rate. This result supports the idea that in areas with more animal husbandry, illegitimacy was quite accepted, and thus led to a higher demand for these children. In contrast, we do not observe a significant difference in the married fertility rates across regions with a high or low dominance of cattle farming. Thus, the impact of the agricultural production structure on overall fertility is rather small.

\footnotetext{
${ }^{30}$ Detailed estimation output from additional OLS and IV estimations is available in Appendix Table D.6.

${ }^{31}$ In approximately 5 percent of all marriages in 1900 , the bride was older than 45 years.
} 


\section{Analysis of the transmission channel}

In a final step, we analyze two hypotheses on the transmission of the cultural norm regarding illegitimacy. The economics literature on cultural transmission distinguishes two broad channels: cultural norms may be shaped by purposeful socialization decisions inside the family or by indirect socialization processes in the wider social group. The former channel is often termed 'direct vertical socialization' and the latter 'oblique and horizontal socialization' (Cavalli-Sforza and Feldman, 1981; Bisin and Verdier, 2011). To test the relative importance of these two channels, we exploit two types of migrants: immigrant mothers to Austria and internal migrant mothers. Migration helps us to obtain variation in vertical and horizontal socialization. First, migrants from the same location of origin can be placed in Austrian regions with different local norms. A comparison among these migrants quantifies the importance of horizontal socialization (while holding vertical socialization constant). Second, migrants from different locations of origin (inside and outside Austria) can be placed in the same Austrian region. This comparison provides variation in vertical socialization. ${ }^{32}$ If we observe that migrants tend to behave according to the norm in their location of origin, then vertical socialization is dominant. In contrast, if we find that migrants behave according to the norm in the receiving location, then horizontal socialization is more important.

Our sample of foreign born women gave birth in the period between 1984 to 2007. We include immigrants from all sending countries with at least 50 births in our sample. For these countries, we would ideally like to obtain data on the historical dominance of animal husbandry and use this to capture the cultural norm. Due to data restrictions, we have to use the historical illegitimacy ratio on the latter. ${ }^{33}$ To generate our sample of internal migrants, we start with all mothers who were born after 1972 and gave birth to a child before 2007. These restrictions guarantee that we observe both events in the Austrian Birth Register. We then define internal migrants as all women, who changed their municipality of residence between her own birth and the time of their first child. Restricting the sample to municipalities of birth and latter residence for which we have information on animal husbandry in 1900 leaves us with 19, 457 mothers.

Tables 11 and 12 summarize a linear probability model of the likelihood of an illegiti-

\footnotetext{
${ }^{32}$ The latter comparison is often called an epidemiological approach. Fernández (2011) defines this approach as the attempt to identify the effect of culture through the variation in outcomes of individuals, who share the same institutional environment, but whose cultural norms are potentially different. Most empirical analyses have focused on immigrants from various sending countries within one receiving country. Compared to the traditional epidemiological approach, we exploit not only variation in the cultural norm across groups of immigrants, but also variation in the local norm within the receiving country.

${ }^{33}$ We aim to measure the historical illegitimacy ratio in 1900. If no data for 1900 are available, we use data from the earliest year possible. For 16 countries, no historical data were available at all. Countries from South America are excluded, since Hartley (1975) discusses the questionable reliability of (historical) illegitimacy ratios from these countries. Details are provided in Appendix Table D.10. Given that the resulting estimations have an unequal number of observations across sending countries - most immigrants come from (former) Yugoslavia, Turkey, and Germany — we verify that the epidemiological correlation is also significant at the country level (see Appendix Figure C.10).
} 
mate birth for the two types of migrants, respectively. For immigrant mothers, we find across specifications that both historical illegitimacy ratios significantly affect the probability of an illegitimate birth. However, the impact of illegitimacy ratio at the place of residence, which is associated with horizontal socialization, has a comparably small effect. The estimates range, depending on the specification, between 0.11 and $0.16{ }^{34}$ The impact of the historical illegitimacy ratio in their (ancestors') country of origin is about 15 times larger. The inclusion of control variables for mothers' religious denominations in column (4), and historic macroeconomic variables in column (5) decreases the ratio to 13 and 11, respectively.

For internal migrants, we find an equivalent result. Considering columns (1) and (2) of Table 12, we find that the historical dominance of animal husbandry in the municipality of birth is a significant predictor for an out-of-wedlock-birth. ${ }^{35}$ In contrast, the historical dominance of animal husbandry in the current municipality is in both cases a precisely estimated zero effect. To ensure that internal migrants mothers are indeed exposed to a different local norm environment, we re-run our estimation for those who moved to another district (column 3) or even another province (column 4).

Across all samples and specifications we find evidence suggesting that the cultural norms regarding illegitimacy is predominantly shaped inside the family (vertically) and socialization by the wider social group (horizontally) is of minor importance. Put differently, the norm seems to be passed down through generations and the enforcement of a prevailing cultural norm at the current place of residence is only of second order importance.

\section{Conclusions}

This paper explores the historical origins of the cultural norm regarding illegitimacy in the context of the Habsburg Empire and its successor countries. We test the hypothesis that traditional agricultural production structures (measured around 1900) influenced illegitimacy ratio in the past, and have a lasting effect until today. Based on data from the Habsburg Empire and modern Austria, we show that regions that focused on animal husbandry (as compared to crop farming) had significantly higher illegitimacy ratios in the past, and female descendants of these societies are today still more likely to approve illegitimacy (in survey data) and give birth outside marriage. Since the differences in the agricultural production structure are completely obsolete in today's economy, we suggest interpreting the persistence in revealed and stated preferences as a cultural norm. Complementary evidence suggests that this norm is passed down through generations, and the family is the most important transmission channel. Our findings are one example for the more general phenomenon that cultural norms can be shaped by economic conditions, and may persist, even if economic conditions become irrelevant. For

\footnotetext{
${ }^{34}$ For comparison, the corresponding estimate for Austrian women is about about 2.5 times larger (see Table 3).

${ }^{35}$ The estimated coefficients are very comparable to the OLS estimates we have obtained in the full sample (see columns 7 to 9 of Table 5).
} 
future research it would be interesting to study how this persistent cultural norm affects teenage pregnancy and the welfare of children and mothers today (Kearney and Levine, 2014).

\section{References}

Ager, P. and Ciccone, A. (2018). Agricultural Risk and the Spread of Religious Communities. Journal of the European Economic Association, 16 (4), 1021-1068.

Akerlof, G. A., Yellen, J. L. and Katz, M. L. (1996). An Analysis of Out-of-Wedlock Childbearing in the United States. Quarterly Journal of Economics, 111 (2), 277-317.

Alesina, A. and Giuliano, P. (2007). Divorce, Fertility and the Value of Marriage. Tech. rep., Harvard University.

— and - (2015). Culture and Institutions. Journal of Economic Literature, 53 (4), 898-944.

- - - and Nunn, N. (2013). On the Origins of Gender Roles: Women and the Plough. Quarterly Journal of Economics, 128 (2), 469-530.

Ang, J. B. (2019). Agricultural Legacy and Individualistic Culture. Journal of Economic Growth, 24 (4), 397-425.

— and Fredriksson, P. G. (2017). Wheat Agriculture and Family Ties. European Economic Review, 100, 236-256.

Becker, A. (2019). On the Economic Origins of Restrictions on Women's Sexuality. Unpublished manuscript, Harvard University.

Becker, S. O., Boeckh, K., Hainz, C. and Woessmann, L. (2016). The Empire Is Dead, Long Live the Empire! Long - Run Persistence of Trust and Corruption in the Bureaucracy. Economic Journal, 126 (590), 40-74.

Bethmann, D. and Kvasnicka, M. (2011). The Institution of Marriage. Journal of Population Economics, 24 (3), 1005-1032.

- and - (2013). World War II, Missing Men and Out of Wedlock Childbearing. Economic Journal, 123 (567), 162-194.

Bisin, A. and Verdier, T. (2011). The Economics of Cultural Transmission and Socialization. In J. Benhabib, A. Bisin and M. O. Jackson (eds.), Handbook of Social Economics, vol. 1, Elsevier Science, pp. 339-416.

Buckles, K. S. and Price, J. (2013). Selection and the Marriage Premium for Infant Health. Demography, 50 (4), 1315-133.

Buggle, J. and Durante, R. (2017). Climate Risk, Cooperation and the Co-Evolution of Culture and Institutions. CEPR Discussion Paper 12380, Centre for Economic Policy Research.

Cameron, A. C. and Miller, D. L. (2015). A Practitioner's Guide to Cluster-Robust Inference. Journal of Human Resources, 50 (2), 317-373. 
- and Trivedi, P. K. (2005). Microeconometrics: Methods and Applications. New York: Cambridge University Press.

Carmichael, S. G., De Pleijt, A., van Zanden, J. and De Moor, T. (2016). The European Marriage Pattern and Its Measurement. Journal of Economic History, 76 (1), 196-204.

Cassidy, M. L. and Lee, G. R. (1989). The Study of Polyandry: A Critique and Synthesis. Journal of Comparative Family Studies, 20 (1), 1-11.

Cavalli-Sforza, L. and Feldman, M. (1981). Cultural Transmission and Evolution: A Quantitative Approach. Princeton, NJ: Princeton University Press.

Conley, T. G. (1999). GMM Estimation with Cross Sectional Dependence. Journal of Econometrics, 92 (1), 1-45.

De Moor, T. and van Zanden, J. (2010). Girl Power: The European Marriage Pattern and Labour Markets in the North Sea Region in the Late Medieval and Early Modern Period. Economic History Review, 63 (1), 1-33.

Dell, M. (2010). The Persistent Effects of Peru's Mining Mita. Econometrica, 78 (6), 18631903.

-, Jones, B. F. and Olken, B. A. (2014). What Do We Learn from the Weather? The New Climate-Economy Literature. Journal of Economic Literature, 52 (3), 740-798.

EHmer, J. (1991). Heiratsverhalten, Sozialstruktur, ökonomischer Wandel, vol. 92. Göttingen: Vandehoeck \& Ruprecht.

Fernández, R. (2011). Does Culture Matter? In J. Benhabib, M. O. Jackson and A. Bisin (eds.), Handbook of Social Economics, vol. 1A, Elsevier, pp. 481-510.

Fernández, R. and Fogli, A. (2006). Fertility: The Role of Culture and Family Experience. Journal of the European Economic Association, 4 ((2-3)), 552-561.

- and Fogli, A. (2009). Culture: An Empirical Investigation of Beliefs, Work, and Fertility. American Economic Journal: Macroeconomics, 1 (1), 146-177.

Fernández-Villaverde, J., Greenwood, J. and Guner, N. (2014). From Shame to Game in One Hundred Years: A Macroeconomic Model of the Rise in Premarital Sex and its De-Stigmatization. Journal of the European Economic Association, 12 (1), 25-61.

Frimmel, W. and Pruckner, G. J. (2014). Birth Weight and Family Status revisited: Evidence from Austrian Register Data. Health Economics, 23 (4), 426-445.

Furtado, D., Marcén, M. and Sevilla, A. (2013). Does Culture Affect Divorce? Evidence From European Immigrants in the United States. Demography, 50, 1013-1038.

Galor, O. and Özak, O. (2016). The Agricultural Origins of Time Preference. American Economic Review, 106 (10), 3064-3103.

Giuliano, P. (2007). Living Arrangements in Western Europe: Does Cultural Origin Matter? Journal of the European Economic Association, 5 (5), 927-952. 
- (2017). Gender: An Historical Perspective. NBER Working paper 23635, National Bureau of Economic Research, Cambridge, MA.

- and Nunn, N. (2017). Understanding Cultural Persistence and Change. Unpublished manuscript, University of Los Angeles, California and Hardvard University.

Grosfeld, I., Rodnyansky, A. and Zhuravskaya, E. (2013). Persistent Antimarket Culture: A Legacy of the Pale of Settlement after the Holocaust. American Economic Journal: Economic Policy, 5 (3), 189-226.

Grosjean, P. (2014). A History of Violence: The Culture of Honor and Homicide in the US South. Journal of the European Economic Association, 12 (5), 1285-1316.

- and Khattar, R. (forthcoming). It's Raining Men! Hallelujah? The Long-Run Consequences of Male-Biased Sex Ratios. Review of Economic Studies.

Guiso, L., Sapienza, P. and Zingales, L. (2006). Does Culture Affect Economic Outcomes? Journal of Economic Perspectives, 20 (2), 23-48.

—, - and - (2016). Long-term Persistence. Journal of the European Economic Association, 14 (6), 1401-1436.

Hajnal, J. (1965). European Marriage Patterns in Perspective. In D. Glass and D. Eversley (eds.), Population in History: Essays in Historical Demography, Chicago: Aldine Publishing Company, pp. 101-143.

- (1982). Two Kinds of Preindustrial Household Formation System. Population and Development Review, 8 (3), 449-494.

Halla, M. (2013). The Effect of Joint Custody on Family Outcomes. Journal of the European Economic Association, 11 (2), 278-315.

Hartley, S. F. (1975). Illegitimacy. Berkeley and Los Angeles, CA: University of California Press.

Haslinger, A. (1982). Uneheliche Geburten in Österreich Historische und regionale Muster. Demographische Informationen, pp. 2-34.

Hecke, W. (1930). Die Unehelichen in Oesterreich. Jahrbücher für Nationalökonomie und Statistik, 77 (4), 572-592.

Heuveline, P., Timberlake, J. M. and Furstenberg, Jr., F. F. (2003). Shifting Childrearing to Single Mothers: Results from 17 Western Countries. Population and Development Review, 24 (1), 47-71.

Kaser, K. (1987). Die Findelkinder der Oststeiermark. Zeitschrift des Historischen Vereines für Steiermark, 78, 277-296.

Kearney, M. S. and Levine, P. B. (2014). Income Inequality and Early Nonmarital Childbearing. Journal of Human Resources, 49 (1), 1-31.

— and Wilson, R. (2017). Male Earnings, Marriageable Men, and Nonmarital Fertility: Evidence from the Fracking Boom. NBER Working paper 23408, National Bureau of Economic Research, Cambridge, MA. 
Kelly, M. (2019). The Standard Errors of Persistence. Unpublished manuscript, University College Dublin.

KherA, S. (1981). Illegitimacy and Mode of Land Inheritance among Austrian Peasants. Ethnology, 20 (4), 307-323.

Klammer, P. (1992). Auf fremden Höfen: Anstiftskinder, Dienstboten und Einleger. Wien: Böhlau.

Knodel, J. (1967). Law, Marriage and Illegitimacy in Nineteenth-Century Germany. Population Studies, 20 (3), 279-294.

KytiR, J. and Münz, R. (1986). Illegitimität in Österreich. Demographische Informationen, pp. $7-21$.

Lackner, M., Halla, M. and Scharler, J. (2016). Does the Welfare State Destroy the Family? Evidence from OECD Member Countries. Scandinavian Journal of Economics, 118 (2), 292-323.

Laslett, P. (1977a). Characteristics of the Western Family Considered over Time. Journal of Family History, 2 (2), 89-115.

- (1977b). Family Life and Illicit Love in Earlier Generations: Essays in Historical Sociology. New York and London: Cambridge University Press.

LEe, W. (1977). Bastardy and the Socioeconomic Structure of South Germany. Journal of Interdisciplinary History, 7 (3), 403-425.

- (1978). Bastardy in South Germany: A Reply. Journal of Interdisciplinary History, 8 (3), $471-476$.

Litina, A. (2016). Natural Land Productivity, Cooperation and Comparative Development. Journal of Economic Growth, 21 (4), 351-408.

Löfgren, O. (1976). Peasant Ecotypes. Problems in the Comparative Study of Ecological Adaptation. Ethnologia Scandinavica. A Journal for Nordic Ethnology, pp. 100-115.

Mantl, E. (1999). Legal Restrictions on Marriage: Marriage and Inequality in the Austrian Tyrol During the Nineteenth Century. The History of the Family, 4 (2), 185-207.

Martin, J. A., Hamilton, B. E., Osterman, M. J., Driscoll, A. K. and Mathews, T. (2015). Births: Final Data for 2015. National Vital Statistics Reports, 66 (1).

Mitterauer, M. (1983). Ledige Mütter. Zur Geschichte illegitimer Geburten in Europa. München: C. H. Beck.

— (1986). Formen ländlicher Familienwirtschaft. Historische Ökotypen und familiale Arbeitsorganisation im österreichischen Raum. In J. Ehmer and M. Mitterauer (eds.), Familienstruktur und Arbeitsorganisation in ländlichen Gesellschaften, Wien: Böhlau, pp. 185-324.

- (1992). Peasant and Non-peasant Family Forms in Relation to the Physical Environment and the Local Economy. Jouranl of Family History, 17 (2), 139-159. 
Nuevo-Chiquero, A. (2015). Out-of-Wedlock Fertility, Post-Pregnancy Choices and Contraceptive Usage. Unpublished manuscript, University of Sheffield.

Nunn, N. and Wantchekon, L. (2011). The Slave Trade and the Origins of Mistrust in Africa. American Economic Review, 101 (7), 3221-3252.

Ortmayr, N. (1984). Beim Bauern im Dienst. In H. C. Ehalt (ed.), Geschichte von Unten, Wien: Böhlau, pp. 95-141.

- (1989). Späte Heirat, Ursachen und Folgen des alpinen Heiratsmusters. Zeitgeschichte, 4, $119-134$.

- (1996). Illegitimacy and Low-Wage Economy in Highland Austria and Jamaica. In M. J. M. A. Waltner (ed.), Gender, Kinship and Power: A Comparative and Interdisciplinary History, New York: Routledge, pp. 245-257.

Ragan, K. S. (2012). Sex and the Single Girl: Cultural Persistence and the Pill. Unpublished manuscript, Stockholm School of Economics.

SCHWEIZERISCHE BundeSRAT (1998). Verordnung über landwirtschaftliche Begriffe und die Anerkennung von Betriebsformen. Decree, Schweizerische Bundesrat.

Shah, P. S., Zao, J. and Ali, S. (2011). Maternal Marital Status and Birth Outcomes: A Systematic Review and Meta-Analyses. Maternal and Child Health Journal, 15, 1097-1109.

Shorter, E. (1978). Bastardy in South Germany: A Comment. Journal of Interdisciplinary History, 8 (3), 459-469.

-, Knodel, J. and Van De Walle, E. (1971). The Decline of Non-Marital Fertility in Europe, 1880-1940. Population Studies, 25 (3), 375-393.

Teibenbacher, P. (2009). Natural Population Movement and Marriage Restrictions and Hindrances in Styria in the 17th to 19th Centuries. History of the Family, 14 (3), 292-308.

VAN DE KAA, D. (1987). Europe's Second Demographic Transition. Population Bulletin, $42(1), 1-59$.

van Velthuizen, H., Huddleston, B., Fischer, G., Salvatore, M., Ataman, E., Nachtergaele, F. O., Zanetti, M., Bloise, M., Antonicelli, A., Bel, J., Liddo, A. D., De Salvo, P. and Franceschini, G. (2007). Mapping Biophysical Factors that Influence Agricultural Production and Rural Vulnerability. Rome: Food and Agriculture Organization of the United Nations and International Institute for Applied Systems Analysis.

Veichtlbauer, O., Zeileis, A. and Leisch, F. (2006). The Impact of Interventions on a Pre-Industrial Austrian Alpine Population. Collegium Antropologicum, 30 (1), 1-11.

Voigtränder, N. and Voth, H. (2012). Persecution Perpetuated: The Medieval Origins of Anti-Semitic Violence in Nazi Germany. Quarterly Journal of Economics, 127 (3), 13391392.

- and Voth, H. (2013). How the West 'Invented' Fertility Restriction. American Economic Review, 103 (6), 2227-2264. 
von Borosini, V. (1913). The Problem of Illegitimacy in Europe. Journal of the American Institute of Criminal Law and Criminology, 4 (2), 212-236.

Wolff, J. O. and Macdonald, D. W. (2004). Promiscuous Females Protect their Offspring. TRENDS in Ecology and Evolution, 19 (3), 127-134.

ZuckeRKANDL, R. (1889). Das neue österreichische Anerbenrecht. Jahrbücher für Nationalökonomie und Statistik, 19 (1). 


\section{Tables and figures (to be placed in article)}

\section{Figure 1: Theory of change and empirical variables}

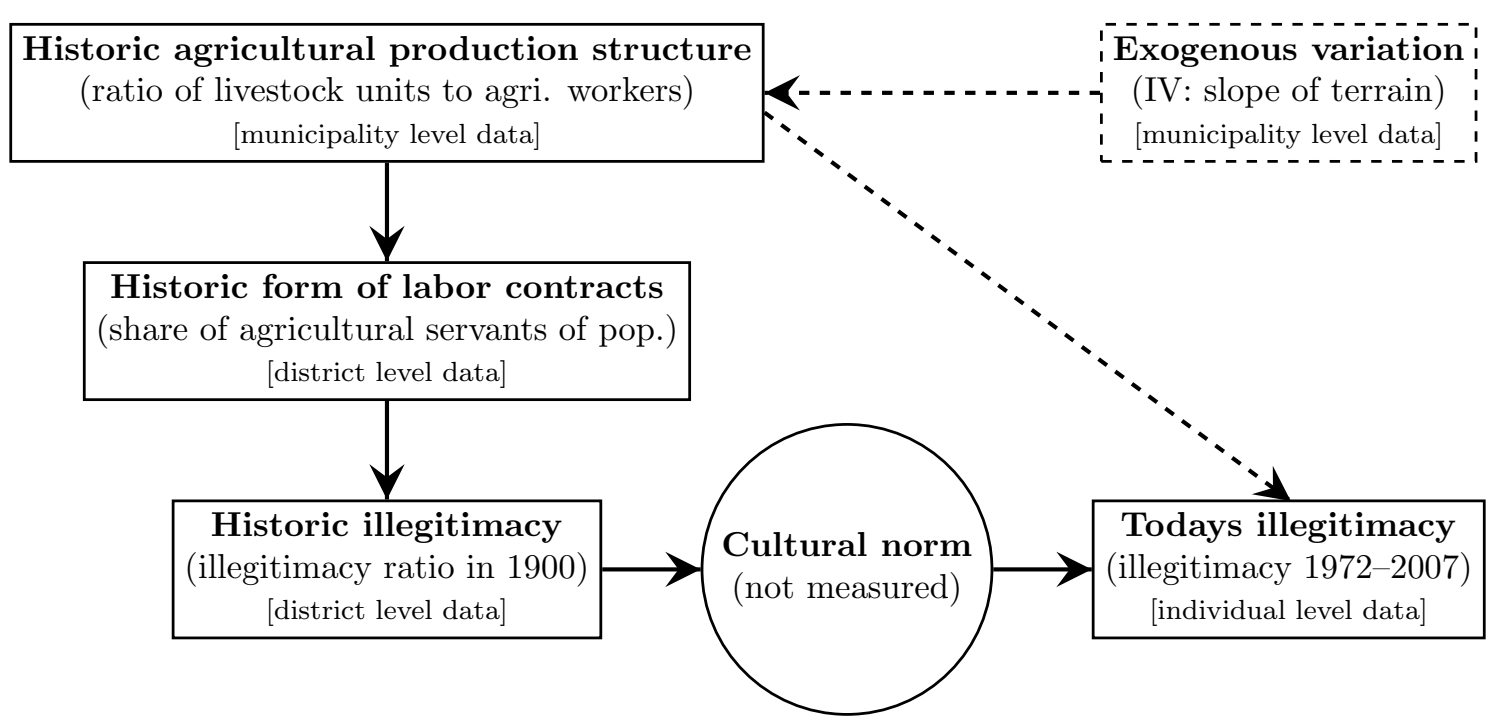

Legend: $\longrightarrow$ Theory of change - - - $\rightarrow$ IV-Estimation

Notes: The term in parenthesis gives the empirical variables that we use as proxies for the different blocks in our argument. In brackets we provide the lowest aggregation level of the available data. 
Figure 2: Development of the illegitimacy ratio in Austria, 1819-2014

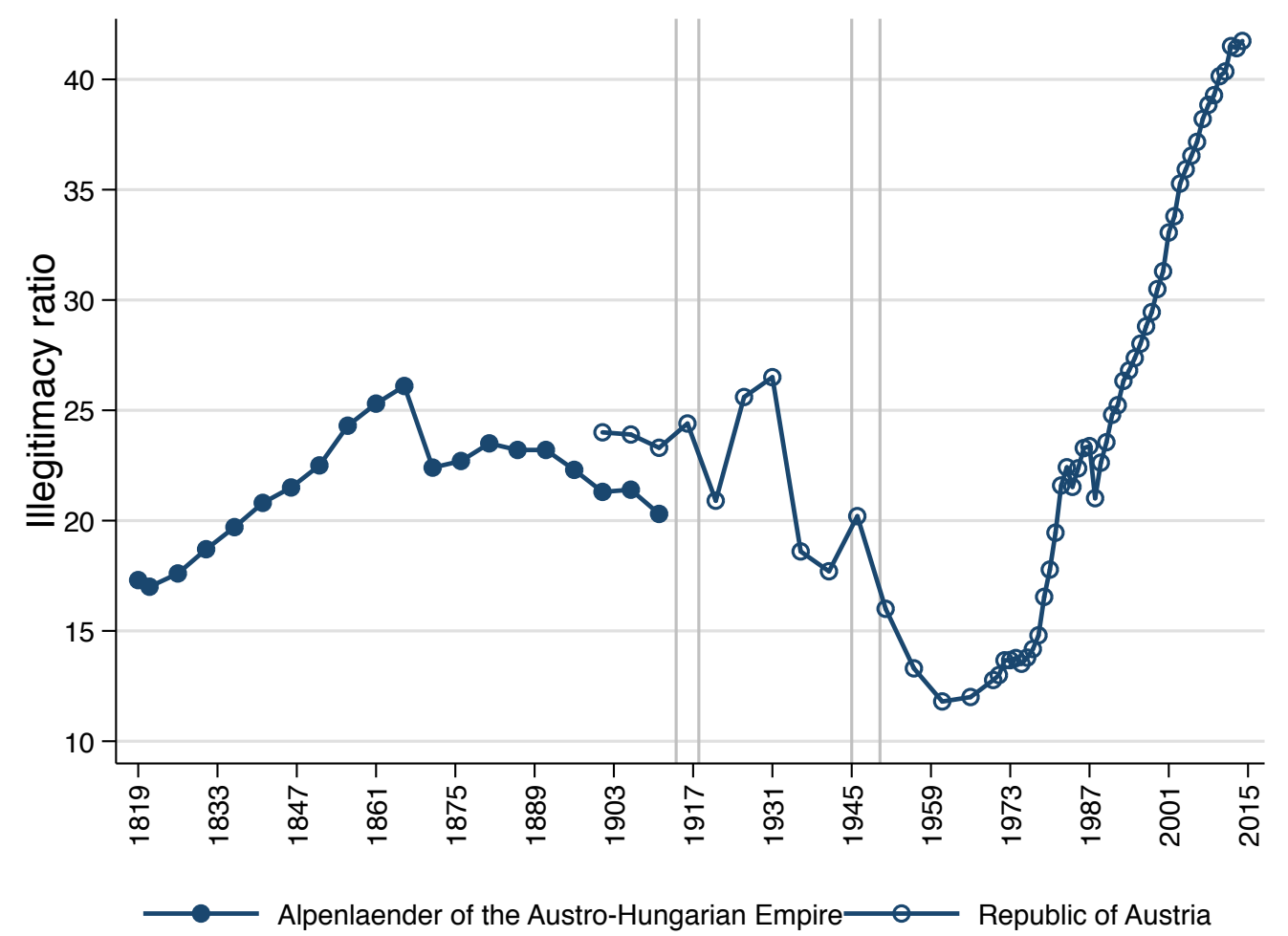

Notes: The illegitimacy ratio is defined as the share of live births to unmarried mothers of all live births. The so-called Alpenländer of the Austro-Hungarian Empire are roughly equivalent to the current territory of the Republic of Austria minus todays province of Burgenland. The province of Burgenland was not part of Austria in 1900. Data for 1819 to 1966 are from Haslinger (1982). Data for 1970 to 2014 are retrieved from the statistical database of Statistics Austria (STATcube, accessed in August 2015). The vertical lines indicate the periods of WWI and WWII. 
Figure 3: Illegitimacy ratios in the Austrian part of the Austro-Hungarian Empire
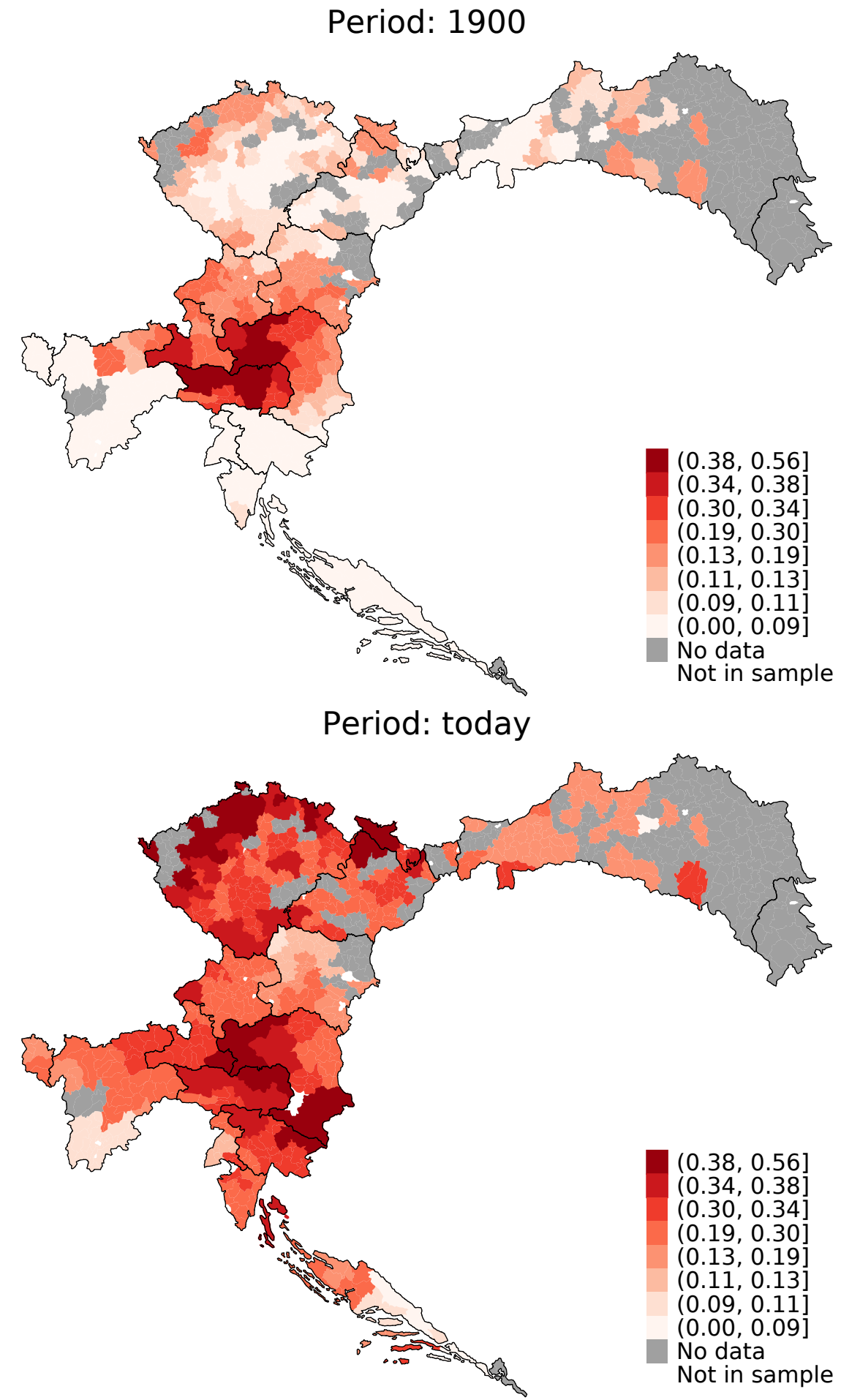

Notes: The illegitimacy ratio is defined as the share of live births to unmarried mothers of all live births. Data are from the population statistics (Bewegung der Bevölkerung) in 1900, the Austrian Birth Register (1971-2007), and population statistics from various countries. Districts correspond to borders in 1900. Missing data points are historic districts that we could not connect to today's regions. Appendix Section A.1 provides details on the sample construction. The outlined borders in black refer to provincial borders in 1900. 
Figure 4: Agricultural structure in 1900 and illegitimacy ratio today in Austrian municipalities

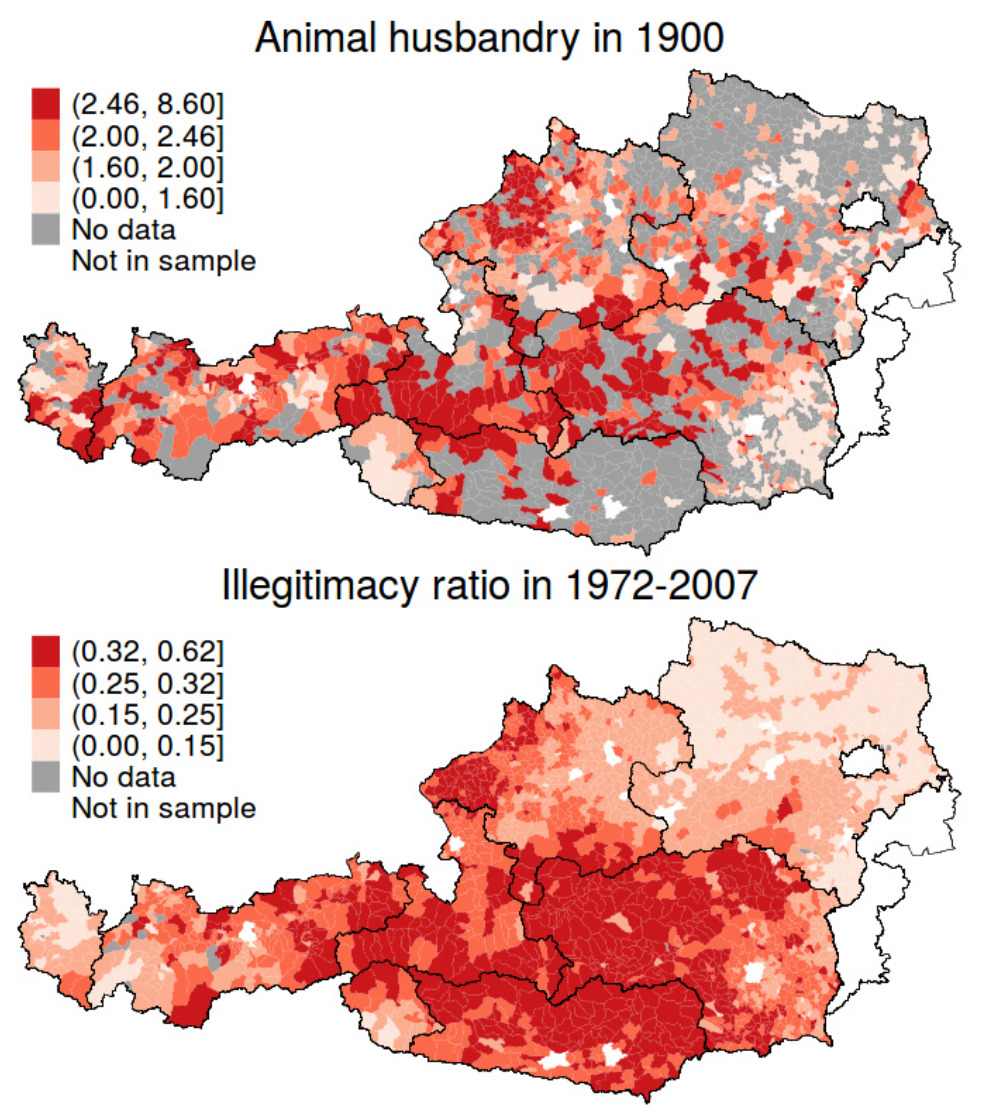

Notes: Animal husbandry is the ratio of livestock units to agricultural workers in 1900 The livestock unit is calculated as follows: cattle $+0.7 \cdot$ horses $+0.25 \cdot$ sheep $+0.26 \cdot$ pigs. Agricultural workers comprises all people working in agriculture: farm owners, family members of the owner, administrative staff in a farm, supervisors in a farm, servants (farmhands), and day laborers. The illegitimacy ratio is defined as the share of live births to unmarried mothers of all live births. Data are from the population census in 1900 and the Austrian Birth Register (1972-2007). We exclude city-districts and the province of Burgenland (which was not part of Austria in 1900) from our estimation sample (shown in white). Missing data points are municipalities that we could not track over time (shown in gray). Appendix Section A.1 provides details on the sample construction. The outlined borders in black refer to provincial borders today. 


\section{Figure 5: t-values with Conley standard errors}

Panel A: OLS regression (Table 5, column 5)

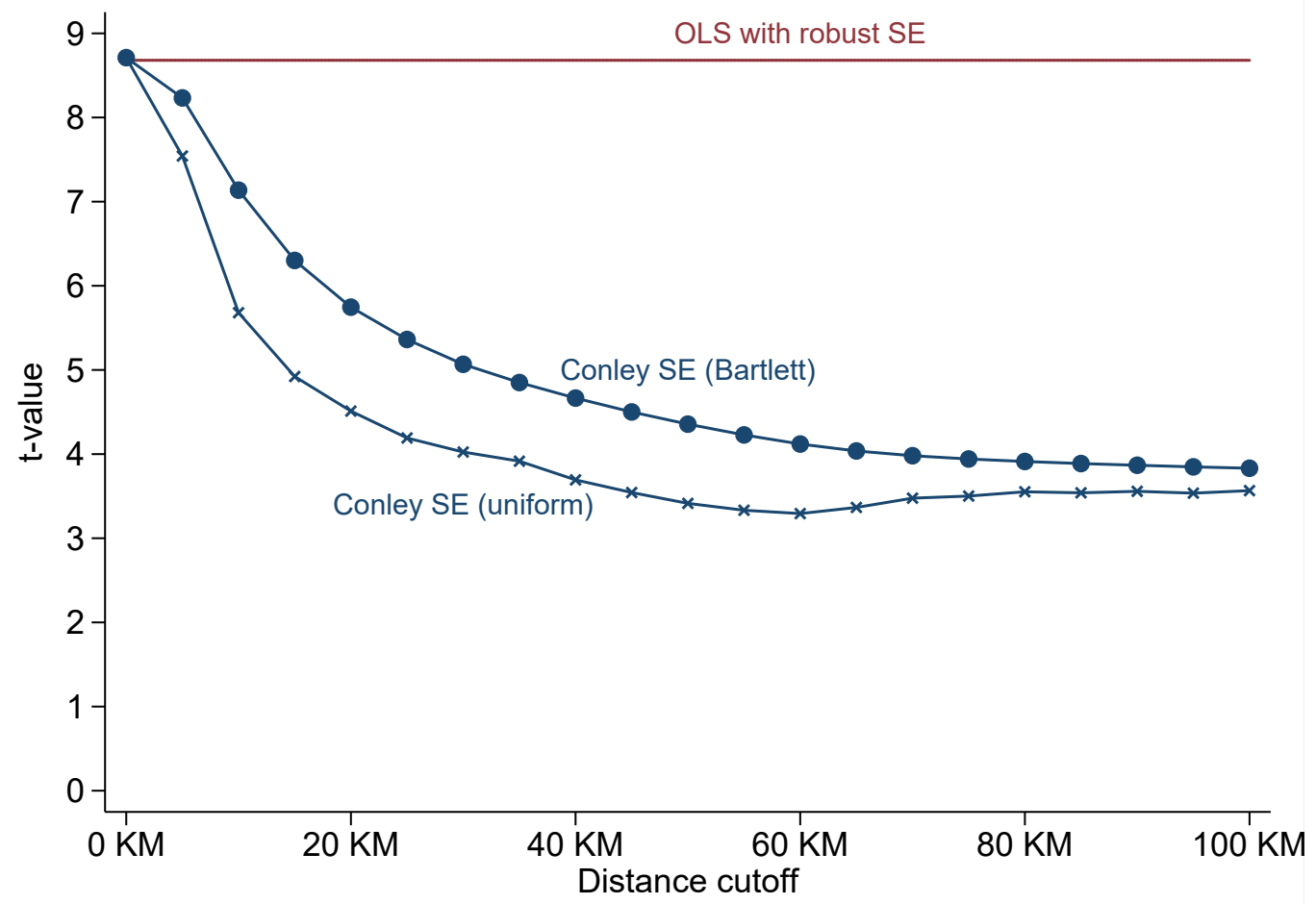

Panel B: 2SLS regression (Table 6, column 2)

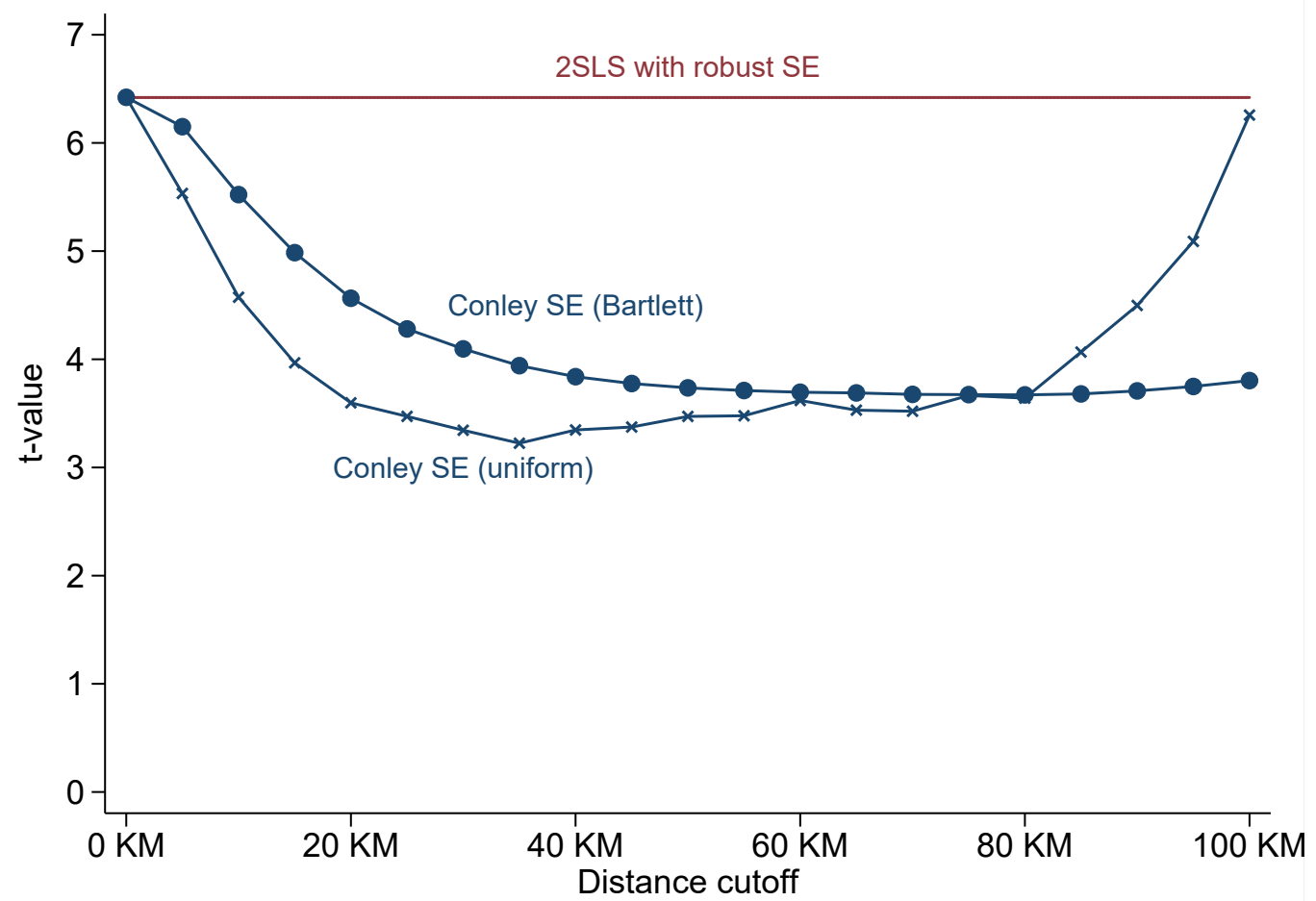

Notes: The figure shows t-values of the replication of a parsimonious version of the main regressions (Table 5, column 5 and Table 6, column 2) for different cutoff distances using Bartlett and uniform kernels. The mean distance between municipalities in our sample is $187 \mathrm{KM}$ (median of $169 \mathrm{KM}$ ) with a maximum of $567 \mathrm{KM}$. 
Table 1: Descriptive statistics: district level

\begin{tabular}{|c|c|c|c|c|c|c|}
\hline & \multirow[b]{2}{*}{ Mean } & \multirow[b]{2}{*}{ Std. Dev. } & \multicolumn{4}{|c|}{$\begin{array}{c}\text { Mean by quartile } \\
\text { of animal husbandry in } 1900\end{array}$} \\
\hline & & & $1 \mathrm{st}$ & 2nd & $3 \mathrm{rd}$ & 4 th \\
\hline \multicolumn{7}{|c|}{ Panel A: Habsburg Empire - district level $(\mathrm{N}=255)$} \\
\hline \multicolumn{7}{|c|}{ Main variables } \\
\hline Illegitimacy ratio in 1900 & 0.12 & 0.09 & 0.08 & 0.12 & 0.14 & 0.24 \\
\hline Illegitimacy ratio today & 0.29 & 0.11 & 0.26 & 0.33 & 0.31 & 0.30 \\
\hline Animal husbandry ${ }^{a}$ & 1.62 & 0.61 & 1.11 & 1.68 & 2.08 & 2.72 \\
\hline Share of agri. servants of total pop. & 0.05 & 0.04 & 0.03 & 0.05 & 0.07 & 0.11 \\
\hline \multicolumn{7}{|l|}{ Covariates } \\
\hline Share of Catholics & 0.93 & 0.16 & 0.90 & 0.94 & 0.97 & 0.99 \\
\hline Urbanization rate ${ }^{b}$ & 0.59 & 0.24 & 0.69 & 0.58 & 0.50 & 0.38 \\
\hline Share of males in population & 0.49 & 0.02 & 0.49 & 0.49 & 0.49 & 0.50 \\
\hline Share of age $<14$ & 0.34 & 0.03 & 0.36 & 0.34 & 0.33 & 0.32 \\
\hline Share of age $15-60$ & 0.57 & 0.03 & 0.56 & 0.57 & 0.58 & 0.59 \\
\hline Share employed in agriculture & 0.62 & 0.21 & 0.70 & 0.52 & 0.55 & 0.60 \\
\hline Share employed in manufacturing & 0.22 & 0.16 & 0.17 & 0.29 & 0.26 & 0.21 \\
\hline Share empl. in comm. and transp. & 0.05 & 0.03 & 0.05 & 0.06 & 0.06 & 0.05 \\
\hline Share of illiterate & 0.17 & 0.22 & 0.28 & 0.09 & 0.07 & 0.09 \\
\hline Log. teacher income ${ }^{c}$ & 7.30 & 0.25 & 7.22 & 7.34 & 7.36 & 7.39 \\
\hline \multicolumn{7}{|c|}{ Panel B: Austria - district level $(\mathrm{N}=66)$} \\
\hline \multicolumn{7}{|c|}{ Main variables } \\
\hline Illegitimacy ratio in 1900 & 0.21 & 0.11 & 0.18 & 0.22 & 0.25 & 0.33 \\
\hline Illegitimacy ratio today (1971-2007) & 0.26 & 0.08 & 0.24 & 0.26 & 0.32 & 0.36 \\
\hline Animal husbandry ${ }^{a}$ & 2.31 & 0.56 & 1.98 & 2.53 & 2.90 & 3.32 \\
\hline Share of agri. servants of total pop. & 0.09 & 0.04 & 0.08 & 0.10 & 0.11 & 0.15 \\
\hline \multicolumn{7}{|l|}{ Instrumental variable } \\
\hline Mean slope of terrain ${ }^{d}$ & 16.37 & 8.43 & 14.70 & 18.15 & 14.81 & 24.34 \\
\hline \multicolumn{7}{|l|}{ Covariates } \\
\hline Share of Catholics & 0.98 & 0.03 & 0.98 & 0.99 & 0.97 & 1.00 \\
\hline Urbanization rate $^{b}$ & 0.43 & 0.21 & 0.48 & 0.34 & 0.29 & 0.45 \\
\hline Share of males in population & 0.50 & 0.01 & 0.50 & 0.50 & 0.50 & 0.50 \\
\hline Share of age $<14$ & 0.31 & 0.02 & 0.31 & 0.32 & 0.32 & 0.31 \\
\hline Share of age $15-60$ & 0.59 & 0.02 & 0.59 & 0.58 & 0.59 & 0.60 \\
\hline Share employed in agriculture & 0.60 & 0.13 & 0.58 & 0.63 & 0.59 & 0.62 \\
\hline Share employed in manufacturing & 0.21 & 0.11 & 0.23 & 0.19 & 0.21 & 0.16 \\
\hline Share empl. in comm. and transp. & 0.05 & 0.03 & 0.05 & 0.05 & 0.06 & 0.05 \\
\hline Share of illiterate & 0.09 & 0.07 & 0.09 & 0.10 & 0.06 & 0.12 \\
\hline Log. teacher income & 7.41 & 0.25 & 7.43 & 7.36 & 7.43 & 7.40 \\
\hline
\end{tabular}

Notes: All variables without an indication of the year are either measured in 1900/1902 or time-invariant. ${ }^{a}$ Animal husbandry is the ratio of livestock units to agricultural workers in 1900. The livestock unit is calculated as follows: cattle $+0.7 \cdot$ horses $+0.25 \cdot$ sheep $+0.26 \cdot$ pigs. Agricultural workers comprises all people working in agriculture: farm owners, family members of the owner, administrative staff in a farm, supervisors in a farm, servants (farmhands), and day laborers. ${ }^{b}$ The urbanization rate is defined as the share of the population that lives in towns with more than 500 inhabitants. ${ }^{c}$ Teacher income measures the mean total income of a male teacher as reported in the Volksschulstatistik 1900. ${ }^{d}$ The mean slope is calculated from a digital terrain model of Austria with a $10 \times 10$ meter grid size. 
Table 2: Descriptive statistics: municipality and individual level

\begin{tabular}{|c|c|c|c|c|c|c|}
\hline & \multirow[b]{2}{*}{ Mean } & \multirow[b]{2}{*}{ Std. Dev. } & \multicolumn{4}{|c|}{$\begin{array}{l}\text { Mean by quartile } \\
\text { of animal husbandry in } 1900\end{array}$} \\
\hline & & & 1 st & $2 \mathrm{nd}$ & $3 \mathrm{rd}$ & 4 th \\
\hline \multicolumn{7}{|c|}{ Panel A: Austria - municipality level $(\mathrm{N}=1,318)$} \\
\hline \multicolumn{7}{|c|}{ Main variables } \\
\hline Illegitimacy ratio today (1971-2007) & 0.25 & 0.09 & 0.22 & 0.26 & 0.30 & 0.30 \\
\hline Animal husbandry ${ }^{a}$ & 2.08 & 0.76 & 1.54 & 2.16 & 2.63 & 3.56 \\
\hline \multicolumn{7}{|l|}{ Instrumental variable } \\
\hline Mean slope of terrain ${ }^{b}$ & 14.24 & 9.56 & 11.04 & 16.26 & 17.22 & 19.30 \\
\hline \multicolumn{7}{|l|}{ Covariates } \\
\hline Share in agriculture in 1934 & 0.56 & 0.20 & 0.59 & 0.57 & 0.54 & 0.41 \\
\hline Log. population & 6.91 & 0.63 & 7.02 & 6.85 & 6.82 & 6.71 \\
\hline Share of males in population & 0.50 & 0.02 & 0.50 & 0.50 & 0.51 & 0.51 \\
\hline Share of Catholics & 0.99 & 0.06 & 0.99 & 0.99 & 0.99 & 0.99 \\
\hline Dummy: market status & 0.03 & 0.17 & 0.05 & 0.02 & 0.01 & 0.00 \\
\hline Dummy: factory & 0.19 & 0.39 & 0.21 & 0.16 & 0.18 & 0.22 \\
\hline Dummy: large land holding & 0.59 & 0.49 & 0.63 & 0.54 & 0.58 & 0.54 \\
\hline \multicolumn{7}{|c|}{ Panel B: Austria - individual level $(\mathrm{N}=591,945)$} \\
\hline \multicolumn{7}{|c|}{ Main variables } \\
\hline Dummy: Illegitimacy (1984-2007) & 0.30 & 0.46 & 0.27 & 0.33 & 0.35 & 0.36 \\
\hline \multicolumn{7}{|l|}{ Binary covariates } \\
\hline Age group 15-20 & 0.08 & 0.28 & 0.08 & 0.08 & 0.09 & 0.08 \\
\hline Age group 21-25 & 0.30 & 0.46 & 0.30 & 0.30 & 0.30 & 0.29 \\
\hline Age group 26-30 & 0.35 & 0.48 & 0.35 & 0.35 & 0.35 & 0.35 \\
\hline Age group $31-35$ & 0.20 & 0.40 & 0.20 & 0.19 & 0.19 & 0.21 \\
\hline Age group 36 plus & 0.07 & 0.26 & 0.07 & 0.07 & 0.07 & 0.08 \\
\hline Catholic & 0.93 & 0.26 & 0.93 & 0.94 & 0.93 & 0.92 \\
\hline Protestant & 0.03 & 0.17 & 0.03 & 0.03 & 0.03 & 0.04 \\
\hline Muslim & 0.01 & 0.09 & 0.01 & 0.01 & 0.01 & 0.01 \\
\hline Other religion & 0.00 & 0.06 & 0.00 & 0.00 & 0.00 & 0.00 \\
\hline Unknown religion & 0.03 & 0.17 & 0.04 & 0.02 & 0.03 & 0.03 \\
\hline First child & 0.43 & 0.50 & 0.43 & 0.42 & 0.43 & 0.45 \\
\hline Second child & 0.36 & 0.48 & 0.36 & 0.36 & 0.36 & 0.36 \\
\hline Third or higher child & 0.21 & 0.41 & 0.20 & 0.23 & 0.22 & 0.19 \\
\hline Compulsory education & 0.21 & 0.41 & 0.21 & 0.22 & 0.22 & 0.20 \\
\hline Apprenticeship & 0.43 & 0.49 & 0.42 & 0.44 & 0.44 & 0.45 \\
\hline Middle school & 0.19 & 0.39 & 0.19 & 0.18 & 0.18 & 0.19 \\
\hline High school & 0.09 & 0.29 & 0.10 & 0.08 & 0.08 & 0.09 \\
\hline College & 0.06 & 0.25 & 0.07 & 0.06 & 0.06 & 0.06 \\
\hline Unknown education & 0.01 & 0.10 & 0.01 & 0.01 & 0.01 & 0.01 \\
\hline
\end{tabular}

Notes: All variables without an indication of the year are either measured in 1900/1902 or time-invariant. ${ }^{a}$ Animal husbandry is the ratio of livestock units to agricultural workers in 1900. The livestock unit is calculated as follows: cattle $+0.7 \cdot$ horses $+0.25 \cdot$ sheep + 0.26 pigs. Agricultural workers comprises all people working in agriculture: farm owners, family members of the owner, administrative staff in a farm, supervisors in a farm, servants (farmhands), and day laborers. ${ }^{b}$ The mean slope is calculated from a digital terrain model of Austria with a $10 \times 10$ meter grid size. 
Table 3: Illegitimacy in 1900 and today: OLS estimates

\begin{tabular}{|c|c|c|c|c|c|c|c|c|c|}
\hline & \multicolumn{9}{|c|}{ Dependent variable: illegitimacy today } \\
\hline & \multicolumn{3}{|c|}{$\begin{array}{c}\text { Habsburg Empire } \\
\text { Illegitimacy ratio today }\end{array}$} & \multicolumn{3}{|c|}{$\begin{array}{c}\text { Austria: district level } \\
\text { Illegitimacy ratio 1971-2007 }\end{array}$} & \multicolumn{3}{|c|}{$\begin{array}{c}\text { Austria: individual level } \\
\text { Illegitimacy indicator } 1984-2007\end{array}$} \\
\hline & $(1)$ & $(2)$ & $(3)$ & $(4)$ & $(5)$ & $(6)$ & $(7)$ & $(8)$ & $(9)$ \\
\hline Illegitimacy ratio in $1900^{a}$ & $\begin{array}{l}0.439 * * * \\
(0.079) \\
{[0.332]}\end{array}$ & $\begin{array}{l}0.413^{* * *} \\
(0.083) \\
{[0.312]}\end{array}$ & $\begin{array}{l}0.424^{* * *} \\
(0.094) \\
{[0.320]}\end{array}$ & $\begin{array}{l}0.559^{* * *} \\
(0.064) \\
{[0.738]}\end{array}$ & $\begin{array}{l}0.420^{* * *} \\
(0.055) \\
{[0.554]}\end{array}$ & $\begin{array}{l}0.396^{* * *} \\
(0.073) \\
{[0.523]}\end{array}$ & $\begin{array}{l}0.353^{* * *} \\
(0.086)\end{array}$ & $\begin{array}{l}0.362^{* * *} \\
(0.084)\end{array}$ & $\begin{array}{l}0.363^{* * *} \\
(0.082)\end{array}$ \\
\hline Province FE & No & Yes & Yes & No & Yes & Yes & Yes & Yes & Yes \\
\hline District controls & No & No & Yes & No & No & Yes & Yes & Yes & Yes \\
\hline $\begin{array}{l}\text { Conception year FE } \\
\text { Mother characteristics }\end{array}$ & & & & & & & Yes & Yes & Yes \\
\hline Age & & & & & & & Yes & Yes & Yes \\
\hline Religious denomination & & & & & & & Yes & Yes & Yes \\
\hline Parity & & & & & & & No & Yes & Yes \\
\hline Educational attainment & & & & & & & No & No & Yes \\
\hline Number of observations & 255 & 255 & 255 & 66 & 66 & 66 & $1,146,613$ & $1,146,613$ & $1,146,613$ \\
\hline Adj. R-squared & 0.106 & 0.631 & 0.658 & 0.538 & 0.858 & 0.857 & 0.163 & 0.222 & 0.230 \\
\hline Mean of dependent variable & 0.291 & 0.291 & 0.291 & 0.262 & 0.262 & 0.262 & 0.320 & 0.320 & 0.320 \\
\hline
\end{tabular}

Notes: Method of estimation is OLS. Standard errors are reported in parentheses. Beta coefficients are reported in brackets. *, ** and *** indicate statistical significance at the 10 percent level, 5 percent level, and 1 percent level, respectively. The unit of observation is either a district according to borders in 1900 or an individual mother. ${ }^{a}$ Illegitimacy ratio in the mother's district of residence $d$ in 1900. District controls include the share of Catholics, the urbanization rate, the share of males, the shares of age groups for below 14 and between 15 and 60 years, the employment shares in agriculture, manufacturing, and commerce and transportation, the share of illiterate and the log teacher income, all measured in 1900 (see Panel A (Habsburg Empire) and Panel B (Austria) in Table 1). Details on mother characteristics are shown in Panel B in Table 2. Data sources are listed in Appendix Table A.1. 
Table 4: Animal husbandry, farmhand societies, and illegitimacy in 1900: OLS estimates

Panel A

\begin{tabular}{|c|c|c|c|c|c|c|}
\hline \multirow{5}{*}{ Animal husbandry in $1900^{a}$} & \multicolumn{3}{|c|}{ Habsburg Empire } & \multicolumn{3}{|c|}{ Austria: district level } \\
\hline & $(\mathrm{A} 1)$ & $(\mathrm{A} 2)$ & $(\mathrm{A} 3)$ & $(\mathrm{A} 4)$ & $(\mathrm{A} 5)$ & $(\mathrm{A} 6)$ \\
\hline & $0.047^{* * *}$ & $0.031^{* * *}$ & $0.030^{* * *}$ & $0.051^{* * *}$ & $0.037^{* * *}$ & $0.041^{* * *}$ \\
\hline & $(0.003)$ & $(0.003)$ & $(0.003)$ & $(0.007)$ & $(0.007)$ & $(0.007)$ \\
\hline & {$[0.748]$} & {$[0.487]$} & {$[0.475]$} & {$[0.665]$} & {$[0.487]$} & {$[0.541]$} \\
\hline Adj. R-squared & 0.558 & 0.726 & 0.806 & 0.433 & 0.605 & 0.765 \\
\hline Mean of dependent variable & 0.051 & 0.051 & 0.051 & 0.094 & 0.094 & 0.094 \\
\hline
\end{tabular}

Dependent variable: share of agricultural servants of total population in 1900

Dependent variable: illegitimacy ratio in 1900

\section{Panel B}

re Empire

Austria: district level

$\begin{array}{lll}(\mathrm{B} 4) & (\mathrm{B} 5) & (\mathrm{B} 6) \\ 1.554^{* * *} & 0.970^{* * *} & 1.477^{* * *} \\ (0.257) & (0.266) & (0.260) \\ {[0.603]} & {[0.376]} & {[0.573]} \\ 0.354 & 0.627 & 0.808 \\ 0.209 & 0.209 & 0.209\end{array}$

Mean of dependent variable

(B1)

(B2)

(B3)

$1.494^{* * *} \quad 0.766^{* * *}$

$[0.675]$

$(0.133)$

0.453

0.658

0.119

0.787

$1.181^{* * *}$

$(0.125)$

0.119

$\begin{array}{lll}\text { No } & \text { Yes } & \text { Yes } \\ \text { No } & \text { No } & \text { Yes } \\ 66 & 66 & 66\end{array}$

nfo for Panel A and B:

Province FE

District controls

No Yes

Yes

255

Yes
Yes

255

66

66

Yes
Yes

66

Notes: Method of estimation is OLS. Standard errors are reported in parentheses.. Beta coefficients are reported in brackets. $*, * *$ and $* * *$ indicate statistical significance at the 10 percent level, 5 percent level, and 1 percent level, respectively. The unit of observation is a district according to borders in 1900. ${ }^{a}$ Animal husbandry is the ratio of livestock units to agricultural workers in 1900 . The livestock unit is calculated as follows: cattle $+0.7 \cdot$ horses $+0.25 \cdot$ sheep $+0.26 \cdot$ pigs. ${ }^{b}$ The share of agricultural servants of the total population is our preferred measure of the prevailing form of labor contracts in the mother's district of residence in 1900. District controls include the share of Catholics, the urbanization rate, the share of males, the shares of age groups for below 14 and between 15 and 60 years, the employment shares in agriculture, manufacturing, and commerce and transportation, the share of illiterate and the log teacher income, all measured in 1900 (see Panel A (Habsburg Empire) and Panel B (Austria) in Table 1). Data sources are listed in Appendix Table A.1. 
Table 5: Historical animal husbandry and illegitimacy today: OLS estimates

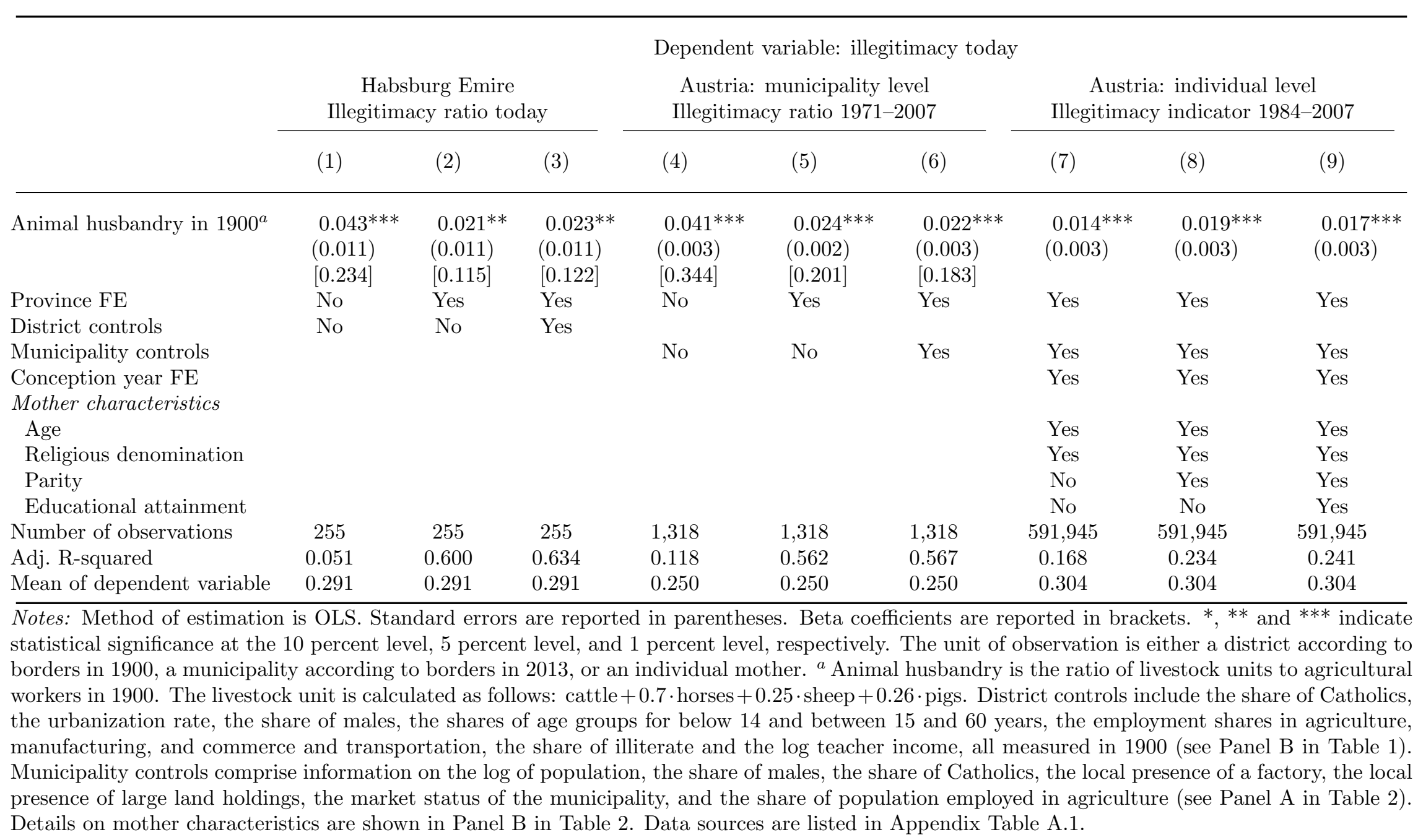


Table 6: Historical animal husbandry and illegitimacy today: IV estimates

Dependent variable: illegitimacy today

Austria: municipality level

Illegitimacy ratio 1971-2007

(1)
(2)
$(3)$

$\begin{array}{ll}0.161^{* * *} & 0.109^{* * *} \\ (0.018) & (0.017) \\ {[1.335]} & {[0.901]} \\ \text { No } & \text { Yes } \\ \text { No } & \text { No }\end{array}$

$0.125^{* * *}$
$(0.021)$
$[1.034]$
Yes
Yes

Austria: individual level

Illegitimacy indicator 1984-2007

Panel A: Second stage estimates

Animal husbandry in $1900^{\circ}$

Province FE

Municipality controls

Conception year FE

Mother characteristics

Age

Religious denomination

Parity

Educational attainment

Number of observations

Mean of dependent variable$$
\text { No }
$$

No

(4)

(5)

Panel B: First stage estimates Mean slope of terrain

F-statistic

Adj. R-squared

1,318
0.250


$0.020^{* * *}$
$(0.002)$
$[0.255]$
91.410
0.064

Panel C: Reduced form estimates

Mean slope of terrain

\begin{tabular}{lccccc}
\multicolumn{7}{c}{ Dependent variable: } & illegitimacy ratio today \\
$0.003^{* * *}$ & $0.002^{* * *}$ & $0.002^{* * *}$ & $0.001^{* * *}$ & $0.002^{* * *}$ & $0.002^{* * *}$ \\
$(0.000)$ & $(0.000)$ & $(0.000)$ & $(0.000)$ & $(0.000)$ & $(0.000)$ \\
0.115 & 0.554 & 0.570 & 0.168 & 0.234 & 0.241 \\
\hline
\end{tabular}

Adj. R-squared

0.115

$0.084^{* * *}$
$(0.021)$

$0.114^{* * *}$

(0.026)

$0.105^{* * *}$

$(0.024)$

Yes

Yes

Yes

Yes

Yes

Yes

Yes

Yes

Yes

Yes Yes

Yes Yes

No Yes

No

591,945

0.304

Yes
No

591,945

Yes

Yes

Yes

Yes

591,945

0.304
1,318

0.250

1,318

0.250
Dependent variable: animal husbandry in 1900 $\begin{array}{llll}0.020^{* * *} & 0.017^{* * *} & 0.017^{* * *} & 0.017^{* * *}\end{array}$

$\left.\begin{array}{llll}(0.003) & (0.002) & (0.004) & (0.004)\end{array}\right)$

$\left[\begin{array}{llll}0.257 & {[0.213]} & {[0.207]} & {[0.206]}\end{array}\right.$

53.051

22.415

$[0.206]$

22.148

47.823

0.355

Notes: Method of estimation is 2 SLS. Standard errors are reported in parentheses. Beta coefficients are reported in brackets. ${ }^{*}, * *$ and ${ }^{* * *}$ indicate statistical significance at the 10 percent level, 5 percent level, and 1 percent level, respectively. The unit of observation is either a municipality according to borders in 2013, or an individual mother. ${ }^{a}$ Animal husbandry is the ratio of livestock units to agricultural workers in 1900 . The livestock unit is calculated as follows: cattle $+0.7 \cdot$ horses $+0.25 \cdot$ sheep $+0.26 \cdot$ pigs. It is instrumented with the mean slope of the terrain in this municipality. Municipality controls comprise information on the log of population, the share of males, the share of Catholics, the local presence of a factory, the local presence of large land holdings, the market status of the municipality, and the share of population employed in agriculture (see Panel A in Table 2). Details on mother characteristics are shown in Panel B in Table 2. Data sources are listed in Appendix Table A.1. 
Table 7: Historical animal husbandry and illegitimacy today: IV estimates robustness checks

Dependent variable: illegitimacy ratio 1971-2007

Panel A: Historic covariates - second stage estimates

Animal husbandry in $1900^{a}$

\begin{tabular}{ccccc}
$(\mathrm{A} 1)$ & $(\mathrm{A} 2)$ & $(\mathrm{A} 3)$ & $(\mathrm{A} 4)$ & $(\mathrm{A} 5)$ \\
\hline $0.123^{* * *}$ & $0.120^{* * *}$ & $0.123^{* * *}$ & $0.127^{* * *}$ & $0.125^{* * *}$ \\
$(0.023)$ & $(0.022)$ & $(0.021)$ & $(0.021)$ & $(0.025)$
\end{tabular}

Additional historic controls ${ }^{b}$

Church controls

School controls

Yes

Yes

Yes

Health care controls

Pop. growth 1890-1900

Number of observations

\begin{tabular}{|c|c|c|c|c|}
\hline & \multirow[t]{3}{*}{ Yes } & \multirow[b]{2}{*}{ Yes } & \multirow{2}{*}{\multicolumn{2}{|c|}{$\begin{array}{l}\text { Yes } \\
\text { Yes }\end{array}$}} \\
\hline & & & & \\
\hline & & & Yes & Yes \\
\hline 1,318 & 1,318 & 1,318 & 1,318 & 1,318 \\
\hline
\end{tabular}

Panel B: Contemporary covariates - second stage estimates

\begin{tabular}{llcccc} 
& $(\mathrm{B} 1)$ & $(\mathrm{B} 2)$ & $(\mathrm{B} 3)$ & $(\mathrm{B} 4)$ & $(\mathrm{B} 5)$ \\
\cline { 2 - 5 } Animal husbandry in $1900^{a}$ & $0.118^{* * *}$ & $0.128^{* * *}$ & $0.159^{* * *}$ & $0.153^{* * *}$ & $0.188^{* * *}$ \\
& $(0.018)$ & $(0.025)$ & $(0.039)$ & $(0.035)$ & $(0.053)$ \\
Additional comtemp. controls & & & Yes \\
Population growth controls & Yes & & & Yes \\
Education controls & & Yes & Yes & Yes \\
$\begin{array}{l}\text { Prosperity controls } \\
\text { Tourism controls }\end{array}$ & & & Yes & Yes \\
Number of observations & 1,318 & 1,318 & 1,318 & 1,318 & 1,318
\end{tabular}

Panel C: Excluding mountainous municipalities - second stage estimates

Animal husbandry in $1900^{a}$

Altitue below (in meters)

Number of observations

Mean of dependent variable

\begin{tabular}{lllll}
$(\mathrm{C} 1)$ & $(\mathrm{C} 2)$ & $(\mathrm{C} 3)$ & $(\mathrm{C} 4)$ & $(\mathrm{C} 5)$ \\
\hline $0.133^{* * *}$ & $0.147^{* * *}$ & $0.154^{* * *}$ & $0.214^{* * *}$ & $0.296^{* *}$ \\
$(0.023)$ & $(0.027)$ & $(0.032)$ & $(0.060)$ & $(0.124)$ \\
1100 & 1000 & 900 & 800 & 700 \\
1,257 & 1,208 & 1,144 & 1,053 & 953 \\
0.248 & 0.247 & 0.244 & 0.241 & 0.237
\end{tabular}

Panel D: Excluding flat municipalities - second stage estimates

Animal husbandry in $1900^{a}$

Mean slope steeper than (in degrees)

Number of observations

Mean of dependent variable

Province FE
Municipality controls

\begin{tabular}{ccccc}
$(\mathrm{D} 1)$ & $(\mathrm{D} 2)$ & $(\mathrm{D} 3)$ & $(\mathrm{D} 4)$ & $(\mathrm{D} 5)$ \\
\hline $0.128^{* * *}$ & $0.133^{* * *}$ & $0.134^{* * *}$ & $0.137^{* * *}$ & $0.167^{* * *}$ \\
$(0.025)$ & $(0.025)$ & $(0.027)$ & $(0.033)$ & $(0.059)$ \\
4 & 6 & 8 & 10 & 12 \\
1,119 & 977 & 842 & 740 & 644 \\
0.260 & 0.264 & 0.268 & 0.273 & 0.277 \\
\hline Yes & Yes & Yes & Yes & Yes \\
Yes & Yes & Yes & Yes & Yes
\end{tabular}

Notes: Method of estimation is 2SLS. Standard errors are reported in parentheses. *, ** and *** indicate statistical significance at the 10 percent level, 5 percent level, and 1 percent level, respectively. The unit of observation is a municipality according to borders in 2013. ${ }^{a}$ Animal husbandry is the ratio of livestock units to agricultural workers in 1900 . The livestock unit is calculated as follows: cattle $+0.7 \cdot$ horses $+0.25 \cdot$ sheep $+0.26 \cdot$ pigs . It is instrumented with the mean slope of the terrain in this municipality. All estimations include province fixedeffects and municipality controls (see Panel A in Table 2). ${ }^{b}$ In about 75 percent of all municipalities a priest was available in 1900, and in about 28 percent a monastery was less than $10 \mathrm{~km}$ away. A doctor was available in about 39 percent, a hospital in about 3 percent, and a midwife in about 66 percent of all municipalities. In about 84 percent a elementary school, and in about 7 percent of all municipalities a kindergarten was available. ${ }^{c}$ Population growth controls are the population growth between 1900 and 1971 and the share of foreigners in 2011. Education controls include the share of, each, the population with apprenticeship, high school, and tertiary education in 2011. Prosperity controls are the average income and the unemployment rate in 2011 . The tourism control is the log number of beds per capita in 2011. Data sources are listed in Appendix Table A.1. 
Table 8: Historical animal husbandry and illegitimacy today: Trust and fairness controls

Dependent var.: illegitimacy ratio today (1971-2007)

(1)

(2)

(3)

Panel A: Second stage estimates

Animal husbandry in $1900^{a}$

Trust towards others ${ }^{b}$

People would try to be fair ${ }^{b}$

Province FE

Municipality controls

Number of observations

Mean of dependent variable

Panel B: First stage estimates

Mean slope of terrain

F-statistic

Adj. R-squared

$\begin{array}{ccc}0.122^{* * *} & 0.121^{* * *} & 0.124^{* * *} \\ (0.025) & (0.020) & (0.025) \\ -0.018 & & 0.021 \\ (0.039) & & (0.044) \\ & -0.102^{* * *} & -0.108^{* * *} \\ & (0.021) & (0.028) \\ \text { Yes } & \text { Yes } & \text { Yes } \\ \text { Yes } & \text { Yes } & \text { Yes } \\ 1,318 & 1,318 & 1,318 \\ 0.250 & 0.250 & 0.250\end{array}$

Dependent variable: animal husbandry in 1900

$\begin{array}{lcc}0.014^{* * *} & 0.017^{* * *} & 0.014^{* * *} \\ (0.002) & (0.002) & (0.002) \\ 33.873 & 49.201 & 33.594 \\ 0.391 & 0.375 & 0.401\end{array}$

Notes: Method of estimation is 2SLS. Standard errors are reported in parentheses. *, ** and $* * *$ indicate statistical significance at the 10 percent level, 5 percent level, and 1 percent level, respectively. The unit of observation is a municipality according to borders in $2013 .{ }^{a}$ Animal husbandry is the ratio of livestock units to agricultural workers in 1900. The livestock unit is calculated as follows: cattle $+0.7 \cdot$ horses $+0.25 \cdot$ sheep $+0.26 \cdot$ pigs. It is instrumented with the mean slope of the terrain in this municipality. ${ }^{b}$ The trust and fairness variables come from the Generations \& Gender Programme survey (First Wave from Austria) and vary only at the district level. The underlying survey questions are as follows: 'Generally speaking, would you say that most people can be trusted or that you need to be very careful in dealing with people?', and 'Do you think most people would try to take advantage of you if they got a chance, or would they try to be fair?'. Municipality controls comprise information on the log of population, the share of males, the share of Catholics, the local presence of a factory, the local presence of large land holdings, the market status of the municipality, and the share of population employed in agriculture (see Panel A in Table 2). Data sources are listed in Appendix Table A.1. 
Table 9: Historical animal husbandry and illegitimacy today: Stated preferences

Dependent variable: binary variable equal to one if strongly agree with respective statement

It should be accepted if a It is all right for an unmarried single woman wants a child, couple to live together even if they but not a long-term relationship have no interest in marriage

(1)

Illegitimacy ratio in $1900^{a}$

Animal husbandry in $1900^{b}$

Province FE

District controls

Individual controls

Number of observations

Adj. R-squared

Mean of dependent variable
(2)

$(3)$

Notes: Method of estimation is OLS. Standard errors in parentheses are clustered on a district level. *,** and *** indicate statistical significance at the 10 percent level, 5 percent level, and 1 percent level, respectively. Individual-level survey data are from the Generations $\&$ Gender Programme survey (First Wave from Austria). ${ }^{a}$ This variable captures the illegitimacy ratio in the respondent's district of residence in $1900 .{ }^{b}$ Animal husbandry is the ratio of livestock units to agricultural workers in the respondent's district of residence in 1900 . The livestock unit is calculated as follows: cattle $+0.7 \cdot$ horses $+0.25 \cdot$ sheep $+0.26 \cdot$ pigs. District controls include the share of Catholics, the urbanization rate, the share of males, the shares of age groups for below 14 and between 15 and 60 years, the employment shares in agriculture, manufacturing, and commerce and transportation, the share of illiterate and the log teacher income, all measured in 1900 (see Panel B in Table 1). Individual controls are a male dummy, indicators for education levels, and birth decade dummies. Data sources are listed in Appendix Table A.1. 
Table 10: Historical animal husbandry and shotgun weddings today: Individuallevel estimates

Dependent variable: Binary variable indicating a shotgun wedding in the universe of all pre-marital conceptions to first-time mothers in Austria between 1984 and 2007

(1)

Panel A: OLS estimates

Animal husbandry in $1900^{a}$

Adj. R-squared

$\begin{array}{ll}-0.022^{* * *} & -0.022^{* * *} \\ (0.004) & (0.004) \\ 0.100 & 0.102\end{array}$

Panel B: 2SLS estimates

Animal husbandry in $1900^{a}$

$$
\begin{aligned}
& -0.109^{* * *} \\
& (0.026) \\
& 24.734
\end{aligned}
$$$$
-0.106^{* * *}
$$

24.658

First-stage F-statistic

Info for Panel A and B:

Province FE

Municipality controls

Conception year FE

Mother characteristics

Age

Religious denomination

Educational attainment

Number of observations

Yes

Yes

Yes

24.372

Mean of dependent variable

Yes

Yes

Yes

Yes

Yes

Yes

No

169,744

169,744

0.236

Yes

Yes

Yes Yes Yes

No Yes $\quad$ Yes

Yes 169,744 0.236

Notes: Method of estimation is OLS/2SLS. Standard errors are clustered on the municipality-level. $*, * *$ and $* * *$ indicate statistical significance at the 10 percent level, 5 percent level, and 1 percent level, respectively. Individual-level data is from the Austrian Birth Register. ${ }^{a}$ Animal husbandry is the ratio of livestock units to agricultural workers in the women's municipality of residence in 1900. The livestock unit is calculated as follows: cattle $+0.7 \cdot$ horses $+0.25 \cdot$ sheep $+0.26 \cdot$ pigs. It is instrumented with the mean slope of the terrain in this municipality. Municipality controls comprise information on the log of population, the share of males, the share of Catholics, the local presence of a factory, the local presence of large land holdings, the market status of the municipality, and the share of population employed in agriculture (see Panel A in Table 2). Details on mother characteristics are shown in Panel B in Table 2. Data sources are listed in Appendix Table A.1. 
Table 11: Transmission channel: Evidence from immigrant mothers

Dependent variable: Binary variable indicating an illegitimate birth in the sample of all births to immigrant first-time mothers in Austria between 1984 and 2007

(1)

Horizontal socialization:

Illegitimacy ratio in $1900^{a}$ (residence)

$0.161^{*}$
$(0.066)$

$0.154^{* *}$

$0.151^{* *}$

$0.135^{* *}$

$0.110^{*}$

Vertial socialization:

Illegitimacy ratio in sending country around $1900^{b}$

\begin{tabular}{lllll}
$2.429^{* * *}$ & $2.672^{* * *}$ & $2.720^{* * *}$ & $1.785^{* * *}$ & $1.244^{* * *}$ \\
$(0.197)$ & $(0.220)$ & $(0.224)$ & $(0.162)$ & $(0.156)$ \\
Yes & Yes & Yes & Yes & Yes \\
Yes & Yes & Yes & Yes & Yes \\
Yes & Yes & Yes & Yes & Yes \\
& & & & \\
No & Yes & Yes & Yes & Yes \\
No & No & Yes & Yes & Yes \\
No & No & No & Yes & Yes \\
No & No & No & No & Yes \\
49,281 & 49,281 & 49,281 & 49,281 & 49,281 \\
0.047 & 0.056 & 0.059 & 0.067 & 0.085 \\
0.186 & 0.186 & 0.186 & 0.186 & 0.186 \\
\hline
\end{tabular}

Province FE

District controls ${ }^{c}$

Conception year FE

Mother characteristics ${ }^{d}$

Age

Educational attainment

Religious denomination

Historic macro variables of sending country ${ }^{e}$

Number of observations

Adj. R-squared
Mean of dependent variable

0.186

0.186

0.186

0.186

.186

Notes: Method of estimation is OLS. Standard errors in parentheses are clustered on a district level. **** and *** indicate statistical significance at the 10 percent level, 5 percent level, and 1 percent level, respectively. Individual-level data is from the Austrian Birth Register. The estimation sample comprises all first-time non-Austrian mothers, who gave birth in Austria between 1984 and 2007, for whose country of origin there are at least 50 cases in our estimation sample, and the historical illegitimacy ratio is available in the literature. ${ }^{a}$ Illegitimacy ratio in the immigrant mother's Austrian district of residence in $1900 .{ }^{b}$ Illegitimacy ratio in the immigrant mother's country of origin, measured around 1900. Details are provided in Appendix Table D.10. ${ }^{c}$ District controls include the share of Catholics, the urbanization rate, the share of males, the shares of age groups for below 14 and between 15 and 60 years, the employment shares in agriculture, manufacturing, and commerce and transportation, the share of illiterate and the log teacher income, all measured in 1900 (see Panel B in Table 1). ${ }^{d}$ Details on mother characteristics are shown in Panel B in Table 2. Data sources are listed in Appendix Table A.1. ${ }^{e}$ Historic macroeconomic variables include log GDP per capita in 1913, the crude birth rate in 1900, and the female labor force participation rate around 1950. The female labor force participation rate for some countries was imputed using the female labor force participation rate in 1990 and dummies for world regions. 
Table 12: Transmission channel: Evidence from internal migrant mothers

Dependent variable: Binary variable indicating an illegitimate birth in the sample of all births to internal migrant mothers in Austria between 1984 and 2007

(1)

$(2)$

Migration between
districts

\section{Horizontal socialization:}

Animal husbandry in $1900^{a}$ (residence)

Vertial socialization:

Animal husbandry in $1900^{a}$ (origin)

Residence: province FE

Residence: municipality controls

Origin: province FE

Origin: municipality controls

Conception year FE

Mother characteristics

Number of observations

Adj. R-squared

0.006

$(0.007)$

0.002

(3)

(4)

Mean of dependent variable

$0.015^{* *}$

(0.006)

-0.001
$(0.010)$

$-0.015$

(0.008)

$0.018^{* * *}$

$0.018^{* *}$

(0.021)

Notes: Method of estimation is OLS. Standard errors in parentheses are clustered on a municipality level. $*, * *$ and $* * *$ indicate statistical significance at the 10 percent level, 5 percent level, and 1 percent level, respectively. Individual-level data is from the Austrian Birth Register. The estimation sample comprises all Austrian mothers, who were born and gave birth in Austria between 1972 and 2007. ${ }^{a}$ Animal husbandry is the ratio of livestock units to agricultural workers in 1900. The livestock unit is calculated as follows: cattle $+0.7 \cdot$ horses $+0.25 \cdot$ sheep $+0.26 \cdot$ pigs. Municipality controls comprise information on the log of population, the share of males, the share of Catholics, the local presence of a factory, the local presence of large land holdings, the market status of the municipality, and the share of population employed in agriculture (see Panel A in Table 2). Details on mother characteristics are shown in Panel B in Table 2. Data sources are listed in Appendix Table A.1. 


\section{Web appendix}

This web appendix (not for publication) provides additional material discussed in the unpublished manuscript 'Economic Origins of Cultural Norms: The Case of Animal Husbandry and Bastardy' by Christoph Eder and Martin Halla.

Table.off tamtents . . . . . . . . . . . . . . . . A.1

B.2 Adjustment of standard errors for spatial correlation . . . . . . . . . . . B.1

C.3 Additional figures . . . . . . . . . . . . . . . . . . . . . . C.1

D.4 Additional tables . . . . . . . . . . . . . . . . . . . . . . D.1

\section{List of Figures}

C.1 Austrian part of the Austro-Hungarian Empire . . . . . . . . . . . . . . . . . C.1

C.2 Development of the illegitimacy ratio in Austria by historical agricultural production structure, $1971-2007 \ldots \ldots \ldots$. . . . . . . . . . .

C.3 Illegitimacy ratio vs. illegitimacy rate . . . . . . . . . . . . . . C.3

C.4 Development of the share of the population in agriculture . . . . . . . . C.4

C.5 Probability of early death by legitimacy status . . . . . . . . . . . . . C.4

C.6 Probability of remaining illegitimate after birth . . . . . . . . . . . . C.5

C.7 Historical animal husbandry and illegitimacy today: IV estimates in subsamples . . . . . . . . . . . . . . . C.6

C.8 Development of animal husbandry and illegitimacy before 1900 by province . C.7

C.9 Development of shotgun weddings in Austria, 1984-2007 . . . . . . . . . . . . C.7

C.10 Epidemiological correlation . . . . . . . . . . . . . . . . . . C.8

\section{List of Tables}

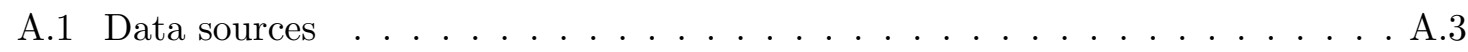

B.1 Simulation results $\ldots \ldots \ldots \ldots \ldots \ldots \ldots \ldots$

D.1 Illegitimacy ratio vs. illegitimacy rate $\ldots \ldots \ldots \ldots \ldots$ D.2

D.2 Income of agricultural servants and day laborers in $1893 \ldots \ldots$. . . . . . D.3

D.3 Descriptive statistics of illegitimate births in $1900 \ldots \ldots$. . . . . . . . D.4

D.4 Different proxies for farmhand societies and illegitimacy in 1900 . . . . . . D.5

D.5 Historical animal husbandry and illegitimacy today: Religiosity controls . . D.6

D.6 Historical animal husbandry and other historical demographic outcomes . . . D.7

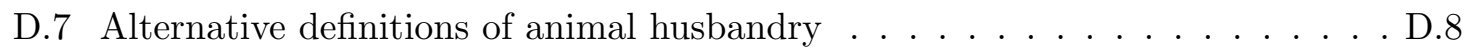

D.8 Measuring the relative dominance of animal husbandry with the share of

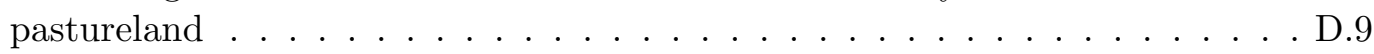

D.9 Outcomes female labor force participation and female labor income . . . . . D.10

D.10 Historical illegitimacy ratios from all countries of origin . . . . . . . . . . D.11 


\section{A.1 Data appendix}

\section{A.1.1 Sample selection}

Our historical data are from the period of the Austro-Hungarian Empire, which constituted the last phase in the constitutional evolution of the Habsburg Monarchy. It was a result of the Austro-Hungarian Compromise of 1867 and was a constitutional union of two monarchies: the Austrian Empire ruled by the House of Habsburg and the Kingdom of Hungary. In our analysis, we focus on the Austrian Empire and define two estimation samples, to which we refer as 'Habsburg Empire' and 'Austria'.

Sample 'Habsburg Empire' We refer her to the Austrian part of the Empire, which was commonly, yet unofficially, denoted Cisleithania (see Appendix Figure C.1). This area consisted of 15 crown lands (Austrian Littoral, Bohemia, Bukovina, Carinthia, Carniola, Dalmatia, Galicia, Lower Austria, Moravia, Salzburg, Silesia, Styria, Tyrol, Upper Austria, Vorarlberg). Further levels of administrative divisions were 380 political districts, 915 court districts, and 28, 801 municipalities. Out of these political districts, 33 were so-called statutory cities. These are larger cities that have been vested with district administration functions in addition to their municipal responsibilities. All numbers refer to the year 1900.

In our district-level analysis, we focus

- on the subset of 380 political districts, which are within the Austrian part of the Habsburg Empire

- Given our focus on (more) rural areas, we exclude 33 statutory cities.

- We also have to exclude 60 political districts, which had changed their borders between 1900 and 1902 (the year when we measure detailed information on the agricultural sector).

- Finally, we exclude 32 districts located in todays Ukraine, for which we could not find today's illegitimacy ratios.

This leaves us with 255 political districts covering areas from today's Austria, Croatia, Czech Republic, Italy, Poland, and Slovenia.

Sample 'Austria' We refer her to the territory of today's Austria (formally the Republic of Austria) minus todays province of Burgenland. The latter was part of the Kingdom of Hungary. This estimation sample comprises (parts of) 7 of the former crown lands (namely, Carinthia, Lower Austria, Salzburg, Styria, Tyrol, Upper Austria, Vorarlberg). In 1900, these 7 crown lands comprised 105 political districts.

In our district-level analysis, we focus

- on the subset of 80 political districts, which are within the borders of todays Austria.

- Given our focus on (more) rural areas, we exclude 9 remaining statutory cities (Vienna, Wiener-Neustadt, Waidhofen an der Ybbs, Linz, Steyr, Salzburg, Graz, Klagenfurt, and Innsbruck).

- Finally, we have to exclude 5 political districts, which had changed their borders between 1900 and 1902 (the year when we measure detailed information on the agricultural sector). 
This leaves us with 66 political districts, which comprises 94 percent of the area of Austria. A problem we face when connecting the historic data of districts with todays birth registry are the border changes over the last century. We solve this by reconstructing historic districts with todays municipalities. This enables us to compare very similar geographic areas over time. Population data for all population censuses are available for current municipalities borders from Statistik Austria. With these data we can compare population figures of reconstructed historic districts with actual population figures of districts in 1900. The numbers shows that on average $95 \%$ of the historic population can be reconstructed. The contemporary illegitimacy ratio for historic districts should therefore contain little measurement error.

In our municipality-level analysis, we include 1,318 municipalities (according to todays borders) that we can cleanly reconstruct with municipality data from 1900 . We drop municipalities from our sample because (a) the province of Burgenland was not part of Austria in 1900 (171 municipalities), (b) we do not use municipalities with city status in 2013 (201 municipalities, including 13 in Burgenland), and (c) a municipality today cannot be represented as a union of municipalities in 1900 (677 municipalities). The municipality sample consists of 66.5 percent of the population in 2011 of all rural municipalities outside the province of Burgenland (potential sample). 


\section{A.1.2 Data sources}

Table A.1: Data sources

\begin{tabular}{l}
\hline Data source \\
\hline K.K. Statistische Zentralkommission. (1902). Bewe- \\
gung der Bevölkerung der im Reichsrathe vertretenen \\
Königreiche und Länder im Jahre 1900. Wien: K.K. \\
Hof- und Staatsdruckerei. \\
K.K. Statistische Zentralkommission. \\
Gemeindelexikon der im Reichsrathe vertretenen \\
Königreiche und Länder. Wien: K.K. Hof- und \\
Staatsdruckerei.
\end{tabular}

K.K. Statistische Zentralkommission. (1909). Ergebnisse der Landwirtschaftlichen Betriebszählung vom 3. Juni 1902 in den im Reichsrathe vertretenen Königreichen und Ländern. Wien: K.K. Hof- und Staatsdruckerei.

K.K. Statistische Zentralkommission. (1902). Ergebnisse der Volkszählung vom 31. Dezember 1900 in den im Reichsrathe vertretenen Königreichen und Ländern. LXIII. Band, 1. Heft. Wien: K.K. Hofund Staatsdruckerei.

K.K. Statistische Zentralkommission. (1903). Ergebnisse der Volkszählung vom 31. Dezember 1900 in den im Reichsrathe vertretenen Königreichen und Ländern. LXIII. Band, 2. Heft. Wien: K.K. Hofund Staatsdruckerei.

K.K. Statistische Zentralkommission. (1903). Ergebnisse der Volkszählung vom 31. Dezember 1900 in den im Reichsrathe vertretenen Königreichen und Ländern. LXIII. Band, 3. Heft. Wien: K.K. Hofund Staatsdruckerei.

K.K. Statistische Zentralkommission. (1903). Berufsstatistik nach den Ergebnissen der Volkszählung vom 31. Dezember 1900 in den im Reichsrathe vertretenen Königreichen und Ländern. LXVI. Band, 2.-7. Heft. Wien: K.K. Hof- und Staatsdruckerei.

K.K. Statistische Zentralkommission. (1903). Statistik der Allgemeinen Volksschulen und Bürgerschulen in den im Reichsrathe vertretenen Königreichen und Ländern auf Grund der Statistischen Aufnahme vom 15. Mai 1900. LXII. Band, 2. Heft. Wien: K.K. Hofund Staatsdruckerei.

\begin{abstract}
Variables
Illegitimate live births, total live births, infant mortality by age, age at marriage by gender

Population, male population, cattle, agricultural area uses as field, factories, large land holdings, religious denomination, market status
\end{abstract}

Number of people in agriculture, servants, number of farms with $\leq 5$ hectare land, number of farms with $>20$ hectare land, total number of farms

Population, total area, District 1900 number of Catholics

Share of illiterate, share of population in locations with more than 500 inhabitants

People of age $<14$, people of age $15-60$, number of married females of age 14-45, number of unmarried females of age 14-45

Number of employed by sector

District

District

Teacher income

District

1900 
Table A.1 - continued from previous page

\begin{tabular}{|c|c|c|c|}
\hline Data source & Variables & Level & Year \\
\hline $\begin{array}{l}\text { Statistik des Bundesstaates Österreich. (1935). Die } \\
\text { Ergebnisse der österreichischen Volkszählung vom } \\
\text { 22. März 1934. Heft 4-11. Wien: Österreichische } \\
\text { Staatsdruckerei. }\end{array}$ & $\begin{array}{l}\text { Population, population in } \\
\text { agriculture }\end{array}$ & $\begin{array}{l}\text { Municipality, } \\
\text { district }\end{array}$ & 1934 \\
\hline Austrian Birth Register & $\begin{array}{l}\text { All live births along } \\
\text { with socio-economic } \\
\text { information on mother }\end{array}$ & $\begin{array}{l}\text { Individual, } \\
\text { municipality }\end{array}$ & $1971-2007$ \\
\hline $\begin{array}{l}\text { Land Kärnten. (2015). Digitales } 10 m- \\
\text { Geländemodell Österreich. Available at: data.gv.at } \\
\text { (downloaded in May 2015). }\end{array}$ & mean slope of terrain & GIS & \\
\hline $\begin{array}{l}\text { Generations \& Gender Programme (see http:// } \\
\text { www.ggp-austria.at) }\end{array}$ & Survey data & $\begin{array}{l}\text { Individual, } \\
\text { district }\end{array}$ & $2008 / 09$ \\
\hline
\end{tabular}




\section{B.2 Adjustment of standard errors for spatial correlation}

A recent contribution by Kelly (2019) argues that estimates in the literature on persistence have likely inflated t-statistics due to spatially correlated observations. We evaluate this critique in our context in two steps. First, we adjust our standard errors as suggested by (Conley, 1999). Second, we perform simulations with spatial noise variables. For these procedures we focus, as suggested by Kelly (2019), on a parsimonious specification of our main regressions. In particular, these are the following specifications:

- OLS: Column 5 of Table 5

- 2SLS: Column 2 of Table 6

\section{B.2.1 Conley standard errors}

Conley standard errors take into account the spatial correlation of residuals (Conley, 1999).For the OLS case, we derive Conley standard errors from the sampling variance of the (robust) OLS estimator

$$
\hat{\operatorname{Var}}[\hat{\beta}]=\left(\mathbf{X}^{\prime} \mathbf{X}\right)^{-1}\left(\mathbf{X}^{\prime} \mathbf{W} \mathbf{X}\right)\left(\mathbf{X}^{\prime} \mathbf{X}\right)^{-1}
$$

where $\mathbf{X}$ is the matrix of explanatory variables and $\mathbf{W}$ is an $N \times N$ matrix with element $\mathbf{W}_{i j}=e_{i} e_{j} K\left(d_{i j}\right)$. The term $K\left(d_{i j}\right)$ is the kernel that governs the depreciation of spatial correlation with distance $d_{i j}$ between two observations (Cameron and Miller, 2015). In the case of the uniform kernel, $K\left(d_{i j}\right)=1$ if $d_{i j} \leq \bar{d}$ and zero otherwise, where $\bar{d}$ is the cutoff distance. The Bartlett kernel assumes $K\left(d_{i j}\right)=1-\frac{d_{i j}}{\bar{d}}$ if $d_{i j} \leq \bar{d}$ and zero otherwise.

In the 2SLS case, we use the same method, but use $\left(\mathbf{X}^{\prime} \mathbf{P}\right)^{\prime}$ instead of $\mathbf{X}$, where $\mathbf{P}=$ $\mathbf{Z}\left(\mathbf{Z}^{\prime} \mathbf{Z}\right)^{-1} \mathbf{Z}$ and $\mathbf{Z}$ is the matrix of instruments (Cameron and Trivedi, 2005). As a consequence the sampling variance of the 2 SLS estimator is

$$
\hat{\operatorname{Var}}\left[\hat{\beta}_{2 S L S}\right]=\left(\mathbf{X}^{\prime} \mathbf{P} \mathbf{X}\right)^{-1}\left(\mathbf{X}^{\prime} \mathbf{P}\right) \mathbf{W}\left(\mathbf{X}^{\prime} \mathbf{P}\right)^{\prime}\left(\mathbf{X}^{\prime} \mathbf{P} \mathbf{X}\right)^{-1},
$$

where $\mathbf{W}$ is defined as above.

To calculate these standard errors, one need to make two decisions: the form of depreciation of spatial correlation as distance between two data points increases and the cutoff distance after which there is no spatial correlation. To be on the safe side, we show t-values based on Conley standard errors for uniform and Bartlett kernels and for all cutoff distances between 0 and 100 kilometers in 5 kilometer intervals.

Figure 5 shows the resulting t-values for our two specifications (OLS in Panel A, and 2SLS in Panel B). We see that t-values for the 'Conley SE (Bartlett)' converge towards 4.0 in the OLS regression and 3.5 in the 2SLS regression. The t-values for the 'Conley SE (uniform)' are a bit lower. But they are never below 3.0, which corresponds to a p-value $<0.0027$.

This analysis has shown that the conventional t-values in our main specifications might indeed be inflated. However, Conley standard errors always obtain statistical significance, irrespective of the specific implementation.

\section{B.2.2 Moran's I statistic and simulation with spatial noise}

The Moran statistic is a measure of the spatial correlation. Following the assumption of Kelly (2019), we use residuals of the baseline regressions and give equal weight to the five nearest neighbors and a weight of zero to all other observations. The z-values of Moran's I are: 
- OLS (column 5 of Table 5): 30.95

- 2SLS (column 2 of Table 6): 20.14

These values are relatively high, which suggests that the residuals of the regressions are spatially correlated. This is not surprising as Austrian municipalities are relatively small geographic units. Thus, we proceed to the suggested simulations. Here we generate a spatially correlated noise variable and then (a) regress the illegitimacy ratio 1971-2007 on the spatial noise variable and (b) regress the spatial noise variable on our measure of historic animal husbandry.

The main choice parameter is the correlation range of the Matérn function, which indicates after which distance (in degrees of longitude $\approx 75 \mathrm{KM}$ ) the correlation has largely depreciated (to about 0.14 ). The North-South correlation range is always half the East-West correlation range (in degrees of latitude $\approx 111 \mathrm{KM}$ ). Kelly (2019) uses a correlation range of 3 , 4, and 5 for studies in Europe and 0.5, 1, and 1.5 for the replication of Dell (2010), which has a smaller sample area. Of course, a higher choice of the correlation range results in a higher z-value of Moran's I (the measure of spatial correlation).

We show in Table B.1 the results of such a simulation exercise for different correlation ranges. When noise is used as the explanatory variable, the noise only ever outperforms our main explanatory variable if we choose a large correlation range, with a z-value of Moran's I that is about twice the size of that found in our regressions. However, the noise variable is relatively often significant at the 5 percent or 1 percent level. Similar findings hold true when noise replaces the main outcome variable.

We suggest a correlation range of 0.125 , which has a similar z-value of Moran's I as the residuals (and dependent and main independent variables) of about 30. In this case, the spatial noise variable never outperforms our main independent variable and significance levels are only modestly inflated. This suggests that the relationship we find in our paper is not an artifact of spatial correlation but there is a fundamental connection between these illegitimacy today and historic animal husbandry. 
Table B.1: Simulation results

\begin{tabular}{|c|c|c|c|c|c|c|c|c|c|c|}
\hline \multirow[b]{2}{*}{$\begin{array}{l}\text { Correlation } \\
\text { range }\end{array}$} & \multirow[b]{2}{*}{$\begin{array}{l}\text { Mean z-value } \\
\text { of Moran's I }\end{array}$} & \multicolumn{5}{|c|}{ Explanatory noise } & \multicolumn{4}{|c|}{ Dependent noise } \\
\hline & & $\begin{array}{c}\text { Out- } \\
\text { performs }\end{array}$ & $\mathrm{p}=0.05$ & $\mathrm{p}=0.01$ & $\mathrm{p}=0.001$ & $\mathrm{p}=0.0001$ & $\mathrm{p}=0.05$ & $\mathrm{p}=0.01$ & $\mathrm{p}=0.001$ & $\mathrm{p}=0.0001$ \\
\hline 0.05 & 6.20 & 0.00 & 0.10 & 0.04 & 0.01 & 0.01 & 0.07 & 0.01 & 0.00 & 0.00 \\
\hline 0.1 & 23.50 & 0.00 & 0.24 & 0.11 & 0.04 & 0.02 & 0.17 & 0.07 & 0.02 & 0.00 \\
\hline 0.125 & 30.45 & 0.00 & 0.27 & 0.15 & 0.06 & 0.02 & 0.22 & 0.11 & 0.04 & 0.01 \\
\hline 0.25 & 48.23 & 0.00 & 0.52 & 0.39 & 0.28 & 0.18 & 0.45 & 0.30 & 0.17 & 0.11 \\
\hline 0.5 & 56.68 & 0.03 & 0.64 & 0.55 & 0.47 & 0.39 & 0.62 & 0.50 & 0.41 & 0.33 \\
\hline 0.75 & 58.76 & 0.05 & 0.74 & 0.68 & 0.60 & 0.53 & 0.68 & 0.58 & 0.46 & 0.38 \\
\hline 1 & 59.54 & 0.12 & 0.80 & 0.73 & 0.65 & 0.57 & 0.72 & 0.61 & 0.54 & 0.47 \\
\hline
\end{tabular}

Notes: The numbers for 'Explanatory noise' and 'Dependent noise' show the share of regressions with a significant correlation with the spatial noise variable. The correlation range indicates the degrees of longitude of spatial correlation. The

North-South correlation range is half of that. $N=400$ for each correlation range. 


\section{C.3 Additional figures}

Figure C.1: Austrian part of the Austro-Hungarian Empire

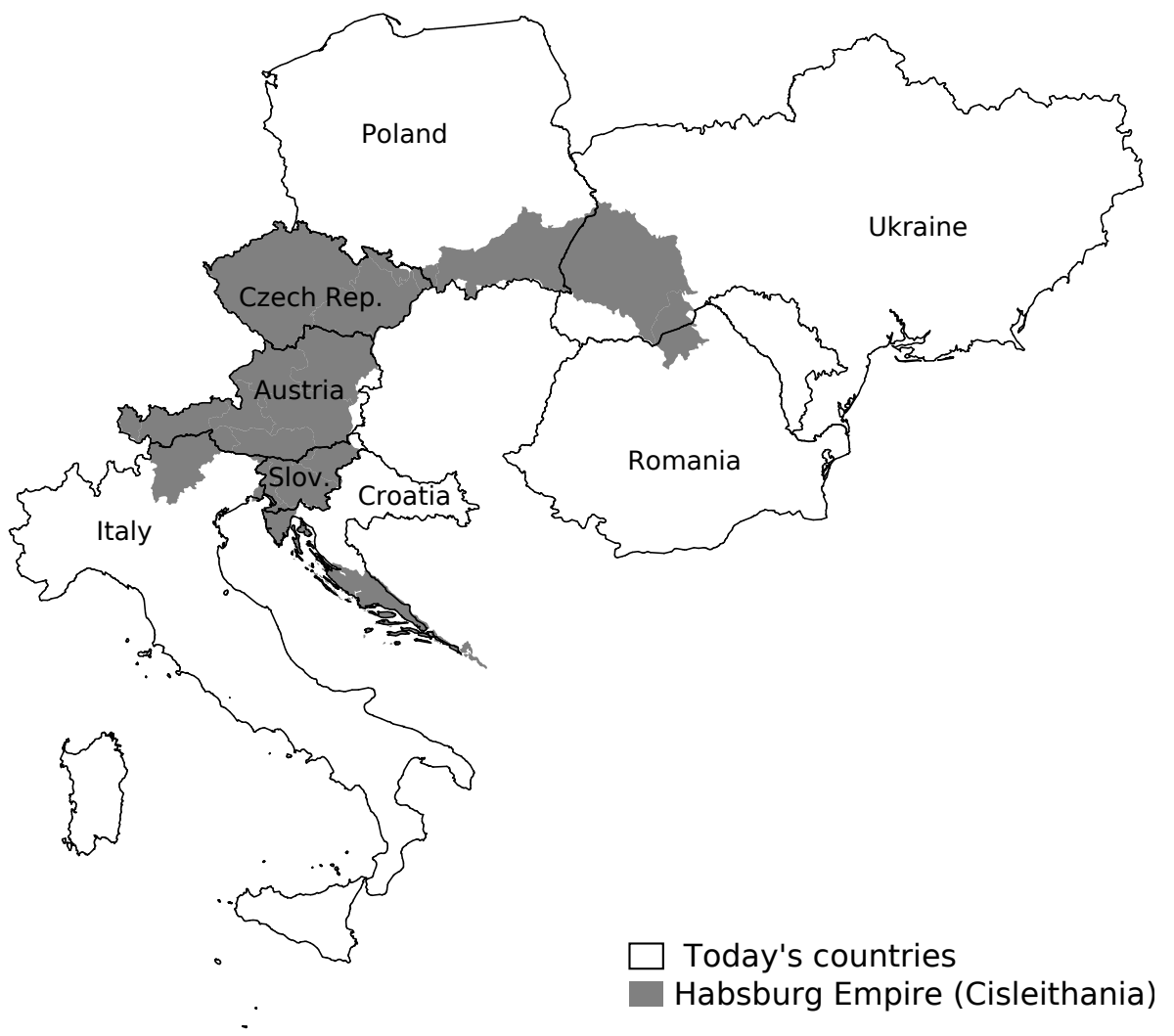

Notes: The map shows borders of today's countries in black and the area of the Austrian part of the Austro-Hungarian Empire (aka Cisleithania) in gray. 
Figure C.2: Development of the illegitimacy ratio in Austria by historical agricultural production structure, 1971-2007

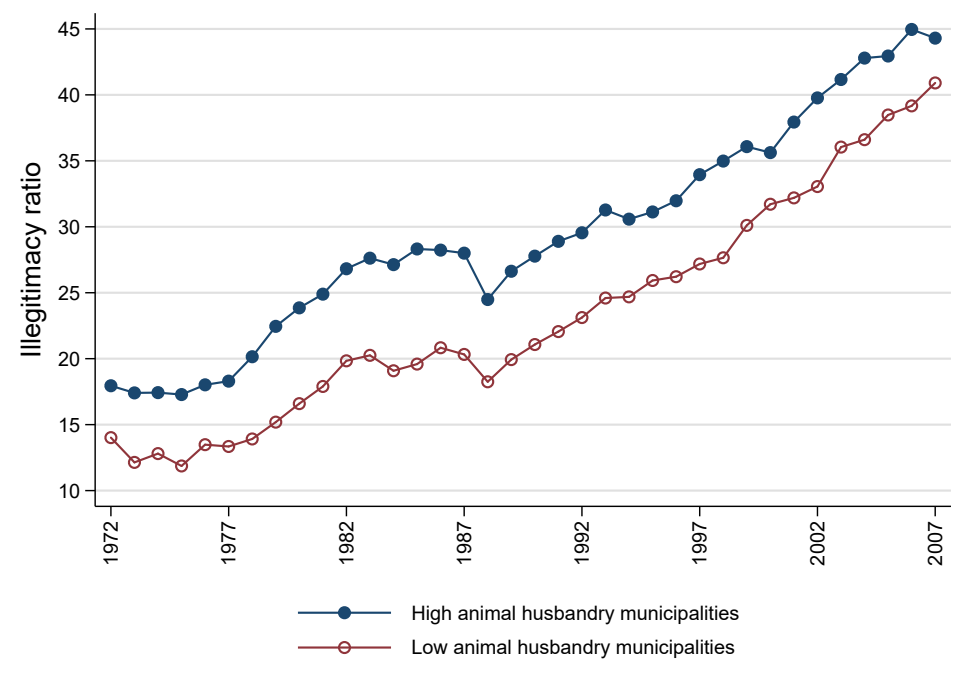

Notes: The illegitimacy ratio is defined as the share of live births to unmarried mothers of all live births. High animal husbandry (low animal husbandry) municipalities are defined as those municipalities with and above (below) median ratio of livestock units to agricultural workers in 1900. 


\section{Figure C.3: Illegitimacy ratio vs. illegitimacy rate}
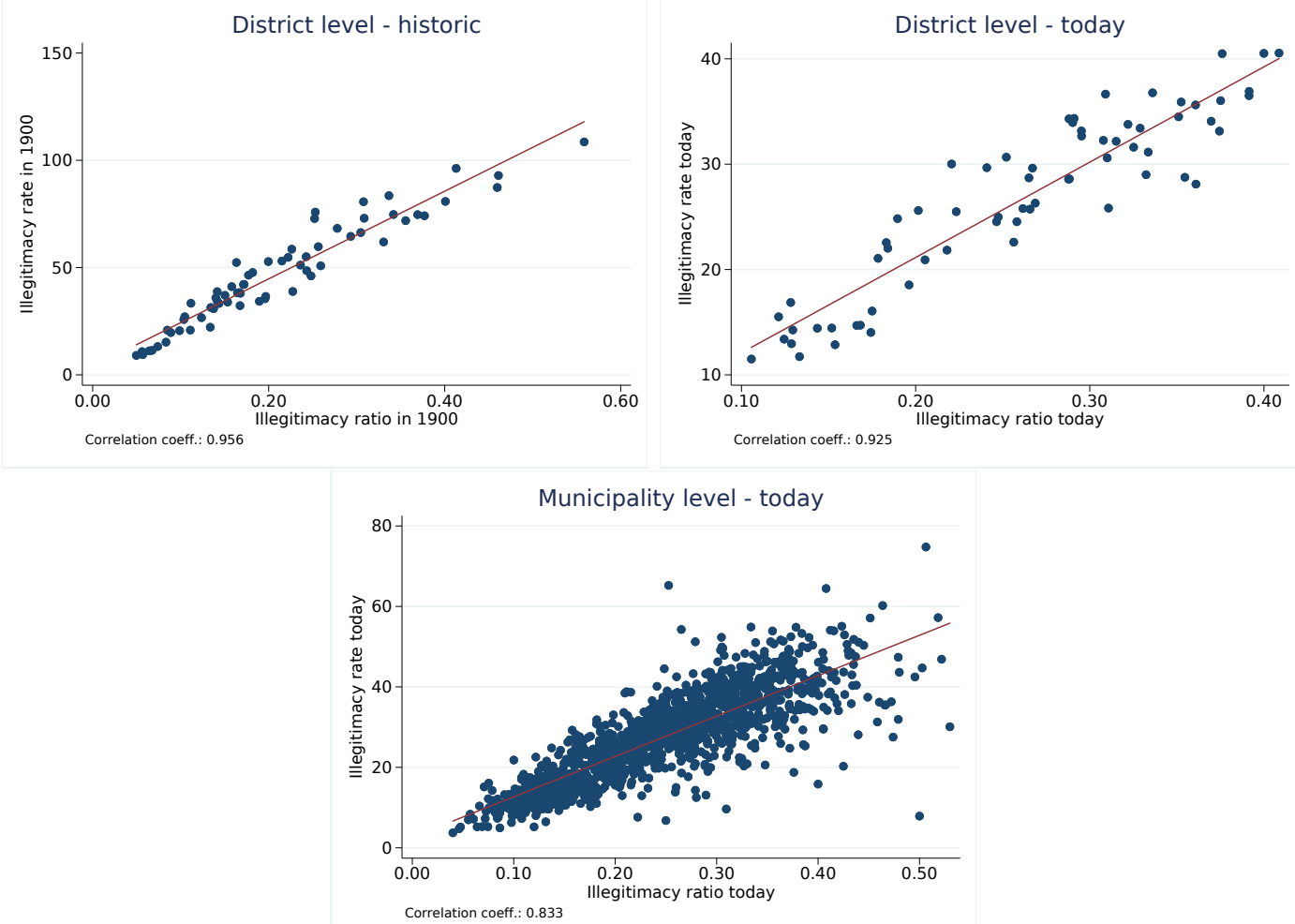

Notes: The illegitimacy ratio is defined as is the number of illegitimate lives births divided by all (illegitimate plus legitimate) live births. The illegitimacy rate is defined as the number of illegitimate lives births per 1,000 unmarried women of childbearing age. 'Historic' refers to the year 1900 and childbearing age is defined as 14 to 45 years of age. 'Today' refers to the average over the period from 1971 to 2007 and childbearing age is defined as 15 to 49 years of age. On a municipality-level, the number of unmarried women of childbearing age is only available in census years $(1971,1981,1991,2001)$. To obtain values for the years in between we used a linear interpolation. For the years 2002 to 2007 we used a linear extrapolation. 
Figure C.4: Development of the share of the population in agriculture

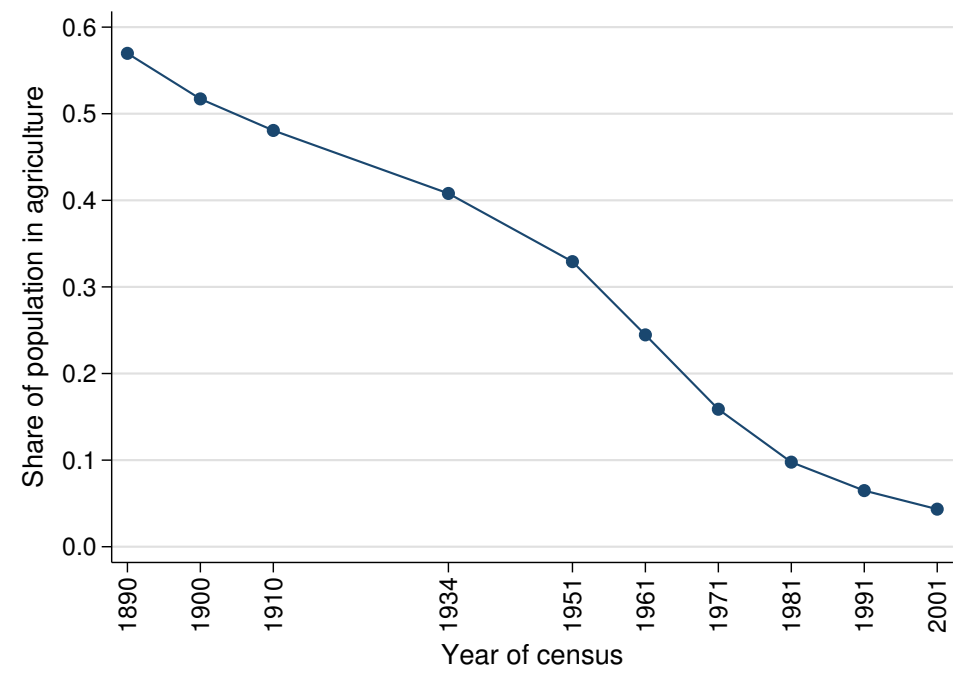

Notes: The graph summarizes the share of the population affiliated with the agricultural sector by year in the area covered by our Austrian sample (see Appendix Section A.1).

Figure C.5: Probability of early death by legitimacy status

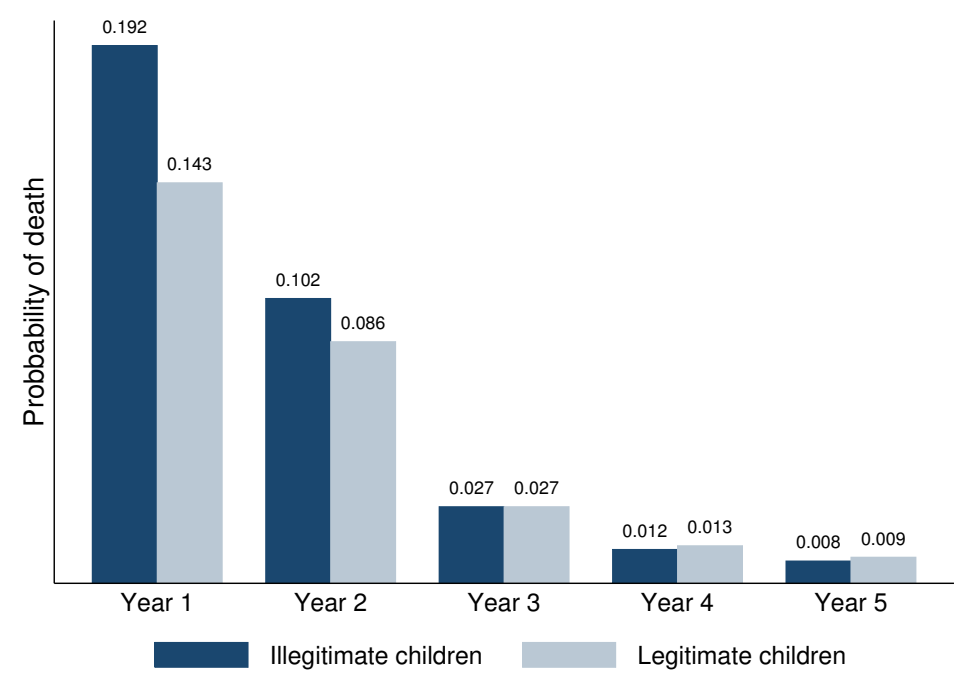

Notes: Data is aggregated for Austria over the birth cohorts 1900-1904. The data come from the publications Bewegung der Bevölkerung of 1900-1909. Because children can get legitimized (but not the other way round), the probability of death for bastards is downward biased, while the probability of death for legitimate children is upward biased. 
Figure C.6: Probability of remaining illegitimate after birth

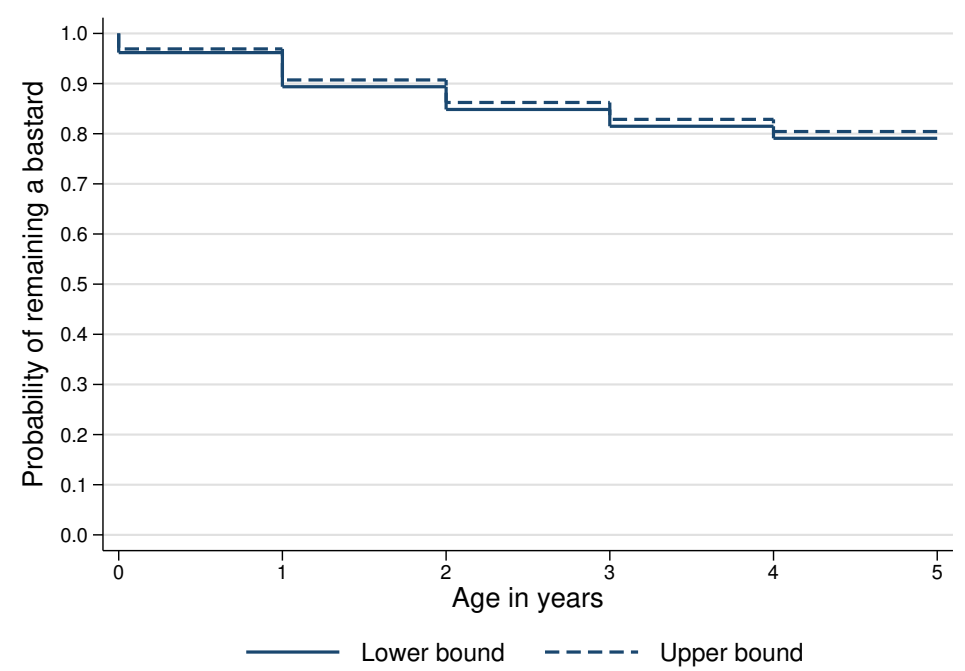

Notes: Data is aggregated for Austria over the birth cohorts 1900-1904. The data come from the publications Bewegung der Bevölkerung of 1900-1909. The probability of legitimization is the number of legitimizations divided by the stock of illegitimate children. The lower bound assumes that all deaths of illegitimate children occurred on Jan. 1, while the upper bound assumes Dec. 31 . 
Figure C.7: Historical animal husbandry and illegitimacy today: IV estimates in sub-samples
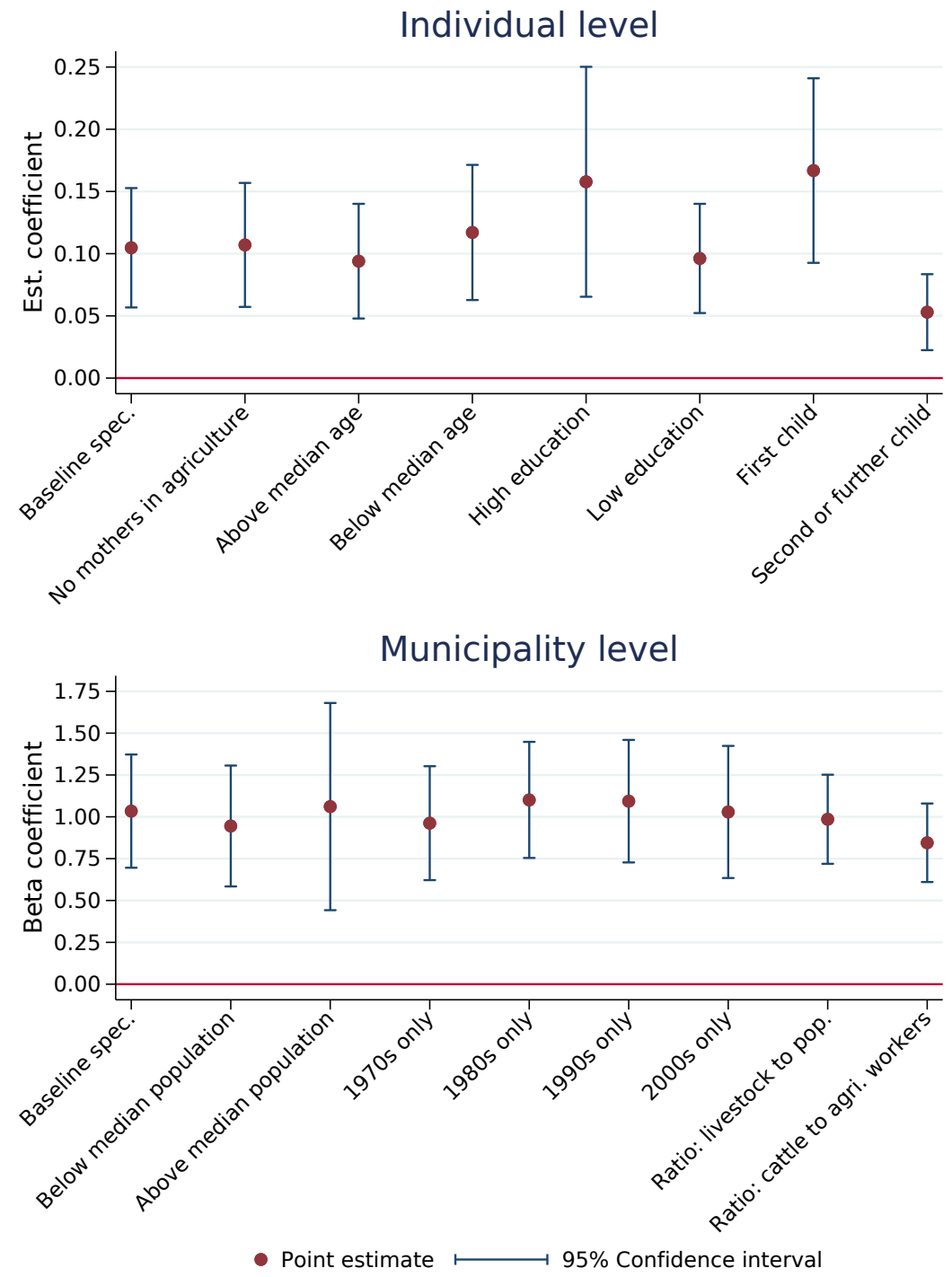

Notes: The first estimate in the upper figure is equal to column (6) of Table 6. It shows the estimated coefficient of the second stage and the corresponding $95 \%$ confidence interval. The remaining estimates replicate this estimation in sub-samples of mothers. The second estimate is based on a sample, which excludes mothers, who had been employed in agriculture before birth. The third estimate is based on the sub-sample of young mothers (below the median age of 27 years). The fourth estimate is based on the sub-sample of older mothers (above median age). The fifth estimate is based on the sub-sample of mothers with low educational attainment (less than upper secondary education). The sixth estimate is based on the sub-sample of mothers with higher educational attainment (at least upper secondary education). The seventh estimate is based on the sub-sample of first-time mothers. The eight estimate is based on the sub-sample of mothers with higher parities. The first estimate in the lower figure is equal to column (3) of Table 6. It shows the estimated beta coefficient and the corresponding 95\% confidence interval. The second (third) estimate is based on the sub-sample of municipalities with below (above) median population mothers. The fourth to the seventh estimate focus on births in $1970 \mathrm{~s} / 80 \mathrm{~s} / 90 \mathrm{~s}$, and 2000s, respectively. The eight and ninth estimate is based on the full sample, but uses two alternative measure of animal husbandry: the ratio of livestock to the total population in 1900, and the ratio of cattle to agricultural workers in 1900. 
Figure C.8: Development of animal husbandry and illegitimacy before 1900 by province

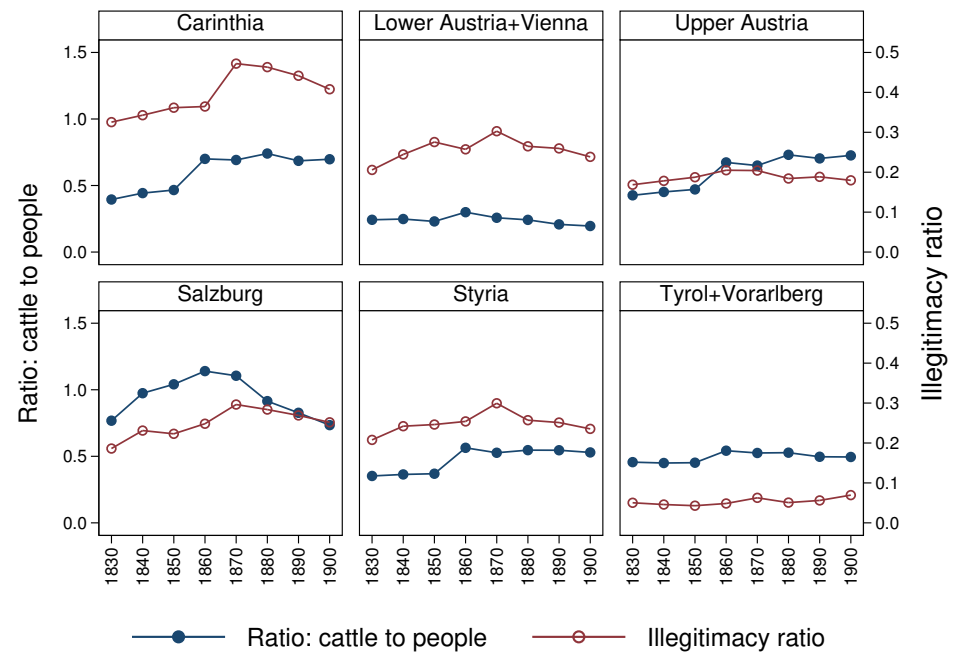

Notes: Data for the variable ratio of cattle to people come from the annually statistical reviews (Statistisches Jahrbuch) between 1831-1860 and the population censuses (Volkszählung) of 1869, 1880, 1890, and 1900. Data on illegitimate births come from the annually statistical reviews (Statistisches Jahrbuch) between 1831-1860 and population statistics (Bewegung der Bevölkerung) in 1880, 1890, and 1900.

Figure C.9: Development of shotgun weddings in Austria, 1984-2007

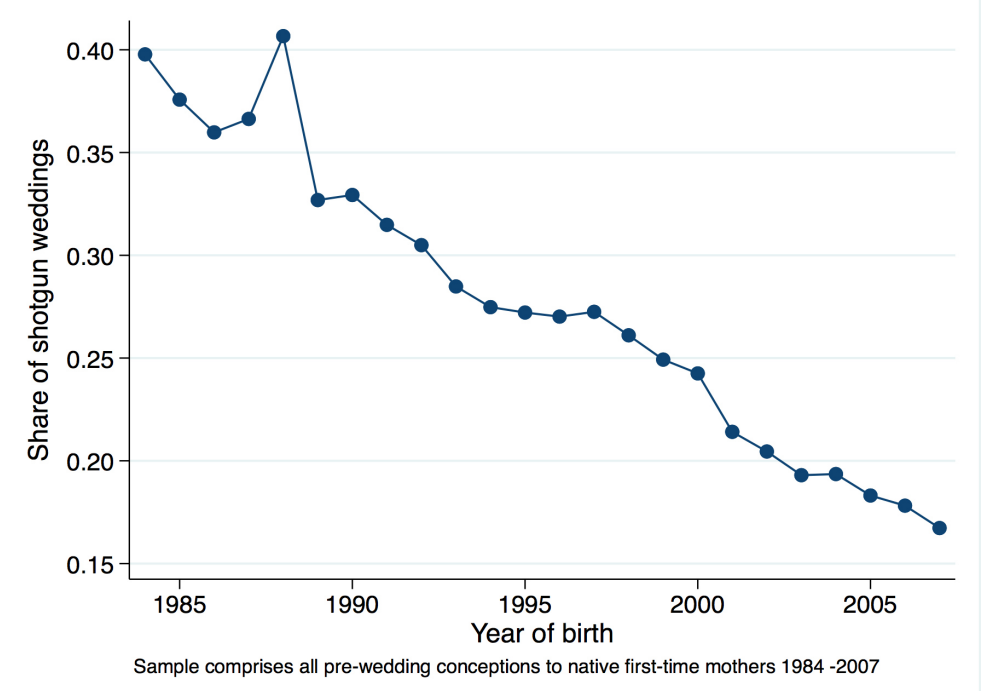

Notes: Own calculations based on the Austrian Birth Register. Figures are based on all pre-marital conceptions to Austrian first-time mothers. A shotgun wedding is defined as a case, where a women was unmarried at the time of conception, but got married before birth. 


\section{Figure C.10: Epidemiological correlation}

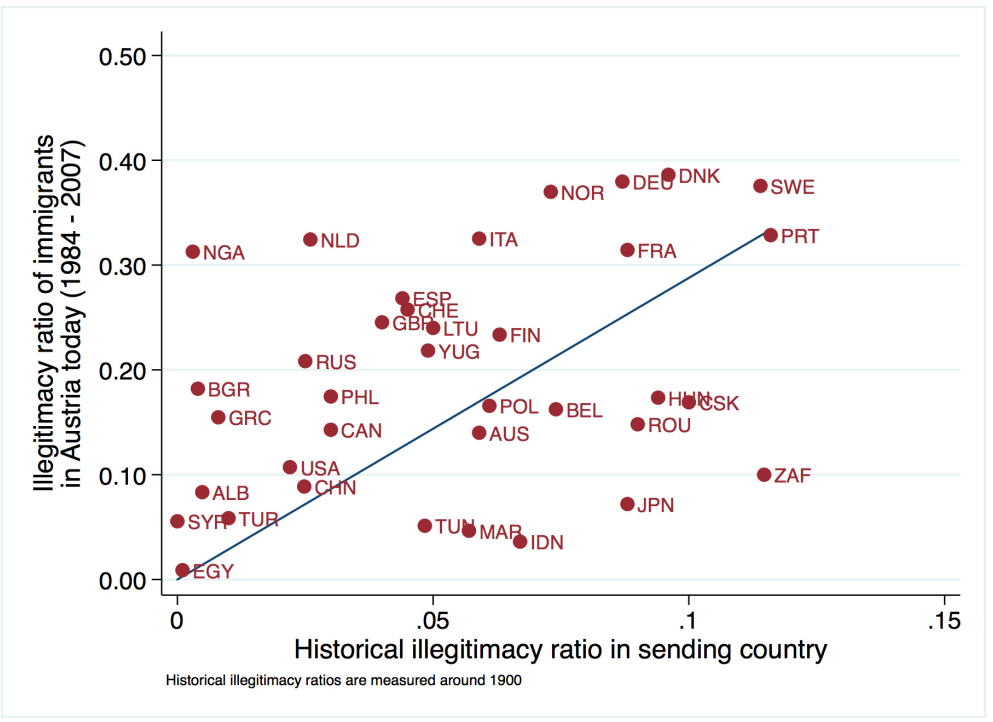

Notes: Data sources for the historical illegitimacy ratio in the sending country are listed in Appendix Table D.10. The average illegitimacy ratio of immigrants in Austria today are own calculations based on the Austrian Birth Register, see notes to Table 11 in the paper. Countries from South America are excluded, since Hartley (1975) discusses the questionable reliability of (historical) illegitimacy ratios from these countries. The correlation coefficient is equal to 0.37 ( $\mathrm{p}$-value=0.025). In a regression which controls for continent fixed-effects the estimated coefficients amounts to 0.74 (p-value $=0.09, N=37$ ). An equivalent estimation, which includes South American countries gives an estimated coefficient of 0.65 (p-value $=0.004, N=44)$. 
D.4 Additional tables 
Table D.1: Illegitimacy ratio vs. illegitimacy rate

(1)

$(2)$

(3)

(4)

\begin{tabular}{|c|c|c|c|c|}
\hline \multirow[b]{2}{*}{ Illegitimacy ratio in $1900^{a}$} & \multicolumn{2}{|c|}{ Illegitimacy ratio today } & \multicolumn{2}{|c|}{ Illegitimacy rate today } \\
\hline & $\begin{array}{l}0.396^{* * *} \\
(0.073) \\
{[0.523]}\end{array}$ & & $\begin{array}{l}34.662^{* * *} \\
(8.044) \\
{[0.468]}\end{array}$ & \\
\hline Illegitimacy rate in $1900^{b}$ & & $\begin{array}{l}0.002^{* * *} \\
(0.000) \\
{[0.507]}\end{array}$ & & $\begin{array}{l}0.159^{* * *} \\
(0.036) \\
{[0.460]}\end{array}$ \\
\hline Province FE & Yes & Yes & Yes & Yes \\
\hline District controls & Yes & Yes & Yes & Yes \\
\hline Number of observations & 66 & 66 & 66 & 66 \\
\hline Adj. R-squared & 0.857 & 0.856 & 0.818 & 0.820 \\
\hline Mean of dependent variable & 0.262 & 0.262 & 26.718 & 26.718 \\
\hline
\end{tabular}

Panel B: OLS estimates, municipality level, replication of Table 5, column (6)

\begin{tabular}{lcc} 
& $\begin{array}{c}\text { Illegitimacy } \\
\text { ratio today }\end{array}$ & $\begin{array}{c}\text { Illegitimacy } \\
\text { rate today }\end{array}$ \\
\cline { 2 - 3 } Animal husbandry in $1900^{c}$ & $0.022^{* * *}$ & $2.449^{* * *}$ \\
& $(0.003)$ & $(0.356)$ \\
Province FE & {$[0.183]$} & {$[0.168]$} \\
Municipality controls & Yes & Yes \\
Number of observations & Yes & Yes \\
Adj. R-squared & 1,318 & 1,318 \\
Mean of dependent variable & 0.567 & 0.493 \\
& 0.250 & 27.702
\end{tabular}

Panel C: IV estimates, municipality level, replication of Table 6, column (3)

\begin{tabular}{lcc} 
& $\begin{array}{c}\text { Illegitimacy } \\
\text { ratio today }\end{array}$ & $\begin{array}{c}\text { Illegitimacy } \\
\text { rate today }\end{array}$ \\
\cline { 2 - 3 } Animal husbandry in $1900^{c}$ & $0.125^{* * *}$ & $11.506^{* * *}$ \\
& $(0.021)$ & $(2.300)$ \\
Province FE & {$[1.034]$} & {$[0.791]$} \\
Municipality controls & Yes & Yes \\
Number of observations & Yes & Yes \\
Mean of dependent variable & 0.318 & 1,318 \\
& 0.250 & 27.702
\end{tabular}

Notes: Method of estimation is OLS/2SLS. Standard errors are reported in parentheses. Beta coefficients are reported in brackets. *,** and *** indicate statistical significance at the 10 percent level, 5 percent level, and 1 percent level, respectively. The unit of observation is a district according to borders in 1900 in Panel A and a municipality according to borders in 2013 in Panels B and C. The illegitimacy ratio is defined as is the number of illegitimate lives births divided by all (illegitimate plus legitimate) live births. The illegitimacy rate is defined as the number of illegitimate lives births per 1,000 unmarried women of childbearing age. Further details are provided in the notes to Appendix Figure C.3. Animal husbandry is the ratio of livestock units to agricultural workers in the women's municipality of residence in 1900. The livestock unit is calculated as follows: cattle $+0.7 \cdot$ horses $+0.25 \cdot$ sheep $+0.26 \cdot$ pigs. In Panel $\mathrm{C}$, animal husbandry is instrumented with the mean slope of the terrain in this municipality. Information on the control variables is provided in the notes to Tables 3, 5, and 6 . 
Table D.2: Income of agricultural servants and day laborers in 1893

\begin{tabular}{|c|c|c|c|c|c|}
\hline \multicolumn{6}{|c|}{ Panel A: Mean daily income incl. in-kind payments in Kreuzer } \\
\hline & $\mathrm{N}$ & Mean & Std. Dev. & Min. & Max. \\
\hline \multicolumn{6}{|l|}{ Agricultural servants } \\
\hline \multicolumn{6}{|l|}{ Males } \\
\hline Simple servant & 104 & 68.0 & 16.3 & 32.9 & 117.3 \\
\hline Higher servant & 94 & 81.6 & 21.0 & 43.8 & 141.9 \\
\hline \multicolumn{6}{|l|}{ Females } \\
\hline Simple maid & 101 & 57.2 & 17.2 & 26.8 & 147.9 \\
\hline Higher maid & 76 & 58.6 & 16.2 & 26.3 & 104.1 \\
\hline \multicolumn{6}{|l|}{ Day laborers } \\
\hline \multicolumn{6}{|l|}{ Males } \\
\hline Male during harvest season & 104 & 109.1 & 30.2 & 55.0 & 200.0 \\
\hline Male during sawing season & 101 & 88.1 & 21.8 & 47.0 & 160.0 \\
\hline Male during shoulder season & 103 & 78.4 & 22.0 & 35.0 & 160.0 \\
\hline \multicolumn{6}{|l|}{ Females } \\
\hline Female during harvest season & 98 & 82.9 & 20.1 & 40.0 & 150.0 \\
\hline Female during sawing season & 97 & 68.1 & 14.3 & 37.0 & 120.0 \\
\hline Female during shoulder season & 98 & 61.3 & 15.2 & 20.0 & 100.0 \\
\hline
\end{tabular}

Panel B: Share of in-kind payments of total income

\begin{tabular}{|c|c|c|c|c|c|}
\hline & $\mathrm{N}$ & Mean & Std. Dev. & Min. & Max. \\
\hline \multicolumn{6}{|c|}{ Agricultural servants } \\
\hline \multicolumn{6}{|c|}{ Males } \\
\hline Simple servant & 104 & 0.641 & 0.097 & 0.207 & 0.833 \\
\hline Higher servant & 94 & 0.583 & 0.096 & 0.143 & 0.806 \\
\hline \multicolumn{6}{|l|}{ Females } \\
\hline Simple maid & 101 & 0.685 & 0.094 & 0.405 & 0.895 \\
\hline Higher maid & 76 & 0.682 & 0.097 & 0.500 & 0.910 \\
\hline
\end{tabular}

Notes: $N$ indicates the number of court districts (subdivision of districts) the estimate is based on. Data source: Die landwirtschaftlichen Löhne in den im Reichsrathe vertretenen Königreichen und Ländern nach dem Stande des Jahres 1893. Bureau der K. K. statistischen Central-Commission. 
Table D.3: Descriptive statistics of illegitimate births in 1900

\begin{tabular}{|c|c|c|}
\hline \multirow[b]{2}{*}{ Age of mother at birth } & \multicolumn{2}{|c|}{ Share of births to } \\
\hline & unmarried mothers & married mothers \\
\hline up to 17 years & $1.0 \%$ & $0.1 \%$ \\
\hline over 17 and up to 20 years & $11.9 \%$ & $1.1 \%$ \\
\hline over 20 and up to 25 years & $43.1 \%$ & $15.4 \%$ \\
\hline over 25 and up to 30 years & $25.1 \%$ & $28.5 \%$ \\
\hline over 30 and up to 40 years & $17.0 \%$ & $46.2 \%$ \\
\hline over 40 years & $2.0 \%$ & $8.8 \%$ \\
\hline
\end{tabular}

\section{Panel B: Illegitimacy ratio by size of location}

Population size of location

Illegitimacy ratio

$\begin{array}{ll}\text { up to } 500 \text { people } & 0.187 \\ 501 \text { to } 2,000 \text { people } & 0.151 \\ 2,001 \text { to } 5,000 \text { people } & 0.155 \\ 5,001 \text { to } 10,000 \text { people } & 0.246 \\ 10,001 \text { to } 20,000 \text { people } & 0.169 \\ \text { more than } 20,000 \text { people } & 0.321\end{array}$

\section{Panel C: Age of groom at marriage by profession}

Share of marriages of

\begin{tabular}{lcc}
\cline { 2 - 3 } Age of groom & agricultural servants & day laborers in agriculture \\
\hline up to 20 years & $0.0 \%$ & $0.0 \%$ \\
over 20 and up to 24 years & $6.2 \%$ & $6.0 \%$ \\
over 24 and up to 30 years & $44.0 \%$ & $38.5 \%$ \\
over 30 and up to 35 years & $23.3 \%$ & $20.7 \%$ \\
over 35 and up to 40 years & $12.6 \%$ & $11.9 \%$ \\
over 40 and up to 50 years & $10.5 \%$ & $11.4 \%$ \\
over 50 and up to 60 years & $3.0 \%$ & $7.2 \%$ \\
over 60 and up to 70 years & $0.3 \%$ & $3.6 \%$ \\
over 70 years & $0.1 \%$ & $0.5 \%$ \\
\hline approximative mean age & 32.2 & 34.7 \\
\hline
\end{tabular}

Notes: Data source: K.K. Statistische Zentralkommission. (1902). Bewegung der Bevölkerung der im Reichsrathe vertretenen Königreiche und Länder im Jahre 1900. K.K. Hof- und Staatsdruckerei. 
Table D.4: Different proxies for farmhand societies and illegitimacy in 1900

Dependent variable: illegitimacy ratio in 1900

(1)

$0.766^{* * *}$
$(0.133)$
$[0.346]$

Share of agri. servants of agri. workers in 1900

Share of non-family agri. workers in 1900

Share of permanent agri. workers in 1900

Province FE

Number of observations

Adj. R-squared

Mean of dependent variable

Standard dev. of dependent variable

Mean of independent variable

Standard dev. of independent variable
(2)

(3)

(4)

Notes: Method of estimation is OLS. Standard errors are reported in parentheses. Beta coefficients are reported in brackets. $*, * *$ and $* * *$ indicate statistical significance at the 10 percent level, 5 percent level, and 1 percent level, respectively. Data sources are listed in Appendix Table A.1. 


\section{Table D.5: Historical animal husbandry and illegitimacy today: Religiosity controls}

Dependent variable: illegitimacy ratio today (1971-2007)

$(2)$

$(3)$

Panel A: Second stage estimates

Animal husbandry in $1900^{a}$

Attend religious service at least once per $\operatorname{month}^{b}$

$\begin{array}{cccc}0.141^{* * *} & 0.168^{* * *} & 0.124^{* * *} & 0.152^{* * *} \\ (0.024) & (0.028) & (0.022) & (0.024) \\ -0.180^{* * *} & & & -0.127^{* *} \\ (0.032) & & & (0.051) \\ & -0.266^{* * *} & & -0.171^{* * *} \\ & (0.045) & & (0.062) \\ & & 0.002 & 0.097^{* * *} \\ & & (0.025) & (0.030) \\ \text { Yes } & \text { Yes } & \text { Yes } & \text { Yes } \\ \text { Yes } & \text { Yes } & \text { Yes } & \text { Yes } \\ 1,318 & 1,318 & 1,318 & 1,318 \\ 0.250 & 0.250 & 0.250 & 0.250\end{array}$

Attend religious service at least twice per month ${ }^{b}$

Important that infant is registered with appropriate religious ceremony ${ }^{b}$

Province FE

Municipality controls

Number of observations

Mean of dependent variable

0.250

0.250

0.250

Panel B: First stage estimates

Dependent variable: animal husbandry in 1900

Mean slope of terrain

\begin{tabular}{lccc}
$0.016^{* * *}$ & $0.016^{* * *}$ & $0.016^{* * *}$ & $0.017^{* * *}$ \\
$(0.002)$ & $(0.003)$ & $(0.002)$ & $(0.003)$ \\
42.322 & 38.604 & 44.185 & 44.962 \\
0.378 & 0.374 & 0.373 & 0.379 \\
\hline
\end{tabular}

Adj. R-squared

Notes: Method of estimation is 2SLS. Standard errors are reported in parentheses. *, ** and *** indicate statistical significance at the 10 percent level, 5 percent level, and 1 percent level, respectively. The unit of observation is a municipality according to borders in 2013. ${ }^{a}$ Animal husbandry is the ratio of livestock units to agricultural workers in 1900. The livestock unit is calculated as follows: cattle $+0.7 \cdot$ horses $+0.25 \cdot$ sheep $+0.26 \cdot$ pigs. It is instrumented with the mean slope of the terrain in this municipality. ${ }^{b}$ Religious variables come from the Generations \& Gender Programme survey (First Wave from Austria) and vary only at the district level. Municipality controls comprise information on the log of population, the share of males, the share of Catholics, the local presence of a factory, the local presence of large land holdings, the market status of the municipality, and the share of population employed in agriculture (see Panel A in Table 2). Data sources are listed in Appendix Table A.1. 
Table D.6: Historical animal husbandry and other historical demographic outcomes

\begin{tabular}{cccc}
\multicolumn{4}{c}{ Dependent variables: } \\
Age at & Share of & Marital & Non-marital \\
marriage & married females & fertility & fertility \\
(females) & (age 46 or older) & (per 1,000 females)
\end{tabular}

(1)

(2)

(3)

(4)

\section{Panel A: OLS estimates}

Animal husbandry in $1900^{a}$

Province FE

District-level covariates

Number of observations

Adj. R-squared

Mean of dependent variable

$\begin{array}{cccc}0.070 & -0.021^{* *} & -5.524 & 20.340^{* * *} \\ (0.258) & (0.008) & (7.206) & (3.813) \\ \text { Yes } & \text { Yes } & \text { Yes } & \text { Yes } \\ \text { Yes } & \text { Yes } & \text { Yes } & \text { Yes } \\ 66 & 66 & 66 & 66 \\ 0.498 & 0.785 & 0.654 & 0.787 \\ 29.172 & 0.391 & 273.107 & 46.611\end{array}$

\section{Panel B: Second stage estimates}

Animal husbandry in $1900^{a}$

$$
\begin{array}{ccc}
-0.079 & -0.098^{*} & -3.488 \\
(1.080) & (0.058) & (30.124)
\end{array}
$$

$59.040^{* *}$

$(28.252)$

Panel C: First stage estimates

Dep. var.: Ratio: livestock units to agri. workers in 1900

Mean slope of terrain

$\begin{array}{llll}0.019 & 0.019 & 0.019 & 0.019 \\ (0.013) & (0.013) & (0.013) & (0.013) \\ 2.088 & 2.088 & 2.088 & 2.088 \\ 0.484 & 0.484 & 0.484 & 0.484\end{array}$

F-statistic

0.484

0.484

0.484

0.484

Notes: Method of estimation is OLS/2SLS. Standard errors are reported in parentheses. ${ }^{*},{ }^{* *}$ and ${ }^{* * *}$ indicate statistical significance at the 10 percent level, 5 percent level, and 1 percent level, respectively. The unit of observation is a district according to borders in 1900. ${ }^{a}$ Animal husbandry is the ratio of livestock units to agricultural workers in 1900. The livestock unit is calculated as follows: cattle $+0.7 \cdot$ horses $+0.25 \cdot$ sheep $+0.26 \cdot$ pigs. It is instrumented with the mean slope of the terrain in this district. District controls include the share of Catholics, the urbanization rate, the share of males, the shares of age groups for below 14 and between 15 and 60 years, the employment shares in agriculture, manufacturing, and commerce and transportation, the share of illiterate and the log teacher income, all measured in 1900 (see Panel B in Table 1). Data sources are listed in Appendix Table A.1. 
Table D.7: Alternative definitions of animal husbandry

\begin{tabular}{|c|c|c|}
\hline \multirow{3}{*}{$\begin{array}{l}\text { Replication of: } \\
\text { Weighting of animal types: } \\
\text { (Cattle - horses - sheep - pigs) }\end{array}$} & \multicolumn{2}{|c|}{ Dependent variable: illegitimacy today } \\
\hline & $\begin{array}{c}\text { OLS } \\
\text { (Table 5, col. 6) }\end{array}$ & $\begin{array}{l}\text { 2SLS: second stage } \\
\text { (Table } 6 \text {, col. } 3 \text { ) }\end{array}$ \\
\hline & (1) & $(2)$ \\
\hline $1-0-0-0$ & $\begin{array}{l}0.032^{* * *} \\
(0.003) \\
{[0.232]}\end{array}$ & $\begin{array}{l}0.116^{\text {*** }} \\
(0.016) \\
{[0.845]}\end{array}$ \\
\hline $1-0-1-0$ & $\begin{array}{l}0.024^{* * *} \\
(0.002) \\
{[0.252]}\end{array}$ & $\begin{array}{l}0.045^{* * *} \\
(0.005) \\
{[0.469]}\end{array}$ \\
\hline $1-1-1-0$ & $\begin{array}{l}0.022^{* * *} \\
(0.002) \\
{[0.236]}\end{array}$ & $\begin{array}{l}0.052^{\text {*** }} \\
(0.006) \\
{[0.551]}\end{array}$ \\
\hline $1-1-1-1$ & $\begin{array}{l}0.009^{* * *} \\
(0.002) \\
{[0.108]}\end{array}$ & $\begin{array}{l}0.087^{* * *} \\
(0.016) \\
{[1.050]}\end{array}$ \\
\hline $1-1-0.5-0.5$ & $\begin{array}{l}0.016^{* * *} \\
(0.002) \\
{[0.149]}\end{array}$ & $\begin{array}{l}0.115^{* * *} \\
(0.021) \\
{[1.099]}\end{array}$ \\
\hline $1-1-0.25-0.25$ & $\begin{array}{l}0.021^{* * *} \\
(0.003) \\
{[0.176]}\end{array}$ & $\begin{array}{l}0.138^{* * *} \\
(0.025) \\
{[1.179]}\end{array}$ \\
\hline $0.75-1-0.25-0.25$ & $\begin{array}{l}0.023^{* * *} \\
(0.003) \\
{[0.157]}\end{array}$ & $\begin{array}{l}0.197^{* * *} \\
(0.041) \\
{[1.356]}\end{array}$ \\
\hline $1-0.75-0.25-0.25$ & $\begin{array}{l}0.022^{* * *} \\
(0.003) \\
{[0.183]}\end{array}$ & $\begin{array}{l}0.126^{* * *} \\
(0.021) \\
{[1.046]}\end{array}$ \\
\hline $\begin{array}{l}\text { Province FE } \\
\text { Municipality controls } \\
\text { Number of observations } \\
\text { Mean of dependent variable }\end{array}$ & $\begin{array}{l}\text { Yes } \\
\text { Yes } \\
1,318 \\
0.250\end{array}$ & $\begin{array}{l}\text { Yes } \\
\text { Yes } \\
1,318 \\
0.250\end{array}$ \\
\hline
\end{tabular}

Notes: Method of estimation is OLS in column (1) and 2SLS in column (2). Standard errors are reported in parentheses. Beta coefficients are reported in brackets. *, ** and *** indicate statistical significance at the 10 percent level, 5 percent level, and 1 percent level, respectively. The unit of observation is a municipality according to borders in 2013 . The independent variable is animal husbandry with different weighting for the four types of animals in our data (cattle, horses, sheep, and pigs). Municipality controls comprise information on the log of population, the share of males, the share of Catholics, the local presence of a factory, the local presence of a large land holding, the market status of the municipality, and the share of population employed in agriculture (see Panel A in Table 2). Data sources are listed in Appendix Table A.1. 
Table D.8: Measuring the relative dominance of animal husbandry with the share of pastureland

Dependent variable: illegitimacy ratio 1971-2007

(1)

Animal husbandry in $1900^{a}$

Share of non-forested land used for pasture

Province FE

District-level covariates

Number of observations

Adj. R-squared

Mean of dependent variable
$(2)$

(3)
(4)

$0.046^{* * *}$
$(0.012)$
$[0.310]$

[0.310]

Notes: Method of estimation is OLS. Standard errors are reported in parentheses. Beta coefficients are reported in brackets. ${ }^{*}, * *$ and ${ }^{* * *}$ indicate statistical significance at the 10 percent level, 5 percent level, and 1 percent level, respectively. The unit of observation is a district according to borders in 1900 . ${ }^{a}$ Animal husbandry is the ratio of livestock units to agricultural workers in 1900 . The livestock unit is calculated as follows: cattle $+0.7 \cdot$ horses $+0.25 \cdot$ sheep $+0.26 \cdot$ pigs. District controls include the share of Catholics, the urbanization rate, the share of males, the shares of age groups for below 14 and between 15 and 60 years, the employment shares in agriculture, manufacturing, and commerce and transportation, the share of illiterate and the log teacher income, all measured in 1900 (see Panel B in Table 1). Data sources are listed in Appendix Table A.1. 
Table D.9: Outcomes female labor force participation and female labor income

\begin{tabular}{|c|c|}
\hline Panel A: Female labor for & ce participation \\
\hline & $\begin{array}{l}\text { Dep. var.: female } \\
\text { labor force part- } \\
\text { icipation in } 2011\end{array}$ \\
\hline & (1) \\
\hline Animal husbandry in $1900^{a}$ & $\begin{array}{c}-0.001 \\
(0.002)\end{array}$ \\
\hline Province FE & Yes \\
\hline Municipality controls $^{b}$ & Yes \\
\hline Number of observations & 1,318 \\
\hline Adj. R-squared & 0.258 \\
\hline Mean of dependent variable & 0.688 \\
\hline
\end{tabular}

Panel B: Female labor income

Dep. var.: Log yearly wages in 2011

(1)

\begin{tabular}{lcc}
\hline Animal husbandry in $1900^{a}$ & $\begin{array}{c}-0.006 \\
(0.012)\end{array}$ & -0.010 \\
& & $(0.012)$ \\
& Yes & Yes \\
Province FE & Yes & Yes \\
Municipality controls & \\
Female characteristics & & \\
Age & No & Yes \\
Immigrant & No & Yes \\
Number of observations & 176,816 & 176,816 \\
Adj. R-squared & 0.021 & 0.044 \\
Mean of dependent variable & 9.717 & 9.717 \\
\hline
\end{tabular}

Notes: Method of estimation is OLS. Standard errors are reported in parentheses and clustered on a municipality level in Panel B. *, ** and *** indicate statistical significance at the 10 percent level, 5 percent level, and 1 percent level, respectively. Panel A: The unit of observation is a municipality according to borders in 2013. Panel B: The unit of observation is a women working in one of our sample municipalities. Data is from the Austrian Social Security Database. ${ }^{a}$ Animal husbandry is the ratio of livestock units to agricultural workers in 1900. ${ }^{b}$ Municipality controls comprise information on the log of population, the share of males, the share of Catholics, the local presence of a factory, the local presence of a large land holding, the market status of the municipality, and the share of population employed in agriculture (see Panel A in Table 2). 
Table D.10: Historical illegitimacy ratios from all countries of origin

\begin{tabular}{|c|c|c|c|c|}
\hline $\begin{array}{l}\text { Country of } \\
\text { origin } c\end{array}$ & $\begin{array}{l}\text { Number } \\
\text { of births } \\
\text { in Austria }\end{array}$ & $\begin{array}{l}\text { Historical } \\
\text { illegitimacy } \\
\text { ratio }^{a}\end{array}$ & $\begin{array}{c}\text { Year of } \\
\text { measurement }\end{array}$ & Source $^{b}$ \\
\hline Yugoslavia $^{c}$ & 26,636 & 4.9 & $1921-25$ & Wimperis \\
\hline Turkey & 15,590 & $1.0^{d}$ & & Ustek-Spilda \\
\hline Germany $^{e}$ & 7,860 & 8.7 & 1900 & Wimperis \\
\hline Romania & 3,680 & 9.0 & $1907-10$ & Wimperis \\
\hline Czechoslovakia $^{f}$ & 2,431 & 10.0 & 1921 & Hecke \\
\hline Hungary & 1,660 & 9.4 & 1900 & Wimperis \\
\hline Poland & 1,611 & 6.1 & 1900 & Wimperis \\
\hline Italy & 907 & 5.9 & 1900 & Wimperis \\
\hline Russian Federation $^{g}$ & 864 & 2.5 & 1900 & Wimperis \\
\hline Switzerland & 726 & 4.5 & 1900 & Wimperis \\
\hline Egypt & 677 & 0.1 & $1949-57$ & UN 1959 \\
\hline Philippines & 670 & 3.0 & 1952 & Hartley \\
\hline Netherlands & 635 & 2.6 & 1900 & Wimperis \\
\hline UK & 489 & 4.0 & 1900 & Wimperis \\
\hline China (PRC) & 430 & . & . & \\
\hline France & 423 & 8.8 & 1900 & Wimperis \\
\hline USA & 420 & 2.2 & $1916-20$ & Wimperis \\
\hline Ukraine & 416 & . & . & \\
\hline Thailand & 415 & . & . & \\
\hline Brazil & 405 & 13.2 & $1949-52$ & UN 1959 \\
\hline India & 400 & . & . & \\
\hline Bulgaria & 390 & 0.4 & $1901-05$ & Wimperis \\
\hline Iran & 310 & . & . & \\
\hline Vietnam & 248 & . & . & \\
\hline Nigeria & 243 & 0.3 & 1953 & Hartley \\
\hline Sweden & 229 & 11.4 & 1900 & Wimperis \\
\hline Albania & 228 & 0.5 & $1951-57$ & UN 1959 \\
\hline Dominican Republic & 206 & 58.6 & 1951 & Wimperis \\
\hline Unknown & 184 & . & . & \\
\hline Ghana & 164 & . & . & \\
\hline Spain & 164 & 4.4 & 1900 & Wimperis \\
\hline Tunisia & 156 & 4.8 & $1949-56$ & UN 1959 \\
\hline Belarus & 142 & . & . & \\
\hline Irak & 134 & . & . & \\
\hline Marokko & 129 & 5.7 & 1949 & Hartley \\
\hline Japan & 125 & 8.8 & 1900 & Hartley \\
\hline China (Taiwan) & 124 & 2.5 & $1949-58$ & UN 1959 \\
\hline Belgium & 117 & 7.4 & 1900 & Wimperis \\
\hline Armenia & 108 & . & . & \\
\hline Syria & 108 & 0.0 & 1954 & Hartley \\
\hline Finnland & 107 & 6.3 & 1900 & Wimperis \\
\hline Canada & 105 & 3.0 & 1929-30 & Wimperis \\
\hline Pakistan & 105 & . & . & \\
\hline Denmark & 101 & 9.6 & 1900 & Wimperis \\
\hline Australia & 100 & 5.9 & $1901-05$ & Wimperis \\
\hline Mexico & 100 & 29.3 & 1952 & Hartley \\
\hline Peru & 98 & 25.8 & 1942 & Wimperis \\
\hline Statelesss & 91 & . & . & \\
\hline Georgia & 85 & . & . & \\
\hline Greece & 84 & 0.8 & 1921 & Hecke \\
\hline \multirow[t]{2}{*}{ Indonesia } & 83 & 6.7 & 1949 & Hartley \\
\hline & & & \multicolumn{2}{|c|}{ Continued on next page } \\
\hline
\end{tabular}


Table D.10 - continued from previous page

\begin{tabular}{lcccc}
\hline $\begin{array}{l}\text { Country of } \\
\text { origin } c\end{array}$ & $\begin{array}{c}\text { Number } \\
\text { of Births } \\
\text { in Austria }\end{array}$ & $\begin{array}{c}\text { Historical } \\
\text { illegitimacy } \\
\text { ratio }^{a}\end{array}$ & $\begin{array}{c}\text { Year of } \\
\text { measurement }\end{array}$ & Source $^{b}$ \\
\hline Columbia & 82 & 28.0 & 1933 & Wimperis \\
Norway & 73 & 7.3 & 1900 & Wimperis \\
Portugal & 70 & 11.6 & $1901-05$ & Wimperis \\
South Africa & 70 & 11.5 & $1949-57$ & UN 1959 \\
Cambodia & 64 &. &. & \\
Mongolia & 63 & $\cdot$ & $\cdot$ & \\
Moldova & 62 & $\cdot$ & $\cdot$ & \\
Afghanistan & 57 & $\cdot$ &. & Wimperis \\
Libanon & 56 & $\cdot$ & 1929 & UN 1959 \\
Cuba & 55 & 30.8 & $1949-58$ & Wimperis \\
Argentina & 54 & 24.8 & $1921-25$ & \\
Lithuania & 50 & 5.0 & $\cdot$ & \\
Bangladesch & 50 & $\cdot$ & & \\
\hline
\end{tabular}

Notes: ${ }^{a}$ The historical illegitimacy ratio (HLR) is calculated as arithmetic mean over the years indicated in the fourth column. ${ }^{b}$ Wimperis stands for: Wimperis, Virginia (1960) The Unmarried Mother and Her Child, Allen \& Unwin Ltd., London. Hartley stands for Hartley, S.F. (1957) Illegitimacy, University of California Press, Berkeley and Los Angeles, CA. UN 1959 stands for: United Nations (1960), Demographic Yearbook 1959, 11th Edition, Department of Economic and Social Affairs, Statistical Office of the United Nations, New York. Ustek-Spilda stands for Ustek-Spilda, Funda and Oguz Alyanak (2016), 'The Case of Children Born out of Wedlock in Turkey: An Empty Category?', About Gender 5(10), 261-281. Hecke stands for Hecke, W. (1930), 'Die Unehelichkeit in Oesterreich', Jahrbücher für Nationalökonomie und Statistik / Journal of Economics and Statistics, DRITTE FOLGE, Vol. 77 (132), No. 4 (1930), pp. 572-592. ${ }^{c}$ This HLR is also used for mothers with a citizenship from the Socialist Federal Republic of Yugoslavia (SFR); Bosnia and Herzegovina, Croatia, Macedonia, Montenegro, Serbia and Slovenia. ${ }^{d}$ This HLR is rather a guesstimate, see UstekSpilda. ${ }^{e}$ This HLR is also used for mothers with a citizenship from former East and West Germany. ${ }^{f}$ This HLR is also used for mothers with a citizenship from Czech Republic and Slovakia. ${ }^{g}$ This HLR is also used for mothers with a citizenship from the Russian Soviet Federative Socialist Republic and the Russian Federation. 